\title{
Assessment of Cold-Climate Environmental Research Priorities
}

Appendixes A, B

J. B. States

April 1983

Prepared for the U.S. Environmental Protection Agency and the U.S. Department of Energy under Contract DE-AC06-76RLO 1830

Pacific Northwest Laboratory Operated for the U.S. Department of Energy by Battelle Memorial Institute 


\title{
DISCLAIMER
}

This report summarizes the process by which the EPA's Cold-Climate Environmental Research Program has been reviewed and revised and is now being implemented. It is intended to convey technical information only and not to constitute agency policy. The report does not supersede specific procedures and documentation for quality assurance, chain-of-custody, and other requirements addressed by Environmental Protection Agency regulations and policy guidance documents currently in effect. The research described in this report has been funded by the United States Environmental Protection Agency through interagency agreement no. AD-89-F-1-845-0 to the United States Department of Energy. As an internal working document, this report has not been subjected to the Agency's required peer and policy review.

This report was prepared as an account of work sponsored by an agency of the United States Government. Neither the United States Government nor any agency thereof, nor any of their employees, makes any warranty, express or implied, or assumes any legal liability or responsibility for the accuracy, completeness, or usefulness of any information, apparatus, product, or process disclosed, or represents that its use would not infringe privately owned rights. Reference herein to any specific commercial product, process, or service by trade name, trademark, manufacturer, or otherwise, does not necessarily constitute or imply its endorsement, recommendation, or favoring by the United States Government or any agency thereof. The views and opinions of authors expressed herein do not necessarily state or reflect those of the United States Government or any agency thereof.

\author{
PACIFIC NORTHWEST LABORATORY \\ operated by \\ BATTELLE \\ for the \\ UNITED STATES DEPARTMENT OF ENERGY \\ under Contract DE-AC06-76RLO 1830
}

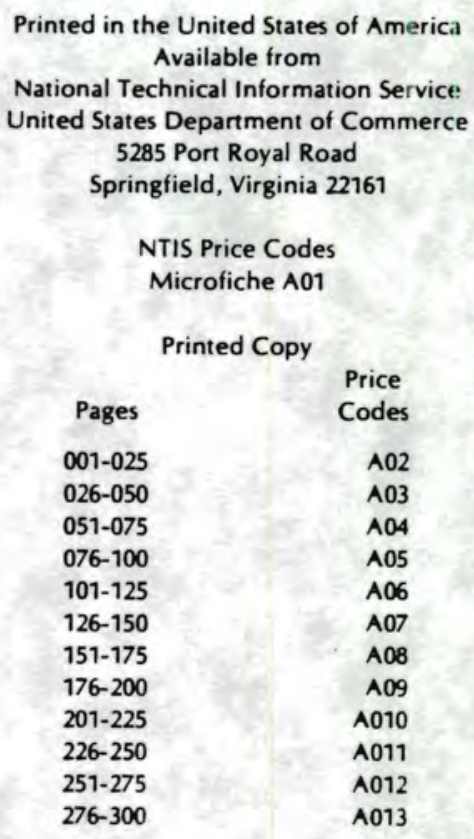


PNL-4581-App. A, B UC-11

ASSESSMENT OF COLD-CLIMATE ENVIRONMENTAL RESEARCH PRIORITIES

Appendixes A, B

J. B. States

Apri1 1983

Prepared for the Environmental Protection Agency and the U.S. Department of Energy under Contract DE-ACO6-76RLO 1830

and Interagency Agreement $A D-89-F-1-845-0$

in cooperation with

Alaska Department of Environmental Conservation Tetra Tech, Inc. University of Alaska 
APPENDIX A

DETAILED RESEARCH PLANS FOR EPA COLD-CLIMATE ENVIRONMENTAL RESEARCH PROGRAM

University of Alaska Task Leaders

Gunter Weller - Air Pollution

Don Button - Water Contamination/Consumption Terry Chapin - Habitat Manipulation/Modification

Tetra Tech., Inc. Task Leader

Robert Sener - Waste Disposal 
CONTENTS OF APPENDIX A

ITEM

PAGE

Introduction

Map Showing Recommended Study Sites

Air Pollution Studies

Urban Studies

Pollutants and Health Effects

Dispersion Under Stable Atmospheric Conditions 10

Vehicle Use and Fuel Additive Studies 12

Transportation System Characterization 12

Alternate Fuels Project $\quad 13$

Photochemistry

$\begin{array}{ll}\text { Industrial Studies } & 15\end{array}$

Pollution Downwash and Deposition and Their Effects 15

$\begin{array}{ll}\text { Background Studies } & 18\end{array}$

$\begin{array}{ll}\text { Arctic Haze } & 18\end{array}$

Natural Concentrations 20

Synthesis of Cold-Climate Air Pollution Studies 22

Water Contamination/Consumption Studies 24

$\begin{array}{ll}\text { Introduction } & 24\end{array}$

Asbestos Levels in Rural Alaskan Drinking Water 24

Cost-Effective Bio-Indicators of Marine Pollution 32

Biodegradation Rates and Toxicity Hydorcarbons in 0iled Waters 36

Ecosystem Impacts of Placer Mining $\quad 40$

Habitat Manipulation/Modification 43

Impact of $0 i l$ Development Upon Coastal Tundra Wetlands 44

Impact of Logging on Interior Alaskan Stream Ecosystems 51

Gravel Removal from Riparian Habitats $\quad 63$

Recommended Research Strategy for Cold-Regions Waste Management 66

$\begin{array}{ll}\text { Introduction } & 66\end{array}$

Determining Effects of Fecal Contamination in the Arctic 78 


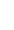




\section{INTRODUCTION}

Following the Chena Hot Springs workshop in Apri1, 1982, team leaders in air pollution, water contamination/consumption, habitat modification and waste management were requested to develop more detailed research plans in a limited number of those topic areas that received highest evaluative scores at Chena Hot Springs.

The results of these past workshop exercises do not correspond exactly to those topic areas detailed in the executive summary. The planning team performed some creative realignments to increase interrelatedness of the research package and include work elements from some of the 49 researchable topics not ranked as highly at Chena Hot springs but performable at relatively little additional cost in association with higher priority studies. See Figure 1 for locations at which coordinated studies might be undertaken.

Collectively, the detailed research plans of each of the four disciplinary groups are more ambitious than present budget forecasts for the EPA Cold-Climate Program would support. We believe, however, that it is preferable to err on the ambitious side to preserve flexibility and to provide the longer outlook as to possible research phasing. It must be emphasized that not all of the research described in any of the sections of this Appendix can be accomplished unless additional resources are brought to the EPA Cold-Climate Program, possibly through cooperative agreements with other agencies having overlapping responsibilities. 


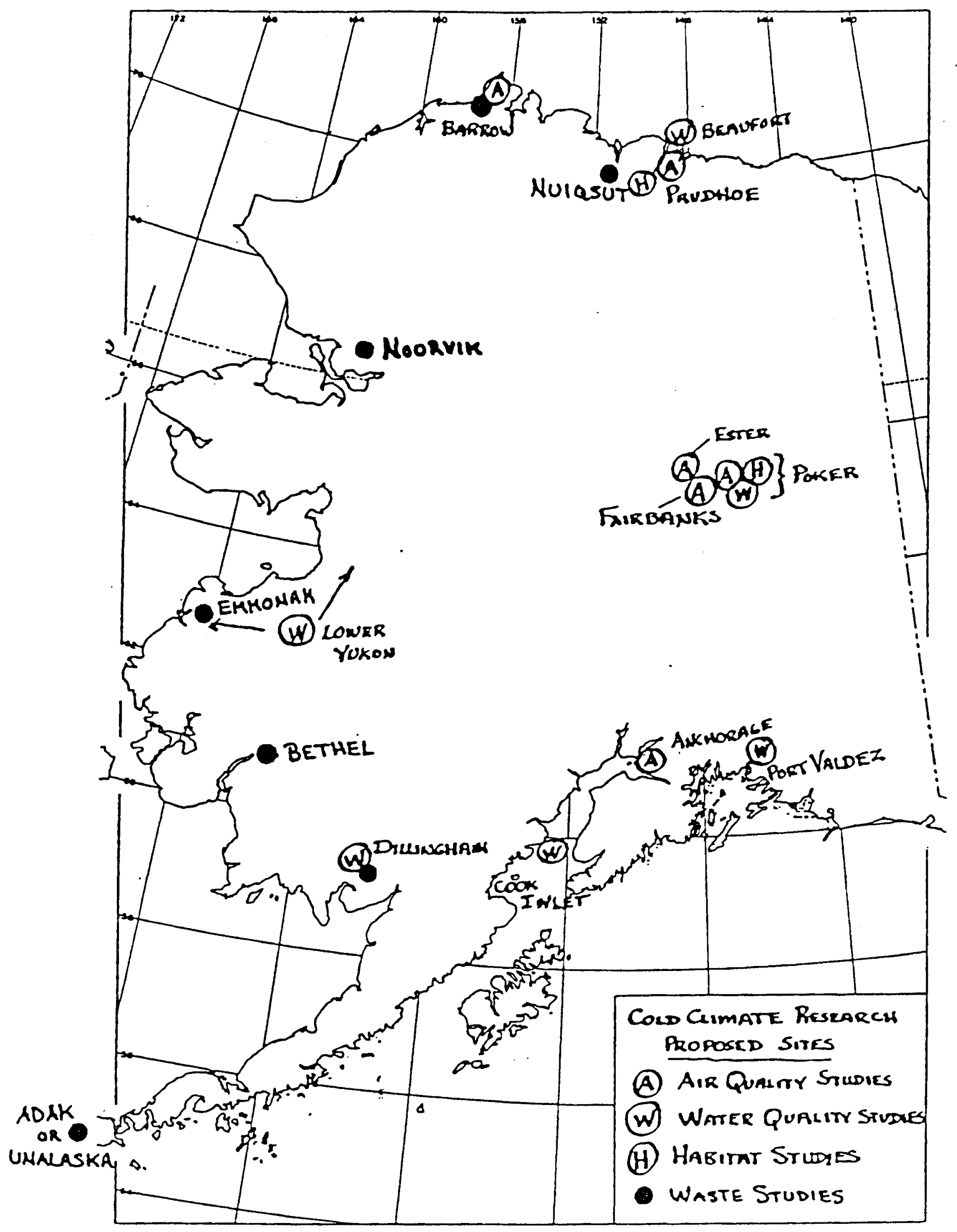

Figure 1 Potential Field Sites 2 


\section{AIR POLLUTION IN ALASKA}

INTRODUCTION

Statement of the Problems

The geographical location of Alaska, its topography present at least three distinct air pollution climates, none of which are typical of the contiguous forty-eight states. The high latitude results in extremes in temperature, solar radiation, and inversion strengths. Mountain ranges extending across the northern and southern portions of the state separate the three regions, and are in part the cause of the unusual air exchange problems.

At the Chena Hot Springs meeting in April, 81 projects were discussed which address the various problems of air pollution in Alaska. A total of 48 topics were suggested for research in all areas at that meeting, including water pollution, habitat modification and waste disposal. Fourteen out of the 18 air pollution projects were identified by the entire group to be within the top half of a priority list of all projects. Air pollution was thus clearly seen by the entire group as the most serious pollution-related problem area in Alaska.

There are four basic tasks into which the 14 projects can be grouped. Three of the tasks involved studies of urban, industrial and background air pollutants. The fourth task is to summarize and draw general conclusions from these studies, to consolidate the existing literature, and to prepare synthesis reports.

In brief, the urban studies include the following subject areas: pollutants and health effects, observing and predicting the dispersion of air pollutants under stable atmospheric conditions, a study of vehicle use patterns and an evaluation of available alternate fuels and fuel additives to alleviate the carbon monoxide problem, and a study of photochemistry.

Studies of industrial pollution should include the following topics; model and field studies of the downwash and deposition of pollutants, and the effects of any associated acid precipitation on the surroundings.

Background studies include the long range transport of pollutants into the state, the concentrations of natural trace gases and their relationship to the phenomenon known as Arctic Haze.

Current State of Knowledge

At the present time the information about air pollution in Alaska that is available is widely scattered in the scientific literature. There is some information for urban areas for a limited number of priority pollutants, but such information is missing or is "proprietary" for the Prudhoe Bay area and for the clean background. Weather and climate information is generally available. Health-related information is essentially an unknown. Only general health criteria can be applied to what is known about the concentrations of a limited number of urban pollutants such as carbon monoxide and lead. Standard dispersion definitions for modeling studies are nearly worthless for the extremely stable inversion conditions of the Interior. There has been some research in this latter area in the past year or so, but it needs to be completed. Information about respirable particles is generally restricted to 
the mass of the particulates and virtually nothing is known about the important parameters of size and number distribution of the particulates anywhere in Alaska or of the toxic components they carry. Photochemical pollution in Alaska is theoretically predicted, has been observed at similar latitudes in Europe, but is a total unknown in real experimental evidence for Alaska. Acid precipitation is a real threat to the environmentally fragile tundra regions of the north, particularly in light of the increased industrial effluents in that area with its poorly buffered lakes. Nothing is known about the current air pollution inputs, let alone projected future inputs. The phenomenon of Arctic Haze has recently received a fair amount of attention, but its sources, transport pathways and chemistry are far from well known, and the potential effects of this pollution on Alaska are not yet understood. In short, there is relatively little information on air pollution in Alaska, and where it exists it is scattered in the technical literature.

Rationale

Within the past decade Alaska has been subject to massive development of some of its resources in one of the most harsh yet most fragile environments. The development will continue on the North Slope and will also affect both the environment and populations of the interior and southern portions of the State. During the summer months, the southern two-thirds of the State receive enough radiation to be able to produce a photochemical smog, given the pollutant materials for it to work on. The northern third may be in a similar situation. Photochemical smog in Alaska has possibly been observed on a few occasions, but is essentially an experimental unknown. During the winter, the State experiences extremes in low temperature, lack of radiation and frequent, highly stable inversions. Pollution dispersion is extremely slow under these conditions.

The State is an ideal laboratory because the anthropogenic pollution sources are nearly isolated, can be readily studied. It also offers environmental conditions during the course of those studies that literally range from one extreme to the other. In one respect, the winter pollution problem in interior cities, such as Fairbanks, are one end member of the pollution spectrum one finds in the United States, as summarized in Table 1.

The knowledge to be gained from the various projects proposed here will not be limited in its application to Alaska. Well over half of the population of the United Sates is located in areas where the average monthly temperature is $0^{\circ} \mathrm{C}$ or colder for at least one month out of the year.

Relationship to Rest of Research Package

Intermediate and long range transport and deposition of airborne pollutants are directly related to some of the concerns of the water contamination and habitat modification groups. Common sites of study include Prudhoe Bay and possibly Poker Flat near Fairbanks.

General Strategy

The group mandate of the Chena Hot Springs conference makes it clear that nearly all of the projects in air pollution, as presented in this outline, should have a high priority in the overall cold-climate pollution studies. Table 2 shows the timing and cost of individual projects, and allows for the 
SPECTRUM OF AIR POLLUTION SETTINGS

\section{Fairbanks - Winter \\ Low Temperature \\ Icefog/Pollution}

Los Angeles - Summer

Smog
Temperature

Temp Inversions

Radiation

Saturation Vapor

Pressure

Chemistry

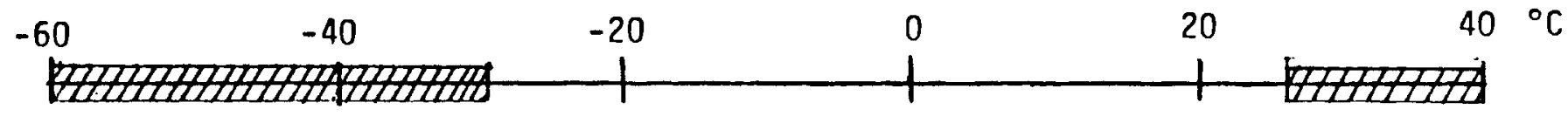

$30^{\circ} \mathrm{C} / 100 \mathrm{~m}$ (Surface)

$10^{\circ} \mathrm{C} / 100 \mathrm{~m}$ (Above Ground)

None during winter

High $\left(>1000 \mathrm{~W} \mathrm{~m}^{-2}\right)$

( $980 \mathrm{~W} \mathrm{~m}^{-2}$ at the summer solstice)

Low $\left(0.05 \mathrm{mb}\right.$ at $\left.-50^{\circ} \mathrm{C}\right)$

High $\left(42.43 \mathrm{mb}\right.$ at $\left.30^{\circ} \mathrm{C}\right)$

Non-oxidizing atmosphere

No photochemical reaction

"Wet" air chemistry

(Low absolute water content

but condensed form present)
Oxidizing atmosphere

Max. photochemical reaction

"Dry" air chemistry

(High absolute water content

but condensed form absent) 
early completion of projects started by other agencies. A phasing of the projects over five years, starting with the high-priority studies allows for the most effective use of the time of the potential investigators.

\section{Special Characteristics}

There are several short projects slated for early (FY82) funding which would have a rapid payoff in results. An initial summary and statement of the problems, including a literature survey, is essential to the orderly progress and future planning of nearly all of the projects. The remaining program has been set up as a five-year study.

Information gains in twelve out of the fourteen areas will be realized in the first six to eighteen months. The body of information will grow in the following two years, leading to final conclusions and recommendations which will be forthcoming in the fourth and fifth years.

Experimental Design

If the overall objectives of the program over five years are to be met, it is imperative that the principal investigators adopt the same sampling protocol, that the same samples and preferably also technician's time and equipment be available to all of the parties concerned. These issues will have to be decided before the work is begun. Failure to do so or an overly broad contract award to numerous agencies and personnel could easily double or even triple the tentative price tag of $\$ 2,000,000$.

Study Sites

The North Slope is a unique chemical and physical environment in which industrial and clean background studies need to be made. The industrial effects, however, are likely to be limited to the Prudhoe Bay vicinity. An already established clean air site is the NOAA/GMCC site near Point Barrow. Two or three sites downwind of Prudhoe (generally to the west and south) should be established for the transport and pollutant deposition studies.

The interior has its major population and industrial center at Fairbanks. The North Star Borough has urban monitoring studies which should be coordinated with the new proposed studies. The University of Alaska research groups maintain two clean air sites for comparison studies within less than an hour's drive from the University. These are located at Poker Flat and at Ester Dome and should be utilized. The pollutants from the farm project near Delta may also have to be considered.

In the southern portion of the State, Anchorage is the main population center to consider. Monitoring facilities already in existence in Anchorage should be utilized whenever possible. 
Table 2

PROPOSED MIR POLLUTIOH STUDIES In ALASKA

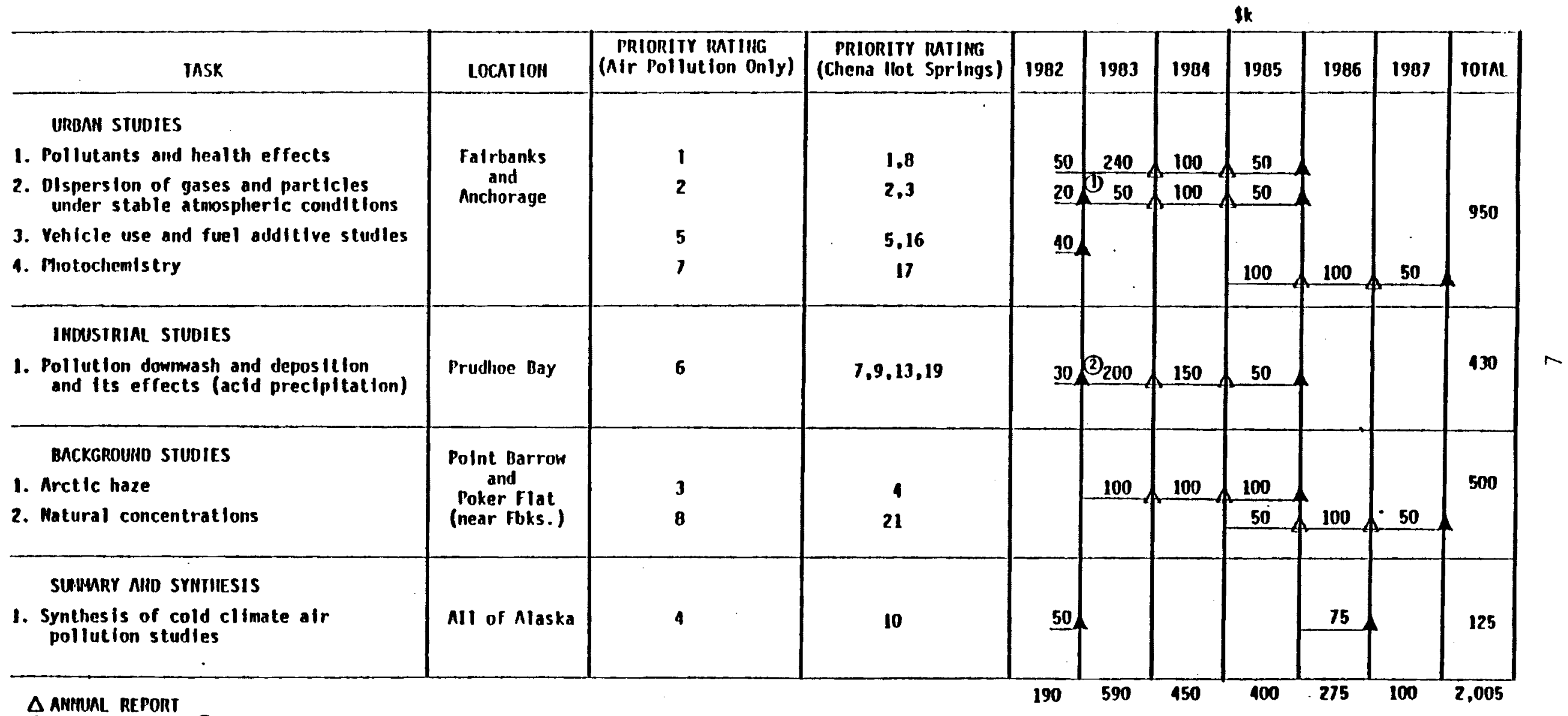

$\triangle$ AMmUAL REPORT

A FINAL REPORT: (QFinal Report on: Prediction of high Co days. Start of dispersion studies.

(2) Final Report on model/windtunnel studies. Start of fleld work. 
Pollutants and Health Effects

\section{Summary}

The objectives are to observe the concentration ind distribution in time and space of pollutants in Alaskan urban centers. Particular attention is to be given to the determination of the concentration of wood smoke and vehicular emissions in different particle size ranges, especially in the respirable size range, and their possible deleterious health effects.

Methodology will emphasize standard and established techniques for the collection and the analysis of samples. Routine calibrated monitoring devices will be used for the determination of carbon monoxide, hydrocarbons, oxides of sulfur, nitrogen (including ammonia) and ozone. High volume samples with a 10 cutoff will be used to collect the samples of particulates for mass loading, trace element and $\mathrm{PAH}$ analyses and toxicity screening studies. Size and number distribution of particles will be determined by means of diffusion batteries, aerosol spectrometers, etc., in regions affected by vehicular emissions and by wood smoke combustion. Some specialty pollutants, etc., aldehydes, PAN, nitric acid and organic nitrated compounds will be analyzed using established procedures such as dinitrophenyl hydrozine cartridges, teflon filters, electron capture gas chromatography, El-Cl/GC-MS, PIXE, etc.

Cost: $\quad \$ 440,000$ over four years to begin immediately in Fy82

Manpower: 1 full-time technican (2.5 man years)

2 part-time technicians (1.5 man years)

5 part-time principal investigators $(1.3$ man years)

Introduction

Urban air pollution in Alaska is important bccause its effects are immediately noticeable and of most direct concern. Air chemistry studies in the past have dealt almost exclusively with carbon monoxide. Much smaller efforts have addressed studies of lead, particulates and hydrocarbons. Other research has dealt with ice fog, but was essentially physical and meteorological in nature rather than chemical. There are only two publications dealing with other chemical species, eg., $\mathrm{SO}_{x}$ and $\mathrm{NO}_{x}$ and halogens. Large gaps exist in the study of compounds such as aldehydes, olêfins and the carcinogenic polycyclic aromatic hydrocarbons (PAH). The latter compounds are important in an understanding of photochemical and summer ozone production. There are no studies of chemical species such as cadmium, mercury, tungsten, nitric acid, arsenate and many others either on particulates or in the vapor phase. These and other substances are almost certainly present in the urban atmosphere, are toxic and are primarily the result of wood, coal and oil combustion.

Air pollution in the Fairbanks area is a phenomenon that occurs on a relatively small spatial scale. Nevertheless, in order to study its effects properly, it is necessary to look at an area which stretches roughly from Healy to Delta, a distance of approximately $350 \mathrm{~km}$ along the valleys in which these towns are located. Meteorological as well as chemical measurement must be part of the research efforts. Air pollution in the Anchorage area needs to be examined on a similar scale. 


\section{Research Approach}

Sampling and analyses will be done in downtown and residential areas, near the road and at known distances from the road or known pollutant sources. The instrumentation will be set up in a mobile laboratory, and on occasion in aircraft. Sampling will be done throughout the year but will concentrate on summer periods in Anchorage and Fairbanks when TSP standards are exceeded, and during periods of ice fog in Fairbanks. Data will be compared with Environmental Conservation samples which are frequently located above and away from roadways and are not necessarily representative of concentrations at street levels where people operate. Particulate sources from distant areas, such as the fires in Delta which heavily influence air quality in Fairbanks, will also be sampled. The analysis of the samples will be as outlined on the previous page.

Health aspects will be determined in two ways. One is to compare the concentrations with recommended levels. The other is to perform Ames mutagenicity and phagocyte tests to ascertain the total synergistic effect. Data from other urban areas now exists for comparison purposes of the latter.

\section{Research Milestones}

- Organization, personnel hiring and equipment acquisition will require three to six months at the beginning.

- Field work will require two full years. Quarterly and annual reports will be available during that period.

- A final analysis of the data will be presented in report form after all of the field work is completed.

If the organizational work, etc., can begin in FY82, the final analysis report will be available in FY85. The nature of the report will be baseline information on a whole suite of pollutants, an evaluation of their health hazards, an indication of the rate of change in the concentrations of the pollutants, and how far they are transported while still in relatively high concentrations.

\section{Required Resources}

Costs and manpower are shown in the summary and in Table 2. Some instrumentation will be required in the first year. Other major analytical equipment is available at institutions such as the University of Alaska at Fairbanks. Personnel from the Geophysical Institute (Fairbanks) and the Department of Environmental Conservation (Juneau) are capable of performing the tasks and the final analyses. Some special, yet routine analyses such as aldehydes and PAN can be subcontracted to laboratories such as ERT, Inc. (Environmental Research Technology, Inc.).

\section{Application of Results}

Research can be integrated into a long-range epidemiological study of air pollution and health. Occurence, concentrations spatial and temporal distribution of primary and other pollutants will be defined for various urban 
regions of Alaska, including Fairbanks and Anchorage. The information generated will allow EPA to determine whether mitigative measures are appropriate in certain areas, and when they should be applied. The transport characteristics of particulates, including lead, can be formulated into a model.

Dispersion of Gases and Particles Under Stable Atmospheric Conditions

Summary

Title - Dispersion of gases and particles under stable atmospheric conditions.

Objectives - Phase 1: To determine from actual case studies the type of meteorological conditions that cause $C O$ concentrations in urban areas to increase.

Phase 2. To determine empirically the dispersion equations that apply to the stable atmospheric conditions in the arctic and subarctic atmospheres.

Method - Phase 1: This is the final step in a project already underway, which examines actual meteorological conditions during high $C 0$ days in urban centers in Alaska. Existing meteorological and $\mathrm{CO}$ data are used to develop and calibrate a model based on statistics.

Phase 2: An artificial tracer, sulfur hexafluoride $\left(\mathrm{SF}_{6}\right)$ will be released and sampled three-dimensionally to determine the dispersion coefficients of the Gaussian gas/particle dispersion equation.

Expected Results - Two major results are expected from these studies. The first is a predictive model for forecasting potentially high CO level periods. The second is a modified Gaussian gas/particle dispersion equation which, unlike the presently used equation, is applicable to the highly stable atmospheric conditions in Alaska.

Relevancy to EPA - The expected results, outlined above, will allow EPA to predict periods with high concentrations of pollutants in urban centers in Alaska. This is required for putting counter-measures and contingency plans into place, especially during high pollution alerts.

experiments.

Cost - $\$ 20,000$ for phase 1 (FY82); $\$ 200,000$ over 3 years for the tracer

\section{Introduction}

Phase 1, the prediction of periods with high co levels, is the last stage of a project already underway, and should obviously be completed. It is included here because of its relevance to the general topic of dispersion of pollutants. Nothing else needs to be said about this phase of the dispersion studies and the rest of the project description deals only with phase 2 .

Although the Gaussian gas/particle equation has been widely used for estimating gas and particle dispersion, its validity in the Arctic under stable arctic conditions has been questionable, especially in the vertical direction. The equation and applied studies have shown that the available vertical diffusion coefficients are only valid for an elevation lower than $12 \mathrm{~m}$ from the 
ground surface under normal temperature profile conditions. The experiments proposed here will provide correct coefficients for the lowest $1000 \mathrm{~m}$ under several temperature conditions, including stable air.

\section{Research Approach}

The proposed experiment will proceed in two stages. The first stage is to determine the coefficients of the dispersion equation in an area which is flat and has no orographic obstructions. The North Slope of Alaska would provide suitable sites at which the winds at various elevations are steady and show the same direction. From a fixed location in the Alaskan Arctic, Sulfur Hexarluoride $\left(\mathrm{SF}_{6}\right)$ gas will continuously be released for an hour to be used as a tracer gas. The gas will be sampled three-dimensionally by an aircraft at various locations. The concentrations of the sampled gas will later be measured by a fast response electron capture gas chromatograph. Several sets of measurements of gas concentrations as a function of temperatures will be taken at different levels along three dimensional coordinates to empirically determine the associated dispersion coefficients.

The second stage is to apply these methods and results to an urban area like Fairbanks. $\mathrm{SF}_{6}$ would again be released, this time at stack height to simulate an industrial release. The dispersion would be measured on the ground and with aircraft.

\section{Milestones}

At the end of the first six months of funding the co study would be completed and the $\mathrm{SF}_{6}$ studies would commence. Initial results from the North Slope experiments would be available at the end of 1983. In 1984 field studies, both on the North Slope and in Fairbanks, would be coripleted and available in rough form to EPA. The final year of the project, 1985, would be spent in writing up the results in detail, both in report form and for publication.

\section{Resources Required}

The budget estimates are outlined in Table 2. Phase 1 costs $\$ 20 \mathrm{~K}$ and phase 2 approximately $\$ 200 \mathrm{~K}$. Phase 1 can be carried out by a single person and is, in fact, a sole-source continuation of a past contract. Phase 2 requires one senior scientist plus technicians. One major expense item is the aircraft charter necessary to sample the released $\mathrm{SF}_{6}$. The institution chosen for this work should have both meteorological and chemical experts and should have experience in this kind of work as well as experience in air pollution studies under the difficult logistics and weather conditions of the North Slope as well as Fairbanks.

\section{Application of Results}

The usefulness and applicability of the results have already been noted in the summary. Almost all the dispersion and modeling estimates presently in use and based upon Pasquill's equation (Gaussian gas/particle diffusion equation) as the best estimates. The diffusion coefficients used are not correct for the stable atmospheres in Alaska, however, but the coefficients to be derived from the proposed experiment will allow EPA to derive correct values of dispersion. 
Vehicle Use and Fuel Additive Studies

Transportation System Characterization Study

Objective. This study will provide data on several aspects of cold temperature vehicular operation which will be used to validate assumptions made in development of the Fairbanks North Star Borough Air Quality Attainment Plan.

Scope of Work. Several assumptions used in preparation of the Borough's At taiñment Plan wiTl be checked. I tems which will be investigated include:

1. Current average vehicle occupancy rates
a) Downtown vs. areawide traffic
b) Commuter vs. noncommuter vehicles
c) Rates vs. temperature

2. Vehicle idling
a) Unattended idling

al. Percent of total vehicles vs. temperature

a2. Average length of time per vehicle vs. temperature

a3. Downtown vs. areawide

b) Attended idling, prior to vehicular movement

a1. Average length of time per vehicle vs. temperature

a2. Downtown vs. areawide

c) Emissions

cl. Average length of time of attended idling prior to vehicular movement vs. total emissions from each segment of driving cycle

c2. Development of emission factor for unattended idling vs. temperature

3. Vehicle population projection

a) Diesel vehicles

Using national projections and consulting with local car dealers, a projection will be made of the future trends in light-duty diesel vehicles as a percentage of total light-duty vehicles.

Schedule. Nine months.

Location. Fairbanks.

Reports. Monthly status reports will be required. A draft final report will be submitted to the appropriate government agencies. The agencies will have one month for review of the draft prior to issuance by the contractor of 
the final report.

Costs. Projected at $\$ 21,000$.

Alternate Fuels Project

Objective. This study will determine the optimal fuel for use in reducing carbon monoxide concentrations in cold-climate areas. follows:

1. Types of alternate fuels - this would include all fuels listed under the generic name of gasohol, octane boosters such as MTBE, and other appropriate fuel mixtures.

2. Technical feasibility - the fuels referred to above will be investigated for operational feasibility in cold-climate areas.

3. Air quality impact - the most promising fuels will be investigated for their air quality impact. Automotive engine emissions will be analyzed, both the Federal Test Procedure cycle and for cold-start conditions. Some tests on possible increases in other pollutants, eg., aldehydes and amines, should be done to be sure that the elimination of one problem does not cause another.

4. Availability - the availability in cold-climate areas (i.e., Fairbanks, Anchorage) of the most promising fuels will be investigated. Discussions with private refiners, distributors, potential industrial plants (such as Alaska Interior Resources Co.) should be included in this section.

5. Economic and institutional feasibility - Private industry will be contacted to get realistic costs to industry and to the consumers for use of each of the most promising fuels. The feasibility of marketing such fuels will also be discussed. Discussions will include the possibility of such fuel use as only a wintertime seasonal strategy as well as such use as a year-round strategy. An analysis will be done to determine how government could subsidize such consumer fuel costs and how much such a program would cost.

Upon completion of the five segments of the study, a recommendation will be made on the best alternate fuel for use in cold-climate areas.

Rationale. Preliminary research has shown that the alternate fuels strategy appears to have the greatest potential for reduction of automotive carbon monoxide emissions of all realistically available strategies. However, very little is known about many of the available fuels. Data gaps include impacts on cold-start emissions, availability in cold-climate areas, and technical, economic and institutional feasibility. This study would answer such questions and provide a recommendation of the optimal alternate fuel for use in cold-climate areas. 
Schedule. One year.

Location. Sections 1,2 and 3 - Fairbanks

Sections 4 and 5 - Fairbanks, Anchorage

Reports. Monthly progress reports will be required. Draft final report will be submitted for review to the appropriate government agencies. Such agencies will have one month for review prior to issuance by the Contractor of final report.

Costs. Projected at $\$ 18,000$.

Photochemistry

Summary

The objectives are to verify the predicted (and observed) photochemical activity at $65^{\circ} \mathrm{N}$ latitude (and possibly higher) and to ascertain the probable duration and intensity of photochemical reactions at high latitudes.

Methodology basically will consist of observations of ultraviolet radiation intensity, organic material and ozone in the air in the vicinity of urban areas and industrial centers, particularly in the March though September time period. Some modeling with existing photochemical parameters coupled with field data will be done in the second year. Ancillary infurmation, eg. $\mathrm{NO}_{\mathrm{x}} / \mathrm{SO}_{\mathrm{x}}$, aldehydes, etc., from other studies are highly desirable. (See Pollutants and Heal th Effects Project.)

Cost: $\$ 250,000$ over a 3 -year period to begin in FY85 or before

Manpower: 3 part-time technicians ( 2 man years)

3 part-time principal investigators (1 man year)

*Note: See also section on Background Studies in Natural Concentrations.

Introduction

Photochemical activity in Alaska has not been evaluated. A few recent ozone measurements at Fairbanks $\left(65^{\circ} \mathrm{N}\right)$ indicate that photochemical activity may occur during the summer. Photochemical activity has been reported in at the relatively high latitude of 0 s 10 , Norway $\left(60^{\circ} \mathrm{N}\right)$, however. Air coming from Fairbanks on sunny days was markedly higher in ozone $(60-120 \mathrm{ppb})$ than air arriving from the open countryside $(40-60 \mathrm{ppb})$. The recommended limit is 120 $\mathrm{ppb}$. Theoretically there is enough u.v. light intensity at $65^{\circ}$ latitude on June 21 (977 watt-hrs m${ }^{-2}$ ) to be comparable to Los Angeles (see Table 1).

Hydrocarbon-based industries and general population growth are occurring in the interior and northern portions of the State. Waste products from these activities are what eventually lead to photochemical smog. Neither the pollutant concentrations nor the ultraviolet radiation have been adequately studied in Alaska. Visible radiation is being monitored at Fairbanks and other latitudes in Alaska, but the critical portion of the ultraviolet spectrum is not. Organic vapors in the Fairbanks air are being studied, but research needs to be modified for these purposes. Other critical components or products of photochemistry, eg., ozone, aldehydes, etc., are proposed for study in this 
overall air pollution project (see Pollutants and Health Effects Project). That information is critical to this study. Data from several of the proposed Alaska air pollution projects need to be consolidated into this study on photochemistry at high latitudes.

\section{Research Approach}

U1 traviolet and ozone meters should be added to the visible energy spectrum being monitored at the University of Alaska at Fairbanks, at least during the period of March through September. Similar installations at other latitudes in the State where radiation measurements are being made should be considered. This information, along with the aldehyde, olefin, $\mathrm{NO}_{\mathrm{x}}$ data, etc., from the pollutant project must be correlated to evaluate the poisntial for photochemical pollution now and in the future. Information for Anchorage, and Prudhoe Bay should be obtained for comparison purposes, at least for the months of June and July.

\section{Research Milestones}

It should be possible after the first summer to say whether or not significant photochemical activity is taking place at high latitudes $\left(65-72^{\circ} \mathrm{N}\right)$ in urban (Fairbanks) and industrial (Prudhoe) areas. After the second year, an evaluation of the likelihood and possible intensity of photochemical smog at high latitudes is anticipated. A full report will be presented in the third year after all of the data have been evaluated and computational models have been attempted.

\section{Required Resources}

Costs and manpower are shown in the summary and in Table 2 . If the existing programs as mentioned earlier are employed, only modest equipment additions are required. Personnel from the Geophysical Institute are already engaged in the type of research required for this project.

\section{Application of the Results}

Ozone and photochemical irritant production are a primary concern to the EPA mission. The urban and industrial centers of Alaska are growing, and essentially nothing is known experimentally about photochemical activity at high latitudes (above $60^{\circ} \mathrm{N}$ ) anywhere in the world. This study will provide historic baseline information.

\section{INDUSTRIAL STUDIES}

Pollution Downwash and Deposition and Its Effects (Acid Precipitation)

\section{Summary}

There are several objectives to this combined study of industrial pollutants in Alaska. The first is to prepare a computer model of the stack downwash phenomenon for the Prudhoe area. Other objectives are field studies of pollutants downwind of the source areas. The field work will examine the concentrations in the air, and the quantities that fall out under dry and wet conditions, for distances up to 100 miles distant. 
It will be through this project that cooperative information exchange will take place with groups involved in habitat modification and water pollution research. The background studies and some urban studies information will interact with this industrial pollutant project.

The methods to be used for the downwash phenomenon consist of a computer modeling study designed for the Prudhoe topography. The analytical methods for the field studies are essentially the same as those described in the urban pollutant-health effects study but the sampling will be somewhat different as discussed below in Research Approach.

Cost: $\quad \$ 430,000$ over 4 years to begin in FY82

Manpower: 2 part-time technicians (2 man years)

2 part-time principal investigators ( 1.3 man years)

Introduction

Recent air quality dispersion modeling of gaseous pollutants emitted from gas turbines has identified that typical climatic conditions exhibited on the North Slope of Alaska may result in downwash of these pollutants to the ground surface at a relatively short distance from the point of emission. Several site-specific parameters, some of which cannot be adequately simulated by the mode1, control the occurrence, relative frequency and magnitude of the downwash events. As a result of the downwash activity, pollutants contained in the turbine exhaust plume are impacted upon the ground surface at a higher concentration than would normally be expected because of the limited plume transport time. A significant frequency of this down'ash phenomena may result in a much greater impact than previously projected upon the health of resident workers and the terrestrial and aquatic ecosystems on the North Slope of Alaska.

The $i 11$ effects of combustion products on the environment were first reported in print in 1661. The term "acid rain" was first used by Smith in England in 1872. The recent environmental impact statement for Lease Sale 71 alone indicates that 40-250 metric tons of "nitrogen" and 1200 to 12,000 metric tons of "sulfur" per year will be emitted. A ten percent increase in the amount of nitrogen oxides to the tundra region has been suggested by investigators to be detrimental. The proposed increases for nitrogen oxides from Lease Sale 71 alone are 5 to 30 times as large as the natural components.

The law, as written for the emissions of oxides of sulfur and of nitrogen, is concerned only with the concentration in the air at any given time or averaged for a set period of time. The wind velocities of the North Slope are generally high, thus the law is unlikely to be violated, yet substantial acid producing material will be emitted. At the other extreme, Fairbanks, during the two weeks to two months of annual ice fog, experiences alkaline rather than acidic $\mathrm{pH}$ in the snow and ice fog ( $\mathrm{pH} 6.8$ to 9.9 , average about $8+$ ). The cause is uncertain at this time. It is suspected to be a combination of light ash fallout from power plants and products from catalytic converters on automobiles. The latter has very serious health implications. Snow from the Fairbanks area during warmer periods still has a high $\mathrm{pH}(7-7.5)$. 
The causes of these wide ranges of $\mathrm{pH}$, their potential impact on the environment and on the health of the people is an area urgently in need of some research before the full impact of petroleum and future mineral development impacts this region of the world with its national parks, picture lakes, waterfowl nesting grounds and growing urban centers. The research effort should be a coordinated effort between air chemists, meteorologists and limnologists. Emissions from homes, power plants, automobiles and industry should be investigated. The transportation and deposition of the emissions for the northern climates need to be evaluated in terms of the extremes of moisture, temperature and ultraviolet radiation.

\section{Research Approach}

It is anticipated that the best manner in which to assess the downwash occurrence, its frequency and magnitude is to simulate climatic conditions, turbine exhaust plumes, and facility parameters in 2 series of wind tunnel experiments. These experiments are to assess the plume downwash phenomena for two discrete facility scale models subjected to a variety of wind speeds, facility orientation and barometric pressures. The field sampling, particularly for the North Slope area, will require extensive use of aircraft throughout the year. Some analyses will be made from the aircraft, eg., NO $\mathrm{SO}_{\mathrm{X}}$, hydrocarbons, particulate counts, ozone, etc., while flying downwind of facilities such as the Prudhoe Bay complex. Similar aircraft-based surveys will be carried out downwind of the refinery and power plants of Fairbanks, and the field burning activities around Delta. Aircraft will also be required to pick up samples of snow and wet and dry precipitation across the tundra. Battery-driven samplers, which open only during snow or rain episodes, are commercially available and will operate at low temperatures. Trace element data from the background studies will be employed along with the $\mathrm{pH}$, and major anion/cation (ion chromatography) and trace gas information determined as a part of this project.

Research Milestones

- The results of the modeling study should be available six to twelve months after the project is started.

- Quarterly and annual reports on the progress of the field work will be prepared.

- A final analysis in the fourth year, based on the data of this study and the feedback information from the habitat modification, water pollution and natural background studies, should show the trend in the importance of the intermediate range (up to 100 miles) transport of pollutants on the arctic environment.

\section{Required Resources}

Manpower and costs are shown in the Summary and in Table 2. The model study should be coordinated under the auspices of DEC personnel. The field study could be a joint project between the Geophysical Institute and DEC. Special sampling devices will be required for purchase in the first year of the project. It is assumed that the pollutant monitoring devices described in the pollutant-health effects project will be periodically available to this project. If not, the cost could be up to $\$ 100,000$ more than what was indicated. 


\section{Applications}

With computer model knowledge, it will be possiu?e to accurately define when and where air quality standards are in jeopardy of violation. In the absence of this research activity and utilization of the knowledge it may generate, it may be necessary, based upon current limited technical knowledge, to place some restrictions upon future industrial growth at these locations to protect the public health and welfare. The present and future impact of industrial pollutants on the environment downwind of the source area can be evaluated for arctic and subarctic regions. Habitat modification and water contamination study projects will find immediate application of the information to be gained from this study.

\section{BACKGROUND STUDIES}

Arctic Haze

Summary

Objectives. To assess the concentrations, composition and transport pathways of trace gases and particles imported into Alaska from Eurasia and Northeastern U.S.A.

Methods.

1. Collect data on anions, cations, heavy metals, trace gases $\mathrm{CO}_{3}, \mathrm{NO}_{\mathrm{x}}$, $\mathrm{SO}_{2}, \mathrm{NH}_{3}$ ), carbon, aerosol size spectra in interior and arctic Alaska."

2. Identify transport pathways.

3. Study conversion processes; gas to particulate nucleation, $\mathrm{H}_{2} \mathrm{SO}_{4}$ aeorsol neutralization, etc.

Expected Results.

1. Establishment of baseline statistics on which to judge future changes.

2. Identification of physical processes acting in well aged polluted air masses, especially the assessment of neutralization of acid rain by $\mathrm{NH}_{3}$ and vapor pressure enhancements due to sorbed $\mathrm{NO}_{3}$.

3. Predictive information to assess buildup of arctic haze over Alaska from future industrial sources constructed at high latitude.

4. An assessment of global climatic perturbation brought about by the presence of carbon aerosol placed over the reflecting polar surface.

Relevance to EPA

1. Basic knowledge of impact of source emissions far fromemissions region (i.e., acid rain in Canada from U.S. industrial emissions). 
2. Sensitivity of high latitude regions to air pollution; increased knowledge of the contribution to Arctic-wide air pollution from U.S. emissions.

Cost. $\$ 100 \mathrm{~K} / \mathrm{yr}$ FY83 start -3 years

Introduction

Industrial aerosols and gases emitted enter dry Eurasian air masses north of the polar front and travel over continental pathways into the high arctic regions. During transport, the aerosol removal rate is small due to the inherent stability of arctic air masses and the low amount of cloud volume available for scavenging. Such polluted arctic air masses reach the American Arctic and travel southward into Alaska bringing with them residues that are characteristic of mesoscale air pollution of the kind that reaches and affects geographical areas far from emission sources (eg., the Canadian or Scandinavian acid rain problem). They are liable to prove more important in causing ecological damage than specific pollutant mixtures near source areas because they affect large areas and because they contain acid aerosol which has converted from sulfur-bearing trace gases.

The Arctic and interior Alaskan air environment with superimposed Arctic Haze traveling in from specific source regions in eastern Europe and the central USSR provides a natural laboratory system to study long-range transport of pollutant material, its major advantage being a lack of interfering locally-derived air pollutants. The objective of research is to determine chemical signatures and concentrations of deleterious pollutants entering Alaska from outside its borders.

Research Approach

Trace aerosol chemical signatures are representative of mesoscale source regions, for example, $M n / V$ and $V / C$ ratios differ by up to a factor of five for North American, Eastern European and Central Soviet Union pollutant sources. The research should therefore characterize in sufficient chemical detail the aerosol in air masses entering Alaska, to differentiate what are thought to be numerous individual distant pollutant sources. Element concentrations of $V, M n$, $\mathrm{Pb}, \mathrm{C}, \mathrm{SO}_{4}=, \mathrm{NO}_{3^{-}}, \mathrm{Ni}, \mathrm{Cd}, \mathrm{Zn}, \mathrm{Fe}, \mathrm{As}, \mathrm{Cr}, \mathrm{Ti}$, are examples of useful tracers and these have to be supplemented with measurements of $\mathrm{Al}, \mathrm{Si}, \mathrm{Na}, \mathrm{Cl}, \mathrm{K}, \mathrm{Mg}$, and $\mathrm{Ca}$ to calculate excess element concentrations over coastal or marine aerosol. The determination of chemical tracers should be performed with a time resolution of $2-3$ days minimum to differentiate air mass alterations. In addition, the size distribution of particles in the range of particle radii $r>0.001$ is needed to assess the rate of conversion of gases to particles. Measurements should be carried out at an uncontaminated sampling site in interior Alaska.

\section{Research Milestones}

Study of aerosol chemical signatures needs to be carried out for several winter seasons to accumulate a sufficient body of statistical data and to search for long-term changes associated with rapid growth of industries in the Scandinavian, Canadian and Soviet Arctics. Winter 1983-84, 1984-85 and 1985-86 data acquisitions are proposed. 
Required Resources

Cost: $\$ 100 \mathrm{~K} / \mathrm{yr}$ FY83 start -3 years

Application of Results

The results of this study should provide a baseline of statistical data on seasonal variation of imported air pollutants entering the American Arctic. It may provide ways to determine specific source regions of air pollutants that cross international boundaries; such information is of vital importance to national interests.

Natural Concentrations

Summary

The objectives of this study are to determine what natural concentration of organic and inorganic compounds arrive at industrial and urban sites in the Arctic and Subarctic. In some cases, this is an important fraction of the pollutant load associated with anthropogenic activity.

The methodology will involve gas chromatography analyses of air samples taken upwind of industrial and urban centers. Some mass spectrographic analyses for identification is to be done. Terpenes and the unusual high concentrations of compounds such as butanol, as reported in the past, will be analyzed. A comparison of these specific analyses with hydrocarbon monitoring equipment will be made. Special sampling and analyses for natural sulfur compounds, eg. dimethyl sulfide will be carried out. Some comparative samples from within and downwind of urban areas should be made. Particulates and trace elements information should be obtained for support data.

Cost: $\quad \$ 200,000$ over 3 years to begin FY85

Manpower: 2 part-time technicians (2 man years)

2 part-time principal investigators (1 man year)

Introduction

Organic constituents in clean air over the tundra have been determined in the past, before any Prudhoe Bay activity, to be over $0.2 \mathrm{ppm}$ during the summer. This is a significant fraction of the recommended limits of hydrocarbons. It is nearly equal to the once-a-year, three-hour concentration guideline of $0.24 \mathrm{ppm}$ of hydrocarbons in urban air. Some of the questions are, how extensive is the phenomenon in the Arctic, and Subarctic, in area and in time? Are these organic compounds of the type that will induce photochemical activity? Nature produces organic sulfur coumpounds from marshy areas (eg., tundra). This compound, in turn, will be oxidized to produce oxides of sulfur and eventually sulfuric acid downwind of its point of origin. These natural components may be partly responsible for the Arctic Haze phenomenon due to oxidation and photochemical activity.

Research Approach

Two clean-air laboratory sites exist in the vicinity of Fairbanks, and another near Point Barrow, Alaska. Samples will be collected at these sites, 
and when possible, analyses performed there. Hydrocarbons in urban atmosphere are important to indicate overall pollution, but more importantly to judge when photochemical smog may occur. A hydrocarbon monitor device will be employed to obtain a measure of the methane and nonmethane hydrocarbon concentrations in the air while a sample is being taken for detailed analyses.

For detailed analyses, low molecular weight $\left(C_{1}-C_{2}\right)$ hydrocarbons in air can be determined directly from a flask sample of the air. " The larger organics will be concentrated on tenax-packed cryogenic traps and returned to the laboratory for routine analyses. Special cryogenic samples for organic sulfur compound analysis during the spring-summer period should be treated according to state-of-the-art literature methods. The principal sampling period will be from April through October when atmospheric concentrations are expected to be the largest and the most varied. A few winter samples should be analyzed as well.

Research Milestones

- Quarterly and annual reports on the research will be submitted.

- The final report in the fourth year will indicate the natural variability and kinds of the organic material present in the clean background as compared to air in urban and industrial areas.

The final analysis should take into account other projects such as photochemistry and the trace element work of the Arctic Haze phenomenon. The objective is to estimate what fraction of the organic material in arctic and subarctic urban and industrial centers is natural versus man-caused and its relationship to the poteniials for photochemical activity and Arctic Haze.

\section{Required Resources}

Cost and manpower are shown in the Summary and in Table 2. Gas chromatographic and mass spectrographic equipment for this research, as well as existing programs in atmospheric organics are to be found at the University of Alaska-Fairbanks Geophysical Institute. Expansion of that program would satisfy the need for the information called for in this project.

\section{Application of Results}

The natural background data is crucial to the ultimate understanding of Arctic Haze and to the understanding of the potential for photochemical activity at high latitudes. The largest expected increase in the exploitation of natural resources in the Arctic is with petroleum. Hydrocarbons, among other things, are crucial to photochemical activity, which is theoretically possible in the Arctic. Past reports indicate that at least during summer months, organic material in the air is quite concentrated. 
Summary

\section{Objectives}

1. At the beginning of the project, compile a synthesis of all available information on air pollution in Alaska. This is to include sources of pollutants, chemical characteristics, transport, effects of the pollutants and mitigative measures taken to date.

2. Towards the end of the project perform a similar synthesis as described under objective 1. This should be an assessment of the air pollution potential and problems for the entire State.

\section{Methods}

The literature search should include EPA and DEC papers and files on the subject as well as the University of Alaska's and other institutions'. Published papers, reports and unpublished materials should be included. The purpose is not so much to produce a systematic, computerized list of references, however, but a synthesis of the available information. Foreign sources of cold-climate air pollution problems, particularly from Canada and Scandinavia, should be included.

\section{Expected Results}

A compilation of data and results in the form of two reports with a comprehensive bibliography (one at the beginning of the project, one at its end).

\section{Relevancy to EPA}

These up-to-date summaries of data and results should allow EPA (and DEC, municipalities, etc.) to:

a. plan future studies, since data and information gaps will be apparent from the reports (particularly the first one)

b. maintain updates of literature and research progress

c. plan mitigative measures to reduce polluiion problems (control standards, siting of industry, routing of traffic, etc.).

Cost

\$50K for initial synthesis (FY82), \$75K for final synthesis (FY86).

\section{Introduction}

The air quality data that exist for the Arctic are scattered through a large number of reports, different technical journals and unpublished manuscripts, and are not to be found in any one repository. A comprehensive synthesis report and summary of this material should have high priority. The 
report should cover the three major climatic regions of Alaska, the North Slope, the interior and the coastal southern areas, and deal with both "clean" background and polluted urban areas.

Air quality cannot be judged by limited data bases. Past and present investigations unfortunately only deal with a few parameters. Furthermore, only a small fraction of that information can be found in the open scientific literature and reports usually serve only the investigator and the funding agency. Reports are available but are relatively difficult to retrieve except perhaps by those working directly in that area of expertise.

Before any research project is undertaken, it is beneficial to know what already exists. This stops duplication of effort, will show where some of the problems are and where the real gaps in the needed information lie. In some cases there may be sufficient information so that little or no additional field research is needed. If this process is repeated after a number of years, progress, if any, can be realistically documented.

\section{Research Approach}

The following types of information should be synthesized in a unified report for the regions and types mentioned earlier.

1. Routine meteorological data for up to 25 years. These would include monthly mean temperatures, ranges of temperatures, strength and persistence of inversions, humidity, sea ice conditions, wind velocities, pressure, precipitation, fog and cloud cover.

2. Less routine physical information such as haze, particulate measurements, insolation, volcanic dust reports, wind trajectories, etc.

3. Current pollution monitoring data where available.

4. The chemical data base. This would include trace elements, methane, specific hydrocarbon data, trace inorganic gases, eg., $\mathrm{CO}, \mathrm{H}_{2}, \mathrm{~N}_{2} \mathrm{O}, \mathrm{NH}_{3}$, sulfides, oxides of sulfur and nitrogen, ozone, freons, etc. Literature from foreign countries at high latitudes should not be overlooked.

5. Hospital and doctors' reports should be culled to find the rate of respiratory and eye irration disease as a function of season and location of residence and work.

Milestones

Only two reports will be produced, both including comprehensive bibliographies. One will be completed six months after the start of funding of the project, the other four years later, towards the end of the presently planned cold-climate research project.

Resources

Budgets are $\$ 50 K$ and $\$ 75 K$ respectively, for the two reports at the beginning and end of the project. This kind of project must be carried out by a multidisciplinary effort of an institution with a wide range of experience of meteorological and chemical air pollution studies in Alaska. An academic 
institution would be ideal for this purpose.

WATER CONTAMINATION/CONSUMPTION STUDIES

INTRODUCTION

Based on the Chena Hot Springs meeting, a program in water consumption/contamination has been assembled. Issues treated ranked highly as shown in the summary sheet. Total proposed budget and budget distribution were decided before analysis was complete so that the total program could now be considered for balance. Water problems are problems in dilute solution analytical chemistry; all topics have this in cormon. The average cost per program segment at a university with equipment available at no charge is about $\$ 150 \mathrm{~K}$ per year. All these programs have been based on preliminary work so that ongoing programs exist at some level. Suggested budgets would allow somewhat more intensive effort among the topic areas. Full working budgets would total about $\$ 450 \mathrm{~K}$ per year.

Two programs, one on the asbestos/cancer probiam and another on oil pollution literature evaluation and biomonitoring evaluation were selected as priority items at the Chena Hot Springs workshop. The fact that neither of these surfaced during deliverations within and outside the water contamination group speaks to the facts that 1) the problems in water contamination in Alaska are many; 2) what is considered a significant problem depends on the vantage point and background of the observer, and 3) the system "worked" in that a fairly wide range of problems found their way into consideration.

Results forecast a program heavily swayed towards applied science. Another important area is development of the fundamentals which underlie proposed programs. Suggested funding is probably insufficient to see this area develop as it should for efficient research. Perhaps this is one focal point to consider in the latter years of the program. Plans for the latter years of a five-year program are summarized in the table 3.

ASBESTOS LEVELS IN RURAL ALASKAN DRINKING WATER

Introduction

This research is directed towards determining the concentration of asbestos in Alaska rivers and in the other drinking water sources of villages on the banks of the rivers in order to estimate the extent of exposure of the population to asbestos.

Asbestos is a carcinogenic agent; exposure occurs from inhalation and ingestion. $(1,2)$ The amount of asbestos in the Yukon River, 40-1, 000 $10^{6}$ fibers/liter, $(3,4,5)$ is at a level higher than frose associated with an increased risk of developing cancer from ingestion. $6, f)$ Exposure in the region of the Yukon could occur ngf only from drinking the river water, but also from eating asbestos-laden fish (4) from the river as well as inhalation of wind-blown dust from river banks and alluvial deposits in the region around the river.

A preliminary survey of Alaskan geology and asbestos mining claims indicates that other rivers probably also contain asbestos. This asbestos appears to come from erosion of natural deposits. It is likely to increase if mining operations resume in the Fortymile and Kobuk regions (as is being 
BUDGET TABLE

PROPOSED WATER CONSUMPTION/CONTAMINATION PROGRAM

\begin{tabular}{|c|c|c|c|c|c|c|c|c|c|c|}
\hline \multirow[b]{2}{*}{ PROBLEM } & \multirow[b]{2}{*}{ AUTHOR } & \multicolumn{3}{|c|}{ RANKINGS } & \multirow[b]{2}{*}{1982} & \multirow[b]{2}{*}{1983} & \multirow[b]{2}{*}{1984} & \multirow[b]{2}{*}{1985} & \multirow[b]{2}{*}{1986} & \multirow[b]{2}{*}{1987} \\
\hline & & $\begin{array}{l}\text { TOTAL } \\
\text { GROUP }\end{array}$ & UNIVERS ITY & WATER & & & & & & \\
\hline
\end{tabular}

Asbestos in Drinking Water

Peat and Placer

Mining Products

in Alaskan

Streams

Applicability of
$\mathbb{G}$ Biomonitoring
Methods and
Responses to
Produced Water

\section{Chemistry of Biodegradation \\ Products of}

Petroleum

Lifetimes of Petroleum in Seawater
H. Meyers

6

D. Sche11

D. Redburn

11

34

D. Button

D. Button

24

30
4

9

23

4

13

10

29

28

2

18

$-20 K-\quad-40 K-$

$-60 K-\quad-60 K-\quad-60 K-$

$-25 \mathrm{~K}-\quad-50 \mathrm{~K}-\quad-50 \mathrm{~K}-\quad-50 \mathrm{~K}-\quad-50 \mathrm{~K}-$

8
$-40 K-\quad-40 K--40 K-$ 
discussed by native land claims corporations). Documentation of the "background" level of waterborne asbestos is necessary in order to determine whether the mining activity has increased the level.

The level at which asbestos can be considered hazardous has not been well established, particularly for ingested asbestos. In establishing standards of hazardous chemicals, EPA has considered that the devilopment of pathological conditions can arise from multiple factors acting together, perhaps in synergy. It is recognized that certain segments of the population will be at greater risk than others.

A chance observation suggests such a situation may be present in a region in rural Alaska where hepatitis $B$ viral infection is endemic; this region includes villages on the lower Yukon and Kuskokwim Rivers. The lower Yukon contains high levels of asbestos, the Kuskokwim, judging from the geology of the watershed and one measurement, $(5)$ probably does not. A liver cancer, primary hepatocellular carcinoma (PHC), is a common sequella of hepatitis B infection, but it is thought that another cocarcinogenic agent must be present for the cancer to develop. $(8,9,10)$ Although the population along the Kuskokwim River is greater, no cases of PHC have been diagnosed in people born in this region, whereas eight, fases have been diagnosed in the lower Yukon population. $(11,12,13$ ) (Four of these cases showed positive signs of previous viral infection, one case was negative, and three were untested.)

The incidence of hepatitis and PHC in rural Alaska are at least ten times the incidence of these diseases in the lower 48 states; 13 ) the diseases are thus of particular concern for Alaskan public health. PHC is actually the most common malignant hard tumor worldwide, occurring primarily among "Third World" populations, as does hepatitis $B$. Researching the hypothesis that asbestos can act as a cocarcinogenic agent with a viral infection is of interest for two reasons. First, given the prevalence of PHC, anything that elucidates the etiology of this cancer is of value from a public health standpoint. Second, from the point of view of setting standards for asbestos exposure, it would be of great value to identify a population at special risk. The present budgetary constraints as well as the small size of the Alaskan population make it unlikely that a definitive experiment can be conducted here on this question. However, the experimental design for the collection of water samples includes collection of samples that will enable examination of the data for consistency with the hypothesis that asbestos is acting as a cocarcinogenic agent with hepatitis $B$ virus.

Research Approach

Because asbestos analyses are expensive, sample sites have to be carefully chosen on the basis of the useful information. to be gained from each site. Each site should be sampled more than once, not only to reduce experimental error, but also because the asbestos content is expected to change between summer and winter. Where possible, two summer and one winter collection are advisable for each water source.

In order to characterize the potential exposure of people to ingested asbestos, it is necessary to sample the water people actually drink. Thus, not only should the river near the village be sampled, but also other major water sources, such as public wells, springs, nearby creeks, or river ice in winter. The extent of use of a water source should also be ascertained during each collection time, in terms of numbers of people using it and the portion of the year the source is used. Five water samples per village, with two to three 
samples taken as a cross section of the river, are suggested for each collection period.

Rivers and villages to be tested should be chosen partly on the basis of the likelihood that there is asbestos in the water. The preliminary survey of the location of asbestos claims and geological formations (ultramafic, oloivine, and serpentine) associated with asbestos indicate that the Yukon, some of its tributaries (the Fortymile, Porcupine, Tanana, and Koyukuk), the Noatak and the Kobuk drain watersheds containing asbestos, as does the Kuskokwim to probably a lesser extent. The preliminary geological survey should be expanded. Information can be obtained from the U.S. Bureau of Mines and the State of Alaska Department of Geological and Geophysical Survey. Rivers and villages should also be chosen for study on the basis of population density so that information regarding the exposure of the greatest number of people will be obtained.

It is not possible to definitively address the question of whether ingested asbestos could be acting as a carcinogen with hepatitis $B$ virus in the development of PHC. Nevertheless, the prediction on which this hypothesis is based, that the asbestos content of drinking water in villages along the Yukon should be higher than in the drinking water along the Kuskokwim, can be tested.

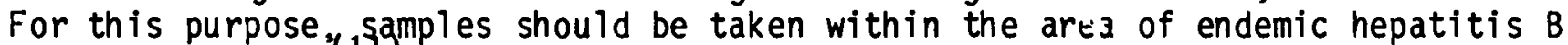
viral infection. (11) The villages of Noatak, Selawik and Fort Yukon occur in areas where waterborne asbestos is predicted to be high. Conversely, there are cases of PHC on and near the Seward Peninsula where there is little evidence of asbestos formation. Any water sampling done in these regions should specifically test these villages where the PHC cases were born.

In summary, the research design is to measure the asbestos content of river water and other drinking water sources of villages along rivers suspected, from geological considerations, to contain significant amounts of asbestos. Because the peculiar geographical distribution of PHC suggests asbestos may be acting as a cocarcinogen in the development of this disease, two to three villages on the Kuskokwim River should also be tested and compared to villages on the lower Yukon. 


\section{RESEARCH TIMETABLE AND MILESTONES}

\section{First Year}

Activity/Product

Time

Selection of villages for testing. Start survey of geographical location of asbestos claims and potential

Spring asbestos containing areas.

First collection of water samples, at a time of maximal erosion so that the asbestos levels will be maximal. Ascertain from villagers during visit the extent of use of the water sources.

Analysis of water samples for asbestos. Product: Tabulations

Fall of water sources, asbestos content, and use of sources. Selections of winter sampling water sources, (in same villages as in summer), some of which may be different from summer.

Second Year

Second collection of water (or ice) samples. Ascertain again extent of use of sources.

Winter

Analysis of water samples for asbestos.

Product: Extended tabulation of water sources, asbestos content and use of sources.

Third collection of water samples, repeating summer collection sources.

Analysis of water samples for asbestos.

Fal1, Winter

Preparation of final report.

Final report should contain:

1) Tabulation of the amount of asbestos in rivers.

2) Discussion of the estimated exposure to asbestos on the basis of asbestos concentration and extent of use of water sources.

3) Discussions of the amount of asbestos in the water in relation to what is known about asbestos-containing rock formations. Recommendations should be made regarding other rivers and villages which ought to be sampled due to the likelihood of the presence of asbestos.

4) Presentation of data to examine the probability of a relationship between asbestos concentrations in drinking water, the presence of hepatitis $B$ virus and the occurrence of PHC. 
Organization Expertise and Qualifications Needed

Asbestos analyses are djfficult and expensive. They should be done by the method approved by EPA 14 in laboratories approved by EPA. Two such laboratories will do water analyses for about $\$ 300 /$ sample. Collaboration with the Center for Disease Control in Anchorage is strongly advised to obtain access to the data regarding the epidemiology of hepatitis B infection and primary hepatocellular carcinoma. The U.S. Fish and Wildlife Service has also been collecting water and fish samples for analysis of asbectos. Collaboration with FWS would be helpful in getting river-water samples, as they already have men in the field with the necessary equipment. Individuals who have the qualifications to perform this work are:

Dr. Edwin Boatman

Head, Division of Environmental Health, Biological Effects Research

School of Public Health and Community Medicine

F-56l Health Sciences Building SC-34

University of Washington

Seattle, WA 98195

Dr. Helen A. Myers

Assistant Professor of Medical Sciences

WAMI Medical Education Program

University of Alaska

Fairbanks, AK 99701

Manpower and Money

This budget is based on sampling at 9 villages with five samples per village per collection, and three collection periods. No overhead is calculated. However, overhead may reduce the number of villages that can be sampled.

First Year

Salary (25\%FTE): experimental design of summer sample collection, data analysis

Travel, per diem (in Alaska) for sample collection

$\$ 15,000$

$\$ 2,500$

Materials, direct costs

$\$ 500$

Asbestos analyses (45 samples)

$\$ 13,500$

$\$ 31,500$ 
Second Year

Salary (40\%FTE): winter and summer sample coliaction, data analysis, preparation of final report

$\$ 24,000$

Travel, per diem (in Alaska) for sample collection

$\$ 6,000$

Computer, materials, direct costs

$\$ 1,000$

Asbestos analyses (90 samples)

$\$ 27,000$

$\$ 58,000$

\section{Application of Results}

The data on the levels of asbestos in the rivers and other drinking water sources will indicate to what extent hazardous amounts of asbestos are present. Should hazardous amounts of asbestos in fact be found, the data could be taken to appropriate state agencies to indicate the need for 1) testing of water supplies in villages not examined by this survey; 2) an educational campaign to alert rural residents to the danger of drinking water containing asbestos; and 3) the development of filters for asbestos which can be used in an innovative way where a public, piped water supply may not be the main source of water.

If mining activities resume, EPA will need the data as a measure of "background" levels of asbestos to determine whether mining activities are polluting the rivers with additional amounts of asbestos.

The data on the amounts of asbestos in the drinking water in relationship to the development of PHC will be examined for consisiancy with the hypothesis that asbestos can act as a cocarcinogen with hepatitis $B$ virus. Definitive proof of this hypothesis will have to be sought from other experiments, whether through the use of animal models or the examination of a larger population exposed to both asbestos and hepatitis $B$ virus. 


\section{REFERENCES}

The references given here contain extensive references to the topic indicated.

1. Selikoff, I. J. Asbestos-Associated Disease. In Public Health and Preventive Medicine. 11 th ed, John M. Last, ed; pp. 568-644, (T980).

2. Becklake, M. R. Asbestos-Related Diseases of the Lung and Other Organs; Their Epidemiology and Implications for Clinical Practice. Amer. Rev. Resp. Dis. 114:187-227 (1976).

3. Delaney, P. W. et al. Assessment of the Effects of the Clinton Creek Mine Waste Dump and Tailings, Yukon Territory. Prepared for Cassiar Resources Ltd. Vancouver, B.C.

4. Metsker, H. U.S. Department of the Interior, Fish and Wildlife Service, Anchorage. Personal Communication regarding analyses prepared by $D$. Marklund, Lake Superior Basin Studies Center, utilizing the method described in \#12 below.

5. Samples collected by Myers, H. A. and H. Metsker; analyses are by E. Boatman, University of Washington, using the method described in \#12.

6. Millette, J. R. et al. The Need to Control Asbestos Fibers in Potable Water supply Systems. Science of the Total Environment 18; 91-102 (1981).

7. Kanarek, M. S. et al. Asbestos in Drinking Water and Cancer Incidence in the San Francisco Bay Area. Am. J. Epidemiol. 112:54-71 (1980).

8. Blumberg, B. S. and W. T. London, Hepatitis B Virus and the Prevention of Primary Hepatocellular Carcinoma. New Eng. J. Med. 304:782-784 (1981).

9. Maltz, C. et al. Hepatocellular Carcinoma: New Directions in Etiology. Amer. J. Gastroenterology 74:361-365 (1980).

10. Kew, M. C. Hepatoma and the HBV. In Viral Hepatitis, ed. Vyas, G. N., Cohen, S. N. and Schmid, R. Franklin Press, 1978.

11. Boss, L. P. et al. Hepatitis B Testing in the Families and Villages of Five Young Eskimos with Primary Hepatocelular Carcinoma. Amer. J. Epidemiol. 114:95-101 (1981).

12. Heyward, W. L. et a1. Primary Hepatocellular Carcinoma in Alaskan Natives, 1969-1979. Int. J. Cancer 28:47-59 (1981).

13. Lanier, A. P. and W. L. Heyward. Personal Communications, Fall, 1981.

14. Anderson, C. H. and J. M. Long. Interim Method for Determinng Asbestos in Water. EPA-ORD Research Report \#EPA 600/4-80-005, p. 34 (1980). 

COLD CLIMATES

This research addresses the question "What biological manifestations of oil pollution stress are most suitable for use as indicators of ecosystem heal th in cold marine environments subjected to chronic pollution?i This is a question of considerable importance to state and federal agencies responsible for the regulation of discharge of waste to the environment. These agencies issue discharge permits which often include stipulations requiring the discharger to monitor the environmental effects of the discharge. This research will identify those bio-indicator systems that offer both scientific validity and cost-effectiveness for use in discharge monitoring. It is important for the permit issuing agencies to be well-informed about which bio-indicator systems are most scientifically valid and cost-effective so that permits can be written that provide the environmental monitoring information which society wants without putting unnecessary financial burdens on the discharger.

This work will draw on a wide range of information already in the technical literature. In the first place, examination of the literature concerning bio-indicator use in temperate waters will be necessary. Considerable effort has already been applied to developing bio-indicator systems for use in temperate marine environments, especially of the United States and Europe (National Academy of Sciences, 1980). The results of work elsewhere, particularly in similar regions such as the North Sea (Widdows et al. 1982), provide a starting place for further work specifically directed toward cold climates.

A second area of background information which will be drawn upon will be literature concerning the basic physiology and biochemistry of marine organisms. The roles of many variables have been investigated, but not directly in response to oil pollution stress. It will be particularly important to examine the natural variability in parameters, since this variability sets a limit on the degree of change as a result of pollution stress which can be detected.

A third background area that will be drawn upon is the literature dealing with cost-effectiveness in environmental decision making (Weinstein 1979). This literature deals with designing research to provide the greatest value to decision makers. Obviously, this research must be constructed so as to be fully useable by those making environmental management decisions.

Research Approach

The approach to this project is based on the premise that two objectives are equally important:

1. Dissemination of information about available bio-indicator systems to environmental decision makers, especially agency personnel involved in permit writing.

2. Scientific research to improve and refine the available bio-indicator systems.

In order to meet these two objectives, a two-phase approach is necessary: 
Phase One: This phase includes a critical review of the scientific Titerature to determine which available bio-indicator systems are most likely to be useful in cold climates and a workshop at which environmental decision makers, industry representatives and research scientists can discuss the pros and cons of various bio-indicators. It is important that the literature search not simply be a computer-controlled retrieval of all work in the field, but a careful evaluation by scientists with the experience and ability to judge the applicability of the work to cold climates. The workshop provides a means to rapidly transmit evaluated information to the user group and also provides a source of feedback from the user group for the final planning of phase two.

Phase Two: This phase consists of scientific research both in controlled Taboratory experiments and in actual field discharge conditions to determine the statistical relationship between selected bio-indicator responses and petroleum exposure. While selection of indicator responses is the subject of phase one, it presently appears that organismal energetics, pathology and enzymatic responses are likely candidates. These (or others) would be investigated first in controlled laboratory conditions where test animals (perhaps Mytilus edulis) are exposed to known concentrations of oil in seawater. In these experiments statistical relationships would be determined for indicator response as a function of petroleum concentration. Finally, these laboratory results would be validated in the field by examining the indicator response along known petroleum pollution gradients resulting from chronic discharge in the marine environment. In Alaska such field gradients could include Port Valdez, where tanker ballast with residual petroleum is discharged; Cook Inlet, where co-produced water is discharged by offshore oil production platforms; and Prudhoe Bay, where co-produced water may be discharged in the future. Laboratory experiments should include oil in seawater preparations simulating both ballast water and co-produced water.

Research Milestones

Milestones for this project are shown in Table 4 . In phase one, funding for the workshop is minimal. Unless additional support can be secured it would be necessary to hold the workshop in conjunction with an established meeting such as the AAAS Alaska Science Conference. Phase two is represented in the milestone chart on a somewhat schematic manner in that laboratory experiments and field verification are strictly alternating. In fact, it will doubtless be advantageous to have some overlap between these two activities. The nature of this overlap will be dictated by the study sites and indicator species selected. The milestone chart does imply that two bio-indicator systems will be investigated; one beginning in year two and the other in year four.

Required Resources

The time and dollar requirements of this project are indicated in the milestone chart, Table 4.

Three distinct areas of expertise will be required of the organization which performs this work: 
Table 4 Milestones

Year

Activity

1

2

3

4

5

Phase One

Literature Search

$20 \mathrm{~K}$

Workshop

$5 \mathrm{~K}$

Phase Two

Laboratory Experiments

$50 \mathrm{~K}$

$50 \mathrm{~K}$

Field Verification

$50 \mathrm{~K}$

Technical Reports and

Interaction with
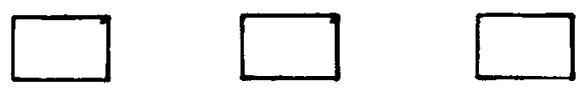

Workshop Participants 
1. Knowledge and experience in the area of biological indicators of marine oil pollution. This will include the ability to perform the critical review of phase one and to design and execute the laboratory and field studies of phase two.

2. Experience and ability to conduct scientific field studies in Alaska. Productive scientific work at remote sites requires judgement based on experience of what is (and is not) logistically possible.

3. Knowledge of the principles of cost-effective environmental information production and familiarity with the agency personnel in Alaska who constitute the primary user group for this work.

Specific individuals and organizations believed to have the ability to perform this work are:

1. Dr. S. Rice

NOAA/Auke Bay Laboratory

Auke Bay, Alaska 99821

2. Dr. D. Shaw

Institute of Marine Science

University of Alaska

Fairbanks, Alaska 99701

Applications of Research

The purpose of this research is to provide environmental decision makers (primarily personnel of permit writing agencies) with up-to-date and critically evaluated information about the available bio-indicator systems for use in cold climates. Therefore the work will include a particular effort to identify and communicate with this user group. This will be done initially with a workshop that presents the results of a critical review of the bio-indicator literature. Subsequently this will involve direct transmission of technical reports related to this work to the workshop participants. Throughout, feedback from this user group to make the research more responsive to their neens will be sought.

\section{References}

National Academy of Sciences (1980). The International Mussel Watch, Washington D.C.

Weinstein, M.C. (1979). Decision Making for Toxic Substances Control: Cost-Effective Information Development for the Control of Environmental Carcinogens, Public Policy 27:333-83.

Widdows, J., T. Bakke, B.L. Bayne, P. Donkin, D.R. Livingstone, D.M. Lowe, M.N. Moore, S.V. Evans, and S.L. Moore (1982). Responses of Mytilus edul is on Exposure to the Water Accommodated Fraction of North Sea Oil. Mar. Biol. $67: 15-31$. 
Introduction

Substantial quantities of dissolved aromatic hydrocarbons, 2.4 metric tons per month, now are discharged into Port Valdez on a continuous basis. Additional amounts are likely to be included with the "produced" water that is separated from oil and discharged into the Beaufort Sea. Current key questions are 1) how long do these aromatic hydrocarbons remain in the water column, 2) what concentrations are attained, 3) what significant organic products are formed during biodegradation, 4) what are the lifetimes of these biodegradation products in the environment, and 5) what is the toxicology of the resulting mixture.

The availability of background data on the constituent questions involved as well as logistic considerations affect the order in which component questions should be addressed. For example, questions regarding toxicology will follow chemical component identification here and the development of an appropriate biomonitoring program (attached).

Many workers (Rice et al., 1971; Griffin and Calder, 1977; Atlas, 1977) have observed that the toxicity of crude oil toward fish is greatly enhanced by "weathering" and presume that the new toxicity is due to microbial oxidation products. Phenolic acids are well known toxins liberated by tropical forests (Whittake and Feeny, 1971) which reduce the insect larvae content of receiving streams. Molecular structures are similar to those which micro-organisms may produce from hydrocarbons. Cerniglia, Malins and coworkers (1980) have begun to characterize some of the photooxidation products of petroleum and believe that these oxidation products are key toxicants. While the visible floating and particulate portions of oil spills have received much attention (Atlas, 1977) the low molecular weight dissolved aromatic fraction is difficult to measure and thus remains to be examined.

It is known that dissolved aromatic hydrocarbons are biodegraded at rates which give lifetimes of from weeks to many decades in Southcentral Alaska (Button, Robertson and Craig, 1981). By way of comparison, the lifetimes under similar conditions in the Gulf of Mexico are only a few days (unpublished observations). So very long lifetimes for dissolved hydrocarbons in seawater are a cold-climate phenomenon. The theory of Tanford as extended by Button (1976) shows that most hydrocarbons in open seawater will be dissolved. Incorporation of these kinetics into estuarine system models give equilibrium concentrations of between 0.1 and $1 \mu \mathrm{g} / 1$ iter in Port Valdez, so something is known of concentrations. The bioconversion process of these aromatic hydrocarbons and related rates remain unstudied in the Beaufort.

Probably missed because of the difficulties in dealing with highly volatile compounds, studies at realistically low hydrocarbon concentrations $(<1 \mu \mathrm{g} / 1 \mathrm{iter})$ show that when biodegradation does occur, metabolism is incomplete, giving rise to partly oxidized products other than carbon dioxide. These products can account for $60 \%$ of the hydrocarbons metabolized (unpublished data). Since these partial oxidation products accumulate in mixed cultures of hydrocarbon oxidizing marine bacteria from the ballast water treatment plant at Port Valdez, it is 
very likely that 1 ) both the treatment plant and the microflora of seawater are generating large quantities of these biochemicals, 2) since they accumulate in mixed cultures, their lifetimes are comparable tn those of the parent hydrocarbons in Alaskan waters (years to decades or centuries in Southcentral Alaska, unknown but possibly quite long in the Beaufort), and 3) they probably contribute to the enhanced toxicology of weathered crude oil. The existence of such unknown organic products is now confirmed by their appearance as several major resolved components after treatment of partly degraded low molecular weight aromatic hydrocarbons with group-specific derivative-forming reagents.

The first step should be the molecular characterization of the material resulting in major portion from the ballast water treatment and from the addition of produced water into oil producing estuaries. With the resulting chemical characterization it is feasible to efficiently confirm the large calculated input rate of metabolic products from ballast water into Port Valdez by direct analysis of suitably concentrated samples. Also, with the knowledge of these product structures suitable mixtures can be prepared in order to directly measure their biodegradation rates in seawater. Field studies may then proceed which combine biodegradation rate measurements of the parent hydrocarbon, biodegradation rate measurements of their products of metabolism, and direct measurement of concentrations, all at the potentially impacted locations from Port Valdez to the Beaufort.

Need for the research is based on observations showing that about half of the large amounts of aromatic hydrocarbons dumped into Alaska waters are converted to peculiar organic products of unknown identity. Identification must precede reasonable testing for potential regulation. Although these products disappear as invisible components of seawater, given the potentially very long 1 ifetimes, the suggestive toxicity data, and the very large amount of material involved, it is entirely appropriate to identify what wo are adding (present and potential) to the ocean. Since toxicity is associated with both the aromatic hydrocarbons and their oxidation products (clearly demonstrated for certain oxygenated derivatives), it is important to understand the lifetimes (biodegradation rates) of both the hydrocarbons and their products so that accumulation processes over decades and centuries can be considered. These data are critical to informed decisions on the adequacy of current treatment processing of oily waste water and the consequences of increased dumping.

Research Approach

The general strategy is to 1) identify the organic products of dilute dissolved aromatic hydrocarbon biodegradation by indigenous Alaskan microflora, 2) quantify the portion of each component produced during attack by the organisms, 3) produce these components in quantity with radiolabel attached, 4) measure the decomposition rates of both these radiolabeled products and their parent hydrocarbons in potential receiving waters of Alaska, and 5) produce a model that forecasts concentrations of both the aromatic hydrocarbons and their products on an estuarine and global scale.

Research Milestones

1. Products of toluene biodegradation identified. Product identification must deal with low concentrations $(<T \mathrm{ppb}$ in order to avoid recycling kinetics) of a common polluting parent aromatic hydrocarbon. Toluene is among the most 
prevalent. This is best done with radiolabeled hydrocarbons so that the components can be located in nanogram quantities and followed during separation steps. These products are produced by incubation of representative hydrocarbons with representative populations and types of microflora at representative seawater temperatures. Following formation, products are separated, collected, and identified as to the chemical conformation. Identification uses a combination of the latest technologies available in order to meet this less than trivial challenge. The data will be transferred to the biomonitoring program for potential testing.

2. Material balances which give the amounts of product entering the environment are established. Ratios of organic products, cell material, and carbon dioxide formed from aromatic hydrocarbons biodegraded are measured at ranges of hydrocarbon concentrations spanning ambient levels and are formed using various species of hydrocarbon degrading bacteria. The process is further studied in the environment by purging treated ballast water (from a treatment plant) of aromatic hydrocarbons, adding radiolabeled hydrocarbons, and measuring the rate of product formation by the accompanying microflora. These data help establish the significance of the problem and the credibility of the rate measurements and identification made. They constitute an aspect of publishable work.

3. Radiolabeled products are produced for in situ degradation studies. In order to establish lifetimes and the accumulation potential of products released into the ocean, their degradation rates are measured with radioactive products. These are formed from radioactive aromatic hydrocarbons by usual Alaskan marine microflora, collected on columns, eluted, and used in biodegradation rate studies. The end product of this milestone is test material for rate studies and a publishable method of separation of the products produced.

4. Biodegradation rates of products. Radioactive products will be incubated with organisms from the Alaskan environment in order to obtain kinetic constants which predict the general behavior of the products in seawater. After knowing how product decomposition rates change with their concentration, these products will be incubated at various points in the Alaskan environment. The laboratory data are used to design the experimental concentrations used. Lifetimes of the products are computed from the portion of the products biodegraded in a given period of time. The end product is a publishable estimate of the lifetime of these products in the environment and an evaluation as to how ballast water treatment changes the water chemistry in Port Valdez.

5. Biodegradation rates of dissolved aromatic hydrocarbons. Rates data are available from about a dozen samples and the decomposition rates have been found to be very location dependent but quite slow. Particular attention will be paid to those rates of biodegradation in the Beaufort where none are now available. Methodology will make use of the rate of conversion of radioactive toluene to $\mathrm{CO}_{2}$ in very fresh samples, and account for the radioactivity diverted to cell material and to organic products above. The end product is a publishable estimate of the expected lifetimes of aromatic hydrocarbons in Alaskan arctic coastal water.

6. Concentrations of aromatic hydrocarbons in seawater. Current models predict that dissolved hydrocarbons should now be reaching directly quantifiable quantities in Port Valdez in areas away from the impacted "diffusion zone." About three laboratories are established which can quantify the expected levels. 
Samples will be collected, the aromatic hydrocarbons transferred to chromatographic columns, sealed and shipped to the appropriate capable laboratory. Samples will also be collected in the Beaufort in order to establish levels there. The expected product is concentration data which are used in order to corroborate computed concentrations of hydrocarbons in seawater.

7. Models which give expected long-term changes in water chemistry due to added hydrocarbons. The rate data collected will be combined with petroleum release rates and oceanic circulation rates in order to give equilibrium concentration trends over the next few decades. This is the final synthesis of the information collected and will be presented as a publishable manuscript.

Required Resources

A budget which would permit reasonable progress given the inherent support of faculty time and research facilities at a strong research university would be a month of principal investigator time, a full-time technician, a share of ship-time, travel to field stations, radioisotopes, chemicals and supplies, and support services such as instrument maintenance, drafting, typing, and overhead. As an aid to these expenses, $\$ 20,000$ has been suggested for the first year and $\$ 40,000$ for years 2 through 5 .

Specific expertise requires centers on the ability to 1) deal with manipulations of extremely small concentrations of organics in water (seawater), 2) design separation procedures for trace organics in seawater, 3) use radiotracers effectively, 4) perform rate experiments with dilute microbial systems and interpret the resulting kinetics, 5) carry out organic chemical reactions and submit their products to chromatographic and spectroscopic analysis, and 6) have access to the impacted environment.

Application of Results

Current policy regulates the dumping of low mnlecular weight aromatic hydrocarbons into the Alaskan environment without knowing either how long they remain or what they form. Current research shows that these chemicals will accumulate in much the same way as DDT and PCBs do in the world ocean. In addition, it shows that entirely unsuspected partial oxidation products accumulate from aromatic hydrocarbon biodegradation similar to the conversion of DDT to DDE, also experienced in the environment. This research will identify how much of what will result from aromatic hydrocarbon dumping of ballast water and co-produced water. Following consideration of accumulation kinetics and toxicology, a reasonable dumping policy can be formulated.

References

Atlas, R. M. 1977. Simulated petroleum biodegradation. CRC Crit. Rev. Microbiol. 5:371-386

Button, D. K. 1976. The influence of clay and bacteria on the concentration of dissolved hydrocarbons in saline solution. Geochim. Cosmochim. Acta. 40:435-440.

Button, D. K., B. R. Robertson and K. S. Craig. 1981. Dissolved hydrocarbons and related microflora in a fjordal seaport: Sources, sinks, 
concentration, and kinetics. Appl. Environ. Micorbiol. 42:708-719.

Cerniglia, C. E. , D. T. Givson and C. Von Baalen. 1980. Oxidation of napthalene by cyanobacteria and microalgae. J. Gen. Micorbiol. $116: 495-500$.

Griffin, L. F. and J. A. Calder. 1977. Toxic effect of water-soluble fractions of crude, refined, and weathered oils on the growth of a marine bacterium. Appl. Environ. Microbio1. 33-1092-1096.

Malins, D. C. 1980. Pollution in the marine environment. Environ. Sci. Technol. 14:32-36.

Rice, S. D. , S. Korn, C. C. Brodersen, S. A. Lindsay and S. A. Andrews. 1981. Toxicity of balast-water treatment effluent to marine organisms and Port Valdez, Alaska. In: Proceedings 1981 0il Spill Conference. American Petroleum Institute, Washington, D.C.

Whittaker, R. H. and P. P. Feeny. 1971. Allelochemics: Chemical interactions between species. Science 171:757-770.

ECOSYSTEM IMPACTS OF PLACER MINING IN ALASKA

Research Description and Questions

The renewal of placer mining activity in Alaska has placed a developmental burden upon several of Alaska's streams and estuaries. Although the introduction of large amounts of suspended particulate matter is the most obvious of the resulting impacts, other potentially more serious perturbations may arise through other less visible insults such as the introduction of heavy metals and large quantities of dissolved and particulate organic matter. These impacts could have either deleterious or positive impacts on stream biota depending upon whether additions were toxic (e.g., mobilized arsenic) or a potential food source to invertebrates (suspended peat particles). Very little coherent information is available on stream ecosystem alteration by developmental impacts in Alaska and most permitting and regulatory action is based upon visible changes in water quality or criteria adopted from temperate latitudes bearing small relevance to the extreme seasonal hydrologic regimes of interior and arctic Alaska.

The research question is posed: Is it possible, through the use of adaptive environmental assessment techniques, to define the impacts of placer mining activities on an Alaskan stream ecosystem, and to evaluate, from an ecosystem standpoint, the severity of the perturbations to the biota, with due consideration also being given to secondary impacts such as loss of recreational or aesthetic values?

Justification

Most "environmental studies" address a particular symptom arising from a perturbation to the environment resulting from human activity. In the case of placer mining, which has undergone a resurgence during the last few years in Alaska, the most obvious impacts have been through habitat destruction and the introduction of large amounts of suspended matter to streams. These problems (or more accurately, symptoms) have been addressed by the State Department of 
Environmental Conservation through permitting requirements and attempts at designing settling ponds for miners. To date this has been a notable failure from a technical and environmental protection point of view.

This research project would approach the problem from an ecological standpoint. Selected indicator species of apical or near-apical position in the foodwebs of the impacted streams would be assessed as to potential impact in a "downward-looking matrix" to predict the likely points of stress on the life cycle or food supply or reproductive requirements of the organisms. These sensitive points would then be studied to see if, indeed, the perturbations were stressing the organisms. Thus, the focus of the studv shifts in an "adaptive environmental assessment" rather than arbitrarily selecting an "obvious" perturbation which may have little real impact on the biota or mask a more serious problem arising from indirect or less visible effects.

\section{Statement of Objectives}

1. Through the use of an interdisciplinary evaluation starting with known apical organisms in a stream select those species of significant human, aesthetic or ecological importance to the ecosystem.

2. Through a "downward-looking" matrix, evaluate the potential impacts on these indicator species arising from current or impending perturbations to the stream.

3. Conduct field studies to determine if projected impacts are occurring and to seek additional changes not anticipated or of differing magnitude than projects.

4. After evaluation of interdisciplinary field studies, adapt the environmental studies to fill newly identified research needs or to extend data bases to enable projection of impacts.

5. Periodically synthesize the environmental and biological data obtained to assist state and federal agencies in evaluating the magnitude of impacts and to realistically regulate human activity with an awareness of the ecological costs involved.

Research Approaches

Study Site Selection

State geological survey personnel have identified several areas of Alaska where placer mining is either active or anticipated in the future. For this project, either the Alaska Gold Company's working dredge in the Nome district or the Goodnews Bay platinum dredging in southwestern Alaska are likely candidates for study. Other smaller operations in the Fairbanks district would also be evaluated due to the proximity to research centers.

\section{Adaptive Environmental Assessment}

This technique of assessing developmental impact has only recently been used in Alaska through the NOAA-Outer Continental Shelf Environmental Assessment Program in their Barrier Island-Lagoon System Study on the coast of the Beaufort Sea. Their success in describing the functioning and impact sensitivities of 
this remote area were encouragement toward continuation of this type of study. For this effort, a small working group of interdisciplinary scientists would be assembled and a preliminary synthesis of the available data made with an attempt to address the consequence of mining activities. Ideally, biological and physical disciplines would be represented by the scientists most knowledgable of the processes and environment of the area. Participation by mining industry personnel and agency personnel would aid in evaluating likely future activity. From this workshop, a study plan would be assembled and the research projects started for the first season.

\section{Field Research}

The projects would be coordinated scientifically and logistically to maximize the efficiency and cost effectiveness. A field camp would be set up near Nome, for example, and common rooming board and transportation used to the study site. A degree of flexibility in scientific goals should be maintained to allow maximum response by scientists to emerging shifts in scientific direction.

\section{Synthesis}

Following the field season and a reasonable time for data processing, a synthesis meeting by concerned parties would be held to: 1) discuss field and lab data; 2) evaluate the data in respect to project goals; and 3) adapt research objectives to meet the direction indicated by the first two steps. The project manager would then set about implementing the changes while still attempting to preserve continuity and efficiency in the program.

After the completion of the final field and laboratory studies, a synthesis meeting would be conducted with the following goals: 2) assemble all of the data and conclusions of the scientific studies; 2) evaluate proposed stipulations and mitigating measures proposed by agency personnel; and 3) identify research questions left unanswered and future research direction.

\section{Time Frames}

An interdisciplinary adaptive environmental assessment program would, by its nature, require at a minimum, two or three field seasons. A more likely time frame would be four or five years.

\section{Suggested Sites}

Although site selection would best be made at the initial synthesis meeting between contract manager and prospective research personnel, likely choices are the Alaska Gold Company operations at Nome, the Goodnews Bay platinum operations or one of the smaller operations such as the Nyack placer operations near Sleetmute.

\section{Constraints}

The major constraints are logistical and the commitment to a long-term project aimed at optimizing scientific information relative to monetary input. Past experience with NOAA-OCSEAP, state agency, and industry personnel have shown that the long-term benefits are cost-effective and valuable to all parties concerned. 
Projected costs for an interdisciplinary study of this type would require approximately $\$ 1$ M/year.

Types of Output

The results and recommendations arising from this study would be disseminated in three major forms:

1. Real time conveyance through synthesis meetings and agency conferences.

2. Research reports to the funding source.

3. Scientific refereed papers and presentations following completion.

\section{HABITAT MANIPULATION/MODIFICATION}

Overall research phasing: habitat group

There were three topic areas that received generally similar ranking of importance by the Chena Hot Springs workshop:

overall ranking

1. $0 i 1$ development in coastal tundra wetlands

15

2. Forest management and aquatic habitats

3. Gravel removal from riparian habitats

26

We have developed detailed research plans for the first two of these issues. We recommend that both be phased in as soon as possible and that the third topic be initiated in the fourth year, as activities decline in the first two topic areas. The recommended phasing is as follows. See individual write-ups for breakdown of activities.

$\begin{array}{lcccccc} & \text { Year 1 } & \text { Year } 2 & \text { Year } 3 & \text { Year } 4 & \text { Year } 5 & \text { Year } 6 \\ \text { 1. Tundra Wetlands } & ? & 80 \mathrm{~K} & 150 \mathrm{~K} & 150 \mathrm{~K} & 150 \mathrm{~K} & 100 \mathrm{~K} \\ \text { 2. Aquatic Habitats } & 120 \mathrm{~K} & 150 \mathrm{~K} & 150 \mathrm{~K} & 150 \mathrm{~K} & 75 \mathrm{~K} & \\ \text { 3. Riparian Habitats } & & & & 50 \mathrm{~K} & 150 \mathrm{~K} & 150 \mathrm{~K}\end{array}$


IMPACT OF OIL DEVELOPMENT UPON COASTAL TUNDRA WETLANDS

Introduction

Statement of Problem: Expanding oil and gas development in tundra wetlands of northern Alaska is a source of increasing environmental impact. In order to develop an environmentally sound management plan, the following research objectives should be met:

1) Define the major community types in North Slope wetlands in terms of vegetation composition, primary production and soil properties. Develop a guide for managers including description of vegetation types with representative air and ground photos of these types.

2) Compare impacted and control areas in each major wetland type with respect to the following disturbances: altered drainage, dust, and production waters (i.e. those contaminated with oil).

3) Determine why certain disturbances are particularly detrimental in sensitive habitats.

4) Rank habitats with respect to sensitivity to each type of disturbance.

5) Recommend guidelines for habitat use and for permissible levels of each disturbance type.

Current Knowledge: There has been a large amount of work done on environmental impact of oil development in Prudhoe Bay wetlands. However, most of this has been contract work for industry, environmental impact statements, and unpublished reports, and is not generally available. The first major task of a project on coastal tundra wetlands is to gather together and evaluate this diffuse set of information.

Two major vegetation classification schemes have been developed for tundra wetlands, one by Webber and Walker and one by Batten and Murray. The Webber/Walker classification scheme has been associated with extensive mapping activities of vegetation and soils and probable sensitivity to offroad vehicles in the Prudhoe Bay area (Walker et al. 1980, Walker and Webber unpub1,)、 If simplified, either of these vegetation classification schemes could serve as a useful basis for land management. Published work on environmental impact in coastal tundra wetlands has considered the short-term impact of offroad vehicles (Babb and B1iss 1974, Gersper and Challinor 1975, Challinor and Gersper 1975, Everett et al. 1978, Webber and Ives 1978, Chapin and Shaver 1981); preliminary examination of one impoundment (Chapin and Shaver 1981); short-term experimental studies of oil spills (e.g. Everett 1978, Walker et al. 1978, Linkins et al. 1978, Webber et al. 1980); and study of effects of development on wildlife (Roby 1978). Although other major studies have been done, the work is not generally available and would require contact with many agencies, industry and individual researchers. This lack of readily available information limits detailed effective planning for future research. 
Rationale: $0 i 1$ and gas development on the North Slope of Alaska has potential for extensive regional impacts as oil development continues to expand. The existing field at Prudhoe Bay covers approximately 150 square miles; drill pads are spaced approximately 2 miles apart (1 drill $\mathrm{pad} / 2560$ acres). Drill pads are connected to a central road and other oilfield facilities (gathering centers/flow stations, operations centers, power plants, camp pads and service company pads) by a network of access roads and pipeline pads. The Kuparuk field is expected to spread over 600 square miles; drill pads are now spaced every two miles but may eventually be spaced every mile. Development of the Milne Point Area is just beginning and the Point Thompson Area will soon be underway. Thus a large area of coastal tundra will be directly affected by oil development.

Impacts from oilfield development have been shown for caribou which calve in areas of projected oilfield expansion, for shorebirds that migrate to the arctic coastal plain from throughout North America, and for the vegetation itself which is in delicate balance with an extreme environment. Past research has shown that some wetland types are much more sensitive to disturbance than others (Walker et al. 1980), although their relative sensitivity depends up on the nature of the disturbance. Beyond the direct loss of wetlands due to gravel fill, impacts may be caused by:

a. Altered drainage patterns due to gravel placement and inadequate culverting.

b. Dust from road traffic and pads.

c. Production waters (i.e. oil-contaminated waters pumped from wells).

d. Toxic materials from drilling mud disposal pits, oil spills on the facilities pads, and oil-contaminated waters used for dust control.

e. Air pollution (particularly $\mathrm{SO}_{2}$ ) from refineries.

f. Brine that is being reinjected into wells.

Information on the extent of impacts due to oilfield development on the North Slope is needed by the Environmental Protection Agency (EPA) in exercising their oversight authority of the Section 404 dredge and fill permitting program (Clean Water Act of 1977) as outlined by the "Guidelines for Specification of Disposal Sites for Dredge or Fill Material" (40 CFR Part 230, Vol. 44, No. 249). Specifically, information on the extent of impacts due to drainage alteration, dust and introduction of toxic materials related to wetland types will be useful for permitting and policy decisions; careful definition of the impacts is important in 
defining ecologically sensitive habitats and in defining the types of human activities that most strongly affect each habitat.

Relationship to workshops and other EPA research: Study of environmental impact of oil development upon North Slope wetlands is a logical consequence of priorities established in EPA workshops. This study received the highest rank of all the habitat modification topics discussed at the EPA Chena Hot Springs meeting. It is clearly related to oil and gas development which was considered by the first EPA workshop to be the most important developmental impact.

The North Slope wetlands study would fit in well with air quality research that will be conducted by EPA on the North Slope (see air pollution group report), because (1) it could use the same logistic base and some of the same environmental data as the EPA air quality group, and (2) the planned study of air quality on vegetation is of immediate concern and interest to the EPA air quality group.

\section{Research Approach}

Three major research approaches are recommended for study of North slope wetlands. These approaches are complementary and should all be undertaken to achieve research objectives.

1. Carry out an extensive literature search and evaluation on the impact of oil development on coastal tundra. A great many studies have already been done in this area and the greatest initial contribution that this project could make would be a summary and evaluation of this work and a set of preliminary conclusions as to which habitats are most likely to be sensitive to environmental damage and which habitats are of particular biological importance. This literature survey would involve contact with industry and agencies as well as survey of the published literature.

2. Develop a simplified habitat classification scheme of major types that are (a) biologically important and (b) readily recognizable from infrared aerial photography. Produce a guide for managers that would enable them to identify these habitats from aerial or ground photography or vegetation data and that would provide a ranking of habitat types in terms of biological importance and sensitivity to disturbance. These rankings would be developed in research approaches 1 and 3 .

3. Determine the time course of impact of various environmental disturbances by comparing control areas with dated disturbances of different ages. Community response would be measured in terms of altered soil properties (temperature, thaw depth, pH, salt content, and nutrient availability), vegetation characteristics (species composition, primary production and biomass by species, plant nutrient content, and pattern of phenological development), and use by mammals and waterfowl. Permanent 
plots would be established in each dated disturbance which would be followed by non-destructive sampling over a period of years to confirm that comparison of different-aged disturbances at one time is a valid measure of the time course of community recovery or degradation. Disturbance types to be studied include several which would receive major effort (dust, impoundment, and oil production waters) and others which would be studied with lesser intensity as time and funding permit ( $\mathrm{SO}_{2}$ pollution, salt, drilling mud, and brine).

Experimental design will depend upon accurate aging and determination of the nature and severity of the initial disturbance, as determined by reconstruction from aerial photography of different ages. Where possible, it is crucial to find replicate disturbances of the same age and type in each habitat type and to compare these areas with valid controls of the same habitat type which was present before disturbance. This would be determined from pre-disturbance aerial photography and examination of peat structure in disturbed sites.

This research has contributions from both the decision-making and scientific viewpoints. It will provide managers with a guide that will enable them to identify habitat types and predict the likely environmental impact of development in these areas. Using aerial photography or vegetation maps they could rationally plan development to use habitats in such a way as to minimize disturbance. The research plan will provide the first careful and thorough documentation of disturbance impacts of Prudhoe Bay oil development and provide the basis for understanding the nature of ecosystem change in response to disturbance in coastal tundra.

Prudhoe Bay is the only reasonable study site because of the long history of oil-related development in the site.

\section{$\underline{\text { Research Milestones }}$}

The following research milestones are suggested:

Milestone

1. Literature review

2. Preliminary managers' guide to vegetation

3. Habitat sensitivity analysis (from aged disturbances)

4. Analysis of permanent plots in disturbances over several years

5. Final guide to habitats and their disturbance sensitivity

\begin{tabular}{|c|c|}
\hline Product & Date \\
\hline $\begin{array}{l}\text { journal paper; } \\
\text { report to EPA }\end{array}$ & Year 1 \\
\hline report to EPA & Year 2 \\
\hline $\begin{array}{l}\text { report to EPA; } \\
\text { journal article }\end{array}$ & Year 3 \\
\hline $\begin{array}{l}\text { report to EPA; } \\
\text { journal article }\end{array}$ & Years $4 \& 5$ \\
\hline $\begin{array}{l}\text { report to EPA, } \\
\text { distributed to } \\
\text { managers. }\end{array}$ & Year 5 \\
\hline
\end{tabular}


Required Resources

The following is an estimate of the resources required to achieve each research milestone.

Year 1 Year 2 Year 3 Year 4 Year 5

\begin{tabular}{|c|c|c|c|c|c|}
\hline \multicolumn{6}{|l|}{ Manpower (months) } \\
\hline Principal Investigator & 0.5 & 2.0 & 2.0 & 2.0 & 2.0 \\
\hline Estimated cost & $\$ 80 \mathrm{~K}$ & $150 \mathrm{~K}$ & $150 \mathrm{~K}$ & $150 \mathrm{~K}$ & $100 \mathrm{~K}$ \\
\hline
\end{tabular}

Major activities

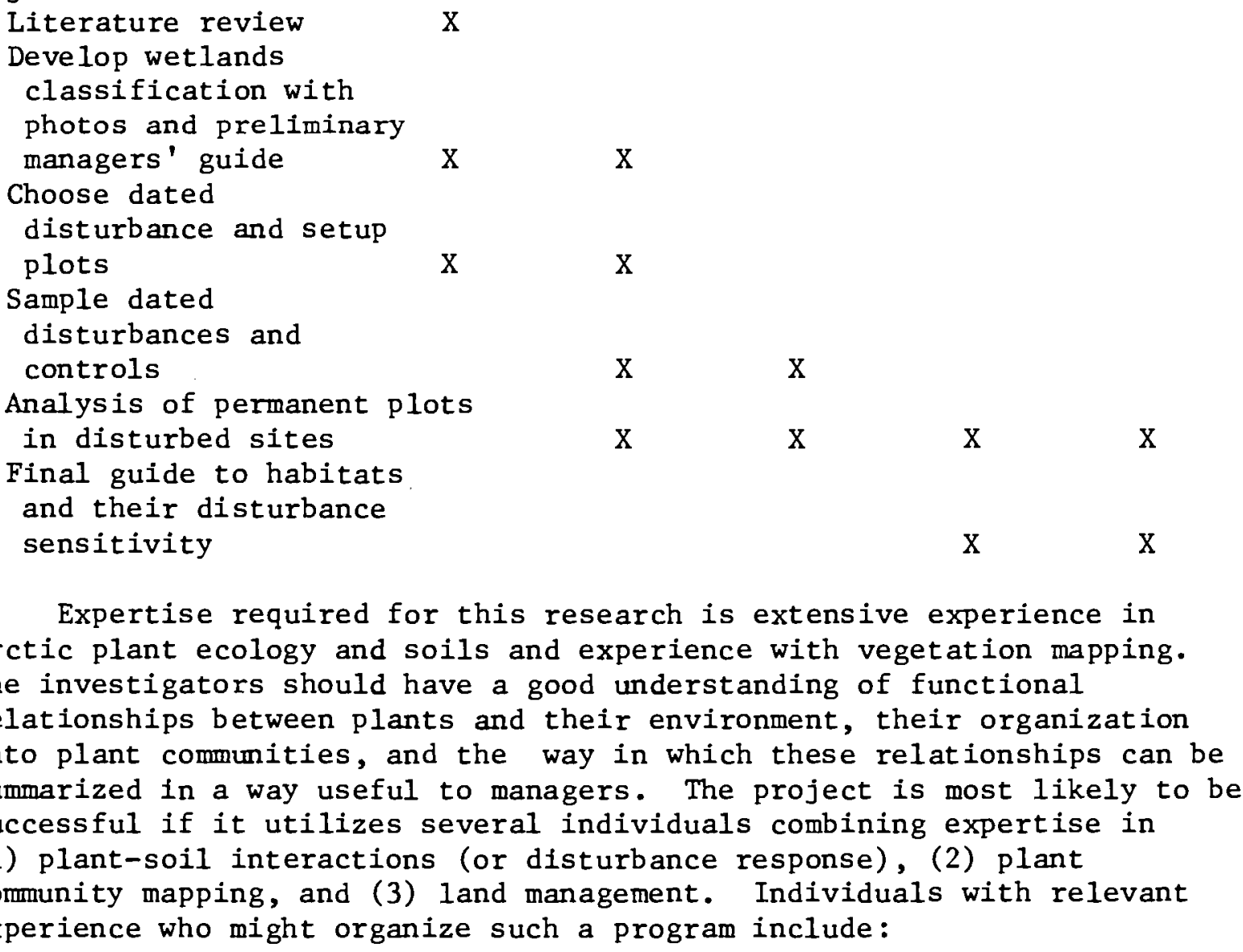

F. Stuart Chapin, III Institute of Arctic Biology, University of Alaska Giles Marion Systems Ecology Research Group, San Diego State U. Patrick Webber Laurence Bliss Kaye Everett Inst. of Arctic \& Alpine Research, U. of $\mathrm{CO}$. Dept. of Botany, Univ. of Washington Inst. of Polar Studies, Ohio State Univ. Stephen MacLean Inst. of Arctic Biology, University of Alaska Larry Johnson CRREL, Army Corps of Engineers 


\section{Application of Results}

The results of this research program should have direct application to EPA's needs in Alaska. It is designed to provide a quick preliminary (2 year) and a more final (5 year) managers' guide that will enable EPA or any other management agency concerned with tundra wetlands with a manual that will define important wetland types and will define sensitivity to various disturbances in each of the major wetland types. The manager can then make environmentally sound decisions on permit applications using the managers' environmental guide and either aerial or ground photography or minimal vegetation data. In future years, if extensive large-scale vegetation mapping or photography were available for North Slope wetlands, long-range management plans could be developed using the managers' guide in such a way as to concentrate development in less sensitive or critical habitats and avoid environmentally important or sensitive areas. 


\section{References}

Babb, T.A., and L.C. Bliss. 1974. Effects of physical disturbance on arctic vegetation in the Queen Elizabeth Islands. J. Appl. Ecol. $11: 549-562$.

Challinor, J.L. and P.L. Gersper. 1975. Vehicle perturbation effects upon a tundra soil-plant system: II. Effects on the chemical regime. Soil Sci. Soc. Amer. Proc. 39:689-695.

Chapin, F.S., III and G.R. Shaver. 1981. Changes in soil properties and vegetation following disturbance of Alaska arctic tundra. J. Appl. Ecol. 18:605-617.

Everett, K.R. 1978. Some effects of oil on the physical and chemical characteristics of wet tundra soils. Arctic 31:260-276.

Everett, K.R., P.J. Webber, D.A. Walker, R.J. Parkinson, and J. Brown. 1978. A geoecological mapping scheme for Alaska coastal tundra. Proceedings Third International Conference on Permafrost, vol. 1, National Research Council of Canada. Pp. 359-365.

Gersper, P.L. and J.L. Challinor. 1975. Vehicle perturbation effects upon a tundra soil-plant system. I. Effects on morphological and physical environmental properties of the soils. Proc. Soil Sci. Soc. Amer. 39:737-744.

Linkins, A.E., R. Antibus, O.K. Miller, and G.A. Laursen. 1978. Differential responses of arctic plant roots to oil perturbations. In D.C. Adriano and I.L. Brisbin (eds.). Environmental Chemistry and Cycling Processes.

Roby, D.D. 1978. Behavioral patterns of barren-ground caribou of the Central Arctic head adjacent to the Trans-Alaska Oil Pipeline. M.S. Thesis. Univ. of Alaska, Fairbanks. 200 pp.

Walker, D.A., K.R. Everett, P.J. Webber, and J. Brown. 1980. Geobotanical atlas of the Prudhoe Bay region, Alaska. CRREL Report 80-14. Hanover, New Hampshire.

Walker, D.A., P.J. Webber, K.R. Everett, and J. Brown. 1978. Effects of crude and diesel oil spills on plant communities at Prudhoe Bay, Alaska, and the derivation of oil spill sensitivity maps. Arctic $31: 242-259$.

Webber, P.J. and J.D. Ives. 1978. Damage and recovery of tundra vegetation. Environmental Conservation $5: 171-182$.

Webber, P.J., P.C. Miller, F.S. Chapin, III, and B.H. McCown. 1980. The vegetation: pattern and succession. Pp. 186-218. In J. Brown, P.C. Miller, L.L. Tieszen and F. Bunnell (eds). An Arctic Ecosystem: The Coastal Tundra at Barrow, Alaska. Dowden, Hutchinson \& Ross; Stroudsburg, PA. 


\section{Rationale and Background Informaticn}

The subarctic taiga environment of interior Alaska (between the Alaska Range on the south and the Brooks Range on the north) is among the least studied forest regions of the United States. Interior Alaska is a region of discontinuous permafrost and extensive forest interspersed with low-lying wetlands and above-treeline alpine tundra. This region has the potential for vastly accelerated development and exploitation, with conflicting management pressures already evidenced by burgeoning population and volatile land ownership issues.

Quantitative, documented information of either undisturbed or managed subarctic upland landscapes and associated stream systems is extremely scarce. Agency response to state and federal land management and regulation directives, notably Section 208 of Public Law 92-500 (Non-point source pollution), is hampered by the current lack of knowledge of both the permafrost-dominated taiga upland environments, and the response of that environment to resource management practices.

The study recommended here is designed to investigate specific impacts of timber harvest in interior Alaska's forests on headwater stream systems. The 1981 ACST report, "Living Resources and Habitat Protection: Research Priorities and Recommendations" (ACST, 1981) notes that "Timber harvesting in the interior of Alaska is also increasing, and even less is known of its impact on fish and wildlife" (ACST, 1981); a specific call is a made for research on "...the effects of logging on the fish and wildlife resources of interior Alaska" (ACST, 1981, p. 7).

In published reviews and position papers concerning non-point or diffuse-source pollution in wildlands, references to subarctic or taiga forest systems are invariably superficial, vague, or (most commonly) entirely absent (e.g. Forest Service, 1977 (EPA-6043-77-036); Federal Water Pollution Control Administration 1968, Meier 1975; EPA 1975; EPA 1976; EPA 1977; Pope 1977).

The primary sources of actual or potential non-point source pollution (NPSP) problems in relation to subarctic forest resource management are now considered to be ( 1 ) forest harvesting and attendant road/skid trail activities, and (2) wildfire, including both actual burning and fire control procedures.

A recent survey of water quality problems in relation to timber harvesting (URS Company/Environaid, 1977), prepared for the state of Alaska in response to Section 208, PL 92-500, stresses (1) the very limited amount of information available concerning interior Alaska (taiga) environments and existing water quality relationships, (2) the 
limited but growing role of forest harvesting in subarctic interior Alaska, (3) the low level of supervision or regulation currently applied to forest harvesting in the region, (4) the probable importance of temporary and permanent roads, including skid trails, and stream crossings in producing increased sediment loading in streams, and (5) the need for research on the entire question of timber harvest/water quality relationships in interior Alaska:

"Hydrologic, silvicultural and biologic investigations concerning the possible effects of large-scale interior logging on streams and streamside environment is necessary at this time. Questions of importance include stream and streamside (groundwater) temperature conditions, alteration of detritus food sources and streambank erosion," (URS Company/Environaid, 1977, p. 137).

\section{Current State of Knowledge and Literature Available}

Recent syntheses of stream ecology (e.g. Cummins 1974, 1979, Hynes 1975) have emphasized the importance of the land-water interface in understanding stream ecology. The watershed, rather than the stream, is the appropriate unit of study. There are two sources of carbon input to the stream: (1) allochthonous input of particulate material (leaves, flowers, etc. from streamside vegetation) and dissolved material from the surrounding landscape; and (2) primary production within the stream by periphyton, mosses and other large plants. Allochthonous inputs dominate most small streams but desert, grassland and perhaps high latitude/altitude streams receive substantial inputs via primary production.

Vannote et al. (1980) described a recent conceptual scheme involving changes in ecological properties with increasing size of streams (the "River Continuum Hypothesis"). An important element in the hypothesis is the change in trophic structure from small headwater streams to larger streams. Specifically, small headwater streams should receive most of their energy from allochthonous sources (litter fall of riparian vegetation) while heavy shading severely limits primary production within the stream. As stream size increases with addition of tributaries, riparian vegetation provides less litter input (per unit stream surface area), and light input (hence primary production) increases. Any management technique which removes riparian vegetation (e.g. logging) should produce effects on the stream analogous to an increase in stream size (see goals and hypotheses, below).

Carbon inputs are incorporated into the stream ecosystem by a variety of macroinvertebrates (primarily insects) which differ functionally. "Shredders" consume large pieces of leaf material and other coarse material following colonization of detritus by microbes (bacteria and fungi). These decay and feeding activities plus physical abrasion produce finer fragments of organic material called FPOM (fine particulate organic material). FPOM in suspension is used by "filter-feeders" (e.g. 
blackfly larvae) while FPOM in the substrate is used by FPOM "gatherers". The periphyton covering submerged surfaces is scraped off by "grazers". These consumers are in turn eaten by predaceous insects and fishes.

The continual downstream transport of both carbon (energy) and nutrients (e.g. phosphorus) produces a downstream "nutrient spiral" rather than a nutrient cycle. Two major processes act to slow the downstream transport of material; (1) capture of FPOM by filter-feeding insects (Wallace et al. 1977) and entrapment of particulate organic material by debris dams (Bilby 1981, Triska and Cromack 1979).

\section{Forestry/Stream Interactions}

Forest harvest (in particular clearcutting) and associated activity (e.g. road building) impacts watersheds and individual streams in many ways (Anderson et al. 1976). The 1iterature on forest harvest/stream interactions is large and will not be reviewed in its entirety here: recent bibliographies/reviews include: Crow et al. (1976), Gibbons and Salo (1973), Lynch et al. (1977), Oswood and Barber (1978) and U.S.D.A. Forest Service (1981).

Removal of streambank vegetation during logging is a controversial topic. Several studies (e.g. Erman et al. 1977) have indicated the utility of buffer strips (riparian vegetation left intact) in protecting streams. However, for a variety of logistical reasons (steep-sided valleys, "windthrow" of isolated timber stands, etc.) streamside vegetation may be removed. Loss of the forest canopy over a stream has several potential effects. The decrease in litter input and increase in solar radiation may cause a change in community structure of stream autotrophs and an increase in stream primary production (Hansmann and Phinney 1973) with a decrease in the allochthonous energy input. It is likely that this will affect the relative abundance of "shredder" vs. "grazer" stream invertebrates. Filter-feeding invertebrates may be influenced in that seston (suspended particulate material) levels may increase following clearcutting (Gurtz et al. 1980). Loss of shade from riparian vegetation affects stream temperatures in several ways. Most importantly, maximum summer temperatures may increase (perhaps to levels lethal to fish or invertebrates). However, at high latitudes increased duration or depth of ice cover associated with loss of the insulating effect of riaparian vegetation may be important.

Logging activities may initially result in input of very large amounts of organic debris to the stream. Fine debris may cause shortterm problems of oxygen loss during decomposition. Larger materials (branches, logs, etc.) potentially have both detrimental (barriers to fish migration) and beneficial effects (cover for fish, habitat for invertebrates and increased retention of particulate carbon and nutrients see Triska and Cromack 1979 and Bilby 1981). Associated logging activities (road building and maintenance, use of heavy equipment, culvert and bridge construction, etc.) have highly variable (and often major) impacts on streams (Megahan 1977, Swanson 1976). 
The net result of timber harvest on any portion of the stream ecosystem is very difficult to predict. For example, stream primary producers (algae, mosses, etc.) may be subjected to increased solar radiation, increased nutrient levels, increased discharge rates, sedimentation by inorganic sediments, and change in grazing pressure by invertebrates. At this stage, it seems most appropriate to examine effects of timber harvest in terms of critical outcome variables (primary production, secondary production, community structure) which integrate these conflicting interactions.

Sediment may enter the stream following logging by several mechanisms, mass movement, bank failure, gully or rill erosion or transported from logging roads. Sediments affect stream communities in a variety of ways. Fine particulate materials ("fines") in stream gravel may directly damage fish eggs or indirectly increase egg mortality through a decrease in intragravel flow. Filling of interstices between large streambed particles reduces habitat'space for both invertebrates and (especially smal1) fishes. The loss of habitat diversity is associated with a decrease in taxonomic diversity of invertebrates and autotrophs.

Loss of riparian vegetation potentially affects stream fishes via loss of riparian cover and loss of terrestrial insects as food. Loss of vegetation over part or all of a watershed may result in decreased evapotranspiration leading to increased discharge (with many secondary effects including transport of dissolved and particulate materials, changes in invertebrate community composition, increased scouring of periphyton during spates, etc.). Change in terrestrial nutrient pools (plants, soils, etc.) may produce change in nutrient inputs to the stream, again with secondary effects (e.g. changes in stream primary producers/primary production).

\section{Relationship to Workshops and other EPA Research}

This topic was considered to be the most important habitat modification issue by the habitat modification planning team. It was ranked second highest of the habitat issues by the entire review group at the Chena Hot Springs EPA workshop. It is an important cumulative and regional effect of development in interior Alaska and will make a direct contribution to understanding the consequences of the altered water quality that occurs with development.

This research would be best done at Caribou-Poker Creeks Research Watershed in central Alaska where the EPA air quality group is recommending a major research focus. The two groups could use many of the same logistic facilities and environmental information. 
$\underline{\text { Research Approach }}$

\section{General Strategy}

Effects of vegetation removal should be examined by both before and after studies and "upstream-downstream" studies following timber harvest. The guiding hypothesis is that vegetation removal will shift the energetic basis of the stream community from dependence upon leaf input from riparian vegetation to increased primary production within the stream itself. This shift should produce a predictable change in community structure of stream invertebrates and changes in utilization of invertebrates by stream fishes. Primary production by stream autotrophs, secondary production of stream invertebrates and community structure of primary producers and invertebrates should be used as integrative measures of changes in stream energetics following vegetation removal. Changes in streambed sediment loads should be investigated as well.

The protocol for examining effects of vegetation removal should involve two study designs: (1) comparison of upstream, experimental (cleared) and downstream (recovery) stream reaches and (2) "before and after" studies of all three stream reaches. Green (1979) lists four prerequisites for an optimal impact study design; (1) the impact must not have occurred so that baseline studies can provide a temporal control, (2) type of impact and place of occurrence must be known so that a sampling design suitable for hypothesis testing can be constructed, (3) it must be possible to measure all relevant biological and physicalchemical variables with individual samples and (4) a non-impacted area must be available to serve as a spatial control. The study design meets all four of the above criteria and thus allows an "optimal impact study design" (Green 1979).

\section{Goals}

1. Determine the effects of removal of streamside vegetation (timber harvest) on the following physical characteristics:

Water temperature

Air temperature

Solar radiation input to the stream

Specific conductance

Turbidity

Non-filterable residue

Volatile residue when applicable

Stream flow

Precipitation

Canopy density

Size distribution of benthic sediments

Stream mapping (substrate types) 
2. Determine the effects of removal of streamside vegetation (timber harvest) on the following chemical stream system characteristics:

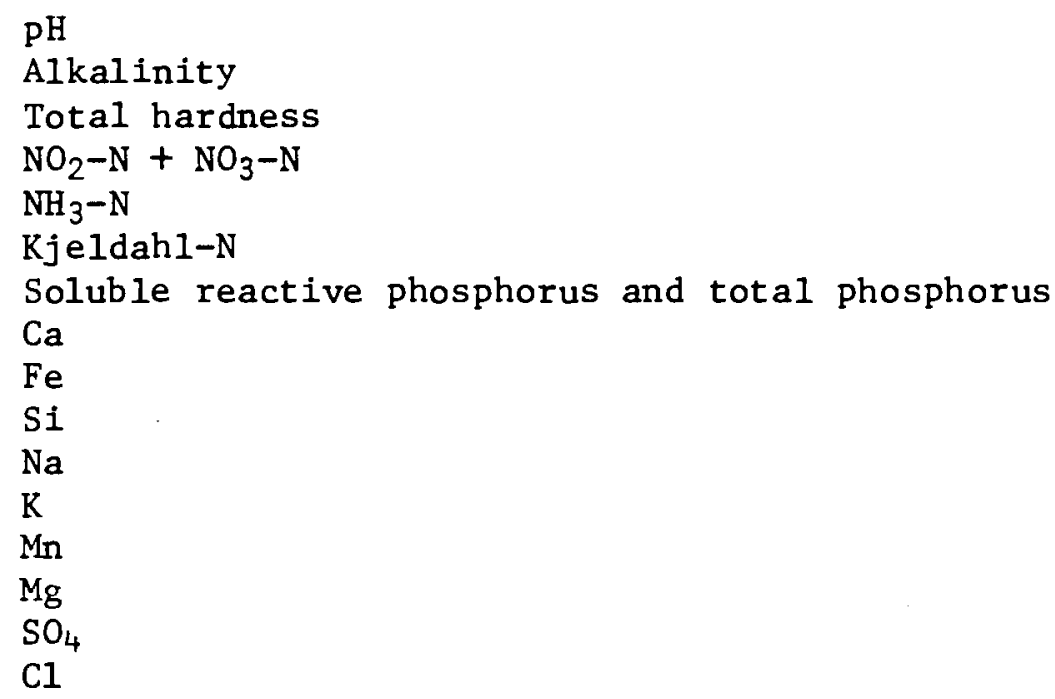

Determine the effects of removal of streamside vegetation (timber harvest) on the following biological stream system characteristics:

Periphyton community structure and diversity

Periphyton standing crop biomass on natural substrates and biomass accumulation rates on artificial substrates Autochthonous (periphyton/moss) production Input of litter from streamside vegetation (allochthonous input)

Benthic macroinvertebrate community structure (both taxonomic and feeding guild structure)

Secondary production of benthic macroinvertebrates Fish density (numerical and biomass)

Fish food habits

\section{Study Site Recommendations}

The recommended study site is the Caribou-Poker Creeks Research Watershed (Fig. 3), a $104 \mathrm{~km}^{2}$ area located $45 \mathrm{~km}$ north of Fairbanks, Alaska. This research area is administered by the Inter-Agency Hydrology Committee for Alaska, with the Institute of Northern Forestry (U.S. Forest Service) serving as lead agency. The Research Watershed (CPCRW) is comprised of two primary stream systems, Caribou Creek and Poker Creek, whose joined flow is tributary to the Chatanika River (in turn tributary to the Tanana River). Elevations range from $210 \mathrm{~m}$ to $826 \mathrm{~m}$.

\section{Research Milestones and Required Resources}

Active experimentation should be approached in two phases. Phase I should concentrate on intensive characterization of an experimental 
(logging) stream reach and characterization of adjacent upstream and downstream reaches. Following one year of pretreatment measurements and analysis, the riparian vegetation along both banks of the experimental stream reach should be removed. Phase II studies at that site should concentrate on determination of the consequences of riparian cover removal for stream biota (possible shift from allochthonous to autochthonous energy base, changes in community structure, etc.) and physical conditions (water temperature, solar radiation input to the channel, channel stability, water chemistry, etc.).

Phase I (preimpact studies) should last one year, so that estimates of yearly allochthonous input/primary production are available and so that seasonal changes in water chemistry, hydrology etc. may be determined. Phase II should last three years with one year of studies during the year of cutting and two years of "recovery" studies.

Analyses of samples of benthic invertebrates and periphyton are time-consuming. It is suggested that reports (data and conclusions to date) lag one year behind field work. Milestones for this two-phased study are shown in Table 5; associated resources required in each year are shown in Table $\dot{0}$.

Table 5 - Research Milestones.

$\begin{array}{lll}\text { Year } & \text { Field Work } & \text { Milestones (Reports) } \\ 1 & \begin{array}{l}\text { Preimpact studies } \\ 2\end{array} & \begin{array}{l}\text { Forest cutting: } \\ \text { impact studies }\end{array} \\ 3 & \begin{array}{l}\text { Recovery Year } 1 \\ \text { studies }\end{array} & \text { Report on preimpact studies } \\ 4 & \begin{array}{l}\text { Recovery Year } 2 \\ \text { studies }\end{array} & \text { Report on impact studies } \\ 5 & \text { None } & \text { None }\end{array}$


Table 6 - REQUIRED RESOURCES

\section{Year/Milestone}

\begin{tabular}{|c|c|c|c|c|c|}
\hline Manpower & $\begin{array}{l}1 / \text { preimpact } \\
\text { studies }\end{array}$ & $\begin{array}{l}2 / \text { preimpact } \\
\text { report }\end{array}$ & $\begin{array}{l}3 / \text { progress } \\
\text { report }\end{array}$ & $\begin{array}{l}4 / \text { recovery } \\
\text { studies } \\
\end{array}$ & $\begin{array}{l}5 / \text { final } \\
\text { report }\end{array}$ \\
\hline $\begin{array}{l}\text { Aquatic Biologist } \\
\text { (Aquatic invertebrates) }\end{array}$ & $2 \mathrm{mo}$ & $6 \mathrm{mo}$. & $6 \mathrm{mo}$. & $3 \mathrm{mo}$. & $3 \mathrm{mo}$. \\
\hline $\begin{array}{l}\text { Aquatic Biologist } \\
\text { (Stream Quality) }\end{array}$ & $2 \mathrm{mo}$. & $6 \mathrm{mo}$. & $6 \mathrm{mo}$. & $3 \mathrm{mo}$. & $3 \mathrm{mo}$. \\
\hline Hydrologist & 1 mo. & 2 mo. & 2 mo. & 2 mo. & 1 mo. \\
\hline Field Technician & 2 mo. & $12 \mathrm{mo}$. & 12 mo. & $12 \mathrm{mo}$. & 3 mo. \\
\hline Lab Technician & 3 mo. & $9 \mathrm{mo}$. & 9 mo. & 9 mo. & $3 \mathrm{mo}$. \\
\hline $\begin{array}{l}\text { Dollars (Salaries, } \\
\text { field equipment, travel, } \\
\text { overhead) }\end{array}$ & \$125K & $\$ 150 \mathrm{~K}$ & $\$ 150 \mathrm{~K}$ & $\$ 150 \mathrm{~K}$ & $\$ 75 \mathrm{~K}$ \\
\hline
\end{tabular}




\section{Application of Results}

The primary "customers" for the knowledge to be gained in this research are natural resource managers operating in Alaska's subarctic, and the agencies/personnel having oversight and regulatory authority over both natural resources management and environmental protection. In practical terms, the principal customers are the State of Alaska (Department of Natural Resources, Division of Forestry, Department of Environmental Conservation, Department of Fish and Game), the federal Bureau of Land Management, and the entities controlling the forest resources. This last group includes State, Borough, and village or regional Corporations, as well as individual private landowners.

In Alaska, State regulatory agencies are currently attempting to exercise oversight on forest management operations, in accord with the 1978 Alaska Forest Practices Act. The agencies are handicapped in developing guidelines and "Best Management Practices", because of lack of quantitative documentation of the impacts of forest harvest on streams in the subarctic. The results of this research will provide sorelyneeded factual data on such effects. The results may substantiate current policy or indicate need for revisions; in either case, the documentation is needed to help ensure that an appropriate level of environmental protection accompanies forest harvest in the taiga uplands. 


\section{References}

Bilby, R.E. 1981. Role of organic debris dams in regulating the export of dissolved and particulate matter from a forested watershed. Ecol. 62:1234-1243.

Crow, M.E., R. Ragagopal, and G.F. Schreuder. 1976. Models of a forest ecosystem. Part B. Effect of stream environment on aquatic resources. Inst. For. Prod. Coll. for Resources. Univ. Washington Contribution $22: 1-92$.

Cummins, K.W. 1974. Structure and function of stream ecosystems. Bioscience 24:631-641.

Cummins, K.W. 1979. The natural stream ecosystem. In Ward, J.V. and J.A. Stanford (eds.). The ecology of regulated streams. Plenum Press, New York. Pp. 7-24.

Erman, D.C., J.D. Newbold, K.B. Roby. 1977. Evaluation of streamside bufferstrips for protecting aquatic organisms. California Water Resources Center. Technical completion report. Contribution No. 165.

Environmental Protection Agency. 1975. Logging roads and protection of water quality. EPA 910/9-75-007. U.S. Environmental Protection Agency, Region X, Seattle, Washington.

Environmental Protection Agency. 1976. Forest harvest, residue treatment, reforestation and protection of water quality. EPA 910/9-76-020. U.S. Environmental Protection Agency, Region X, Seattle, Washington. $273 \mathrm{pp}$.

Environmental Protection Agency. 1977. Silvicultural chemicals and protection of water quality. U.S. Environmental Protection Agency, Region X, Seattle, Washington, 323 pp.

Forest Service, USDA. 1977. Non-point water quality modeling in wildland management: A state-of-the-art assessment. (2 vols.) EPA-600.377-036,-078, Environmental Research Laboratory, U.S. Environmental Protection Agency, Athens Georgia. $156+574$ pp.

Gibbons, D.R. and E.O. Salo. 1973. An annotated bibliography of the effects of logging on the fish of the western United States and Canada. U.S. Forest Service Gen. Tech. Report PNW-10. 145 Pp.

Green, R.H. 1979. Sampling design and statistical methods for environmental biologists. John Wiley and Sons, N.Y. 257 Pp.

Gurtz, M.E., J.R. Webster, and J.B. Wallace. 1980. Seston dynamics in southern Appalachian streams: Effects of clearcutting. Can. J. of Fish and Aquatic Sci. 37:624-631. 
Hynes, H.B.N. 1975. The stream and its valley. Verh. Internat. Verein Limol. $19: 1-15$.

Jinkinson, W.M., F.B. Lotspeich and E.W. Mueller. 1973. Water quality of Caribou-Poker Creeks Research Watershed, Alaska. Working Paper No. 24, Arctic Environmental Research Laboratory. EPA, College, Alaska. 25 pp.

Koutz, F.R. and C.W. Slaughter. 1972. Geological setting of the CaribouPoker Creeks Research Watershed, Interior Alaska. Technical Note, USACRREL. $32 \mathrm{pP}$.

Lotspeich, F.B., R.L. Jackson, and A.E. Helmers. 1976. Climatological and Water Quality Data, Caribou-Poker Creeks Research Watershed. AERS Working Paper No. 30 (CERL No. 014) Arctic Environmental Research Station, U.S. Environmental Protection Agency. College, Alaska. $41 \mathrm{pp}$.

Lotspeich, F.B. and C.W. Slaughter. 1981. Preliminary Results of a Study on the Structure and Functioning of a Taiga Research Watershed. IWR Report, Institute of Water Resources, University of Alaska, Fairbanks, Alaska.

Lynch, J.A., E.S. Corbett, and R. Hoopes. 1977. Implications of forest management practices on the aquatic environment. Fisheries 2(2):16-22.

Megahan, W.F. 1977. Reducing erosional impact of roads. In Kunkle, S.H. and J.L. Thomas (eds.). Guidelines for watershed management. Pp. 237-260. FAO Conservation guide. Food and Agriculture Organization of the United Nations, Rome.

Meier, M.S. 1975. Watershed Management - or Regulation. In Watershed Management: Proceedings of a Symposium. Pp. 583-590. American Society of Civil Engineers, 345 E. 47th Street, New York, N.Y.

Oswood, M.W. and W.E. Barber. 1978. [Development of a] Fisheries Habitat Survey [System for the Tongass National Forest]. Submitted to U.S. Forest Service, Ketchikan, Alaska. 119 pp.

Pope, P.E. 1977. Water Quality and Forestry: A review of water quality legislation and the impacts of forestry practices on water quality. Station Bulletin No. 161, Dept. of Forestry and Natural Resources, Purdue University. West Lafayette, Indiana. 19 pp.

Rieger, S., C.E. Furbush, D.B. Schoephorster, H. Summerfield, Jr., and L.C. Geiger. 1972. Soils of the Caribou-Poker Creeks Research Watershed in Taiga. Soil Conservation Service, USDA, and USACRREL. Technical Report 236, USACRREL, Hanover, New Hampshire. 11 pp. and map. 
Swanston, D.N. 1976. Erosion processes and control methods in North America, IVRRO 16th World Congress Proceedings Division I:251-275.

Triska, F.J. and K. Cromack, Jr. 1980. The role of wood debris in forests and streams. In Waring, R.H. (ed.). Forests: Fresh Perspectives from ecosystem analysis. Pp. 171-190. Oregon State University Press, Corvallis.

Troth, J.L., F.J. Deneke and L.M. Brown. 1976. Upland Aspen/Birch and Black Spruce Stands and their Litter and Soil Properties in Interior Alaska. Forest Science 22(1):33-44.

URS Company/Environaid. 1977. Timber Harvesting/Water Quality Problem Description. Alaska Water Quality Management Planning Program, PL 92-500 Section 208. Alaska Department of Environmental Conservation, Juneau, Alaska. 159 pp.

U.S.D.A. Forest Service. 1981. Fisheries Survey Handbook. FSH 2609. 23 R-10. Juneau, Alaska.

Vannote, R.L., G.W. Minshall, K.W. Cummins, J.R. Sedell, and C.E. Cushing. 1980. The river continuum concept. Can .J. of Fish. and Aquatic Sci. $37: 130-137$.

Voge1, T.C. and C.W. Slaughter. 1972. A Preliminary Vegetation Map of Caribou-Poker Creeks Research Watershed, in Interior Alaska. Technical Note, USACRREL. 10 pp.

Wallace, J.B., J.R. Webster, and W.R. Woodall. 1977. The role of filter feeders in flowing waters. Arch. Hydrobiol. 97:506-532. 


\section{GRAVEL REMOVAL FROM RIPARIAN HABITATS}

Research Question: To what extent does removal of gravel from and routing of oil and gas pipelines and associated work areas through, riparian habitats of arctic Alaska endanger the unique and unusually productive biological resources of these areas?

Research Objectives:

a. Provide a classification and survey of riparian habitats of the arctic slope of Alaska to identify those that are particularly productive, critical to animal populations, or vulnerable to development;

b. Document the plant diversity, community structure, and productivity of representative riparian stands with respect to seasonal flooding and stage of riparian succession;

c. Document the use of riparian communities by grazing vertebrates, invertebrate herbivores, and nesting birds, and assess the importance of riparian communities to populations of these animals on the arctic slope of Alaska.

Justification: Consideration of the need for habitat protection should begin with habitats that support an unusually diverse, abundant, or valuable biological resource and with habitats that are directly threatened by development activities. When these are found in a single habitat, immediate action is called for. This is the case for riparian habitats of the arctic slope of Alaska.

The major river systems of the arctic slope flow north from the Brooks Range to the Arctic Ocean, bringing nutrient-rich basic sediments to the acid tundra of the Arctic Coastal Plain. The plant and animal communities of arctic riparian systems are richer in species and higher in productivity than surrounding tundra. The presence of medium to tall shrubs $(1-2.5 \mathrm{~m})$, especially willow (Salix spp.), in riparian stands far north of their distribution on open tundra is particularly conspicuous. The reasons for this are not altogether clear. Possible reasons include (a) protection from winter winds, (b) deeper soil thaw, warmer soil temperatures, and rapid decomposition and nutrient cycling in coarse, well-drained alluvial sediments, and (c) the annual input of nutrients from spring flooding.

The willows and herbaceous perennial plants of riparian communities are highly preferred by a number of herbivorous animals. Moose extend all the way to the arctic coast and are increasing in abundance in riparian communities; they are rarely found away from riparian willow stands. The rapid increase in the musk ox population introduced 
to the Sadlerochit River drainage is related to their use of extensive riparian communities. Populations in the Canning and Hulahula River drainages, with less extensive riparian communities, have not increased as rapidly. Riparian areas are the most important winter and spring habitat for ptarmigan, which feed upon willow buds and catkins. Ground squirrels burrow along river bluffs and forage extensively in adjacent riparian stands. The herbivorous insects using deciduous shrubs, especially willows are far more diverse and abundant than those of other plant growth forms, and these insects provide the prey for a rich assemblage of breeding birds. Willow warblers, gray-cheeked thrushes, and northern shrikes are only a few of the bird species associated with riparian habitats in arctic Alaska.

Riparian habitats are particularly vulnerable to development for at least two reasons. First, they provide an easily accessible and abundant source of gravel for the roads and work pads that are needed for development in the arctic. The huge quantity of gravel used at Prudhoe Bay has been removed from the Sagavanirktok, Putuligayuk, and Kuparuk Rivers. Gravel removal produces a large, but local effect: total loss of habitat. In addition, river valleys are the most economical and feasible routes for roads and pipelines, as is clearly indicated by the routing of the oil pipeline and Dalton Highway. The likely construction of a gas pipeline, which could require a work pad entirely separate from that of the oil pipeline, and the development of new oil and gas fields with feeder lines to the major oil and gas pipelines, will contribute to a cumulative and regional alteration or loss of riparian habitat. An evaluation of habitat values must enter the early phases of development planning to prevent the gradual loss of valuable habitat.

Research Approach: The first objective, a survey of riparian habitats of arctic Alaska, will be addressed using high altitude aerial photography. Ground truth in the eastern part of the arctic slope is available in extensive vegetation surveys already completed in the Sadlerochit River drainage, and planned for other rivers from the Canning to the Jago in the Arctic National Wildlife Refuge. The intensive study area described below will provide ground truth in the Sagavanirktok River system. Additional ground truth in the Colville River and other river systems to the west will probably be advisable.

Objectives $\mathrm{b}$. and $\mathrm{c}$. will be addressed by establishment of an intensive study site somewhere along the Sagavanirktok River, easily accessible from the Dalton Highway. The site will be chosen to provide extensive stands a variety of riparian communities, within walking distance of each other, to minimize logistic requirements. Study plots within these stands will be used for regular, systematic observations. Study plots will extend onto adjacent, non-riparian tundra to determine the use of such habitat by riparian species. 
We hypothesize that the presence of riparian habitat will increase the use of adjacent, non-riparian habitat, so that the riparian effect will actually be greater than the extent of riparian habitat.

Time Frame: We propose a one-year study of existing photo imagery followed by a three-year field program.

Cost: We envisage faculty - graduate student - undergraduate student assistant teams as the most cost-effective means of conducting this research. One might propose six such teams, as follows:

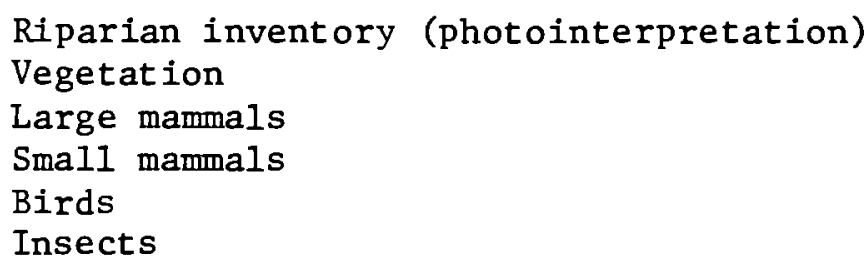

Each would involve one-month of faculty support $(\$ 4,000)$, a graduate research assistantship $(\$ 7,500)$, and undergraduate summer salary $(\$ 2,500)$. These teams would share in logistics and study plots, and would be approximately $\$ 150,000$, including logistic support.

Anticipated Products and Outputs:

a. Six master theses filed at the University of Alaska containing detailed reports of field observations and their interpretations.

b. A series of papers published in the scientific literature describing the most interesting scientific discoveries of the research.

c. Annual reports and a final project report to EPA emphasizing integration and synthesis of results in a manner useful to environmental managers responsible for decisions regarding developments.

d. Specific recommendations regarding habitats deserving special attention and protection, and steps that might be included in development programs to minimize their effects upon riparian habitats and the organisms that use them.

Interrelationships with previous or ongoing research: Since riparian areas make up only a small part of the terrain of arctic Alaska, they received limited attention in early biological studies. A clear exception to this is studies on birds, which are much more liverse in riparian areas than in other habitats (Kessel and Cape 1953, Childs 1969). Research on the process of herbivory at Atqasuk on the Meade River, clearly showed the concentration of palatable plants and of herbivory in riparian habitats (Batzli 1980). Studies on musk oxen reintroduced to the North Slope were concentrated in the Sadlerochit River drainage which is occupied by a rapidly increasing population. 


$\frac{\text { RECOMMENDED RESEARCH STRATEGY }}{\underline{\text { FOR }}}$

COLD REGIONS WASTE MANAGEMENT

\section{INTRODUCTION}

Under Subcontract No. B-A3544-A-L to Battelle Pacific Northwest Laboratories, Tetra Tech has conducted a very limited planning program to identify and prioritize needed areas of research in cold regions waste management. The three broadly recognized categories of waste -- solid, liquid, and hazardous -were considered with respect to three primary criteria:

- Urgency of existing problems,

- Lack of available information, and

- Potential for actual environmental improvement.

Following an initial meeting in Fairbanks on February 10-11, 1982, 25 research plan abstracts were developed and reviewed at a second Fairbanks meeting on March 16-17, 1982. These abstracts covered a broad diversity of waste disposal problem areas selected in accordance with the above criteria. Topics presented and reviewed at the March 16-17 meeting are summarized in Attachment 1.

Upon completion of the March 16-17 meeting, five topics were selected for further development and presentation at a larger workshop conference sponsored by Battelle at Chena Hot Springs on March 30 - April 2, 1982. The workshop included invited representatives of pertinent agencies, the University of Alaska, and Tetra Tecin, and was attended by representatives of the Environmental Protection Agency (EPA), the sponsoring agency. Participants ranked the five waste disposal research topics, along with 44 other topics in the areas of air pollution (18), habitat modification (6), water contamination (13), and miscellaneous others (7), in accordance with 12 ranking criteria developed during the first day of the workshop. The waste disposal topics were ranked $12,20,25,28$, and 36 in the field of 44. Workshop results are summarized in Attachment 2, prepared by Battelle.

The planning process confirmed several points of potential difficulty for EPA which were, to some extent, evident and predictable at the outset of the program. Among these concerns are three which, from the vantage of hindsight, clearly distinguish the waste management portion of the program from the other areas covered : 
1) Although any really comprehensive literature review or systematic interviewing of experts was beyond the scope and funding of the waste management program, a limited number of agency, academic, and industry representatives was contacted for input. There was little or no consistency among these contacts with respect to placing priorities on waste disposal problems. No single area of concern was identified by any person as urgently requiring attention at a level of priority beyond the general range of waste management problems surveyed. There was no evident pattern of priority to guide the further selection of topics beyond those already identified by Tetra Tech early in the program.

2) Three major areas of concern were selected by Tetra Tech for further attention, largely on the basis of the broad experience of planning team members with Alaskan waste disposal problems. The three areas were:

o Offshore disposal of seafood processing wastes,

- Cost-effective waste treatment and disposal alternatives for rural communities, and

- A statewide (Alaskan) hazardous materials identification and management system and procedures.

Further investigation showed that all three of these areas were being covered by contracts in progress. Because these problems were already receiving priority attention by other federal and state agency programs, they created a potential for redundancy in the EPA cold regions research planning program. The final selection of topics for presentation at the Chena Hot Springs workshop retained only one of the three areas: cost-effective waste treatment and disposal alternatives for rural communities. This topic was retained because the related contract in progress emphasized wastewater treatment, but not the treatment and disposal of solid wastes.

3) There was a growing realization on the part of the planning team that research itself may not be the most important requirement for alleviating the demonstrably adverse impact of inadequate waste management on cold regions environments. It could be argued that existing knowledge is sufficient to diminish significantly a large majority of existing liquid, solid, and hazardous waste disposal problems. It was apparent that socioeconomic and cultural patterns were important in establishing waste management procedures in ways which were readily observable, and that most of the suggested research avenues would have little or no impact on these patterns. In addition, the improvement of control technologies and their application is receiving considerable attention by industry and by academic environmental engineers, and is an area which would itself require some intensive research to avoid duplication of effort. Moreover, many such improvements fall within the province of industry's obligations under permit stipulations issued prior to resource extraction and other development activities in cold regions. 
In light of the points of concern summarized above, the waste disposal planning team has concluded that EPA will obtain the most benefit if a much more focused and intensive effort is established exclusively in the area of waste disposal, prior to the initiation of research on any one topic. A five-year strategy for implementing waste management research following such a planning effort is presented below. At the same time, we have selected a single research topic as a recommended three-year research program which could be implemented either immediately or after further review by a more focused effort.

The research topic chosen for further development, "Research Plan to Determine the Effect of the Arctic on Risk of Fecal Contamination," is a refinement of the research plan abstract which we recommended for highest priority during the Chena Hot Springs waste disposal presentation: "Effect of Arctic Climate on Solid and Liquid Waste Decomposition" (Attachment 1). We have selected this topic because it is one area in which field and laboratory research can make a new and significant contribution to the existing body of knowledge. The contribution will be significant because it will provide information on the severity of a potentially serious health hazard, and because this research will result in decay coefficients which can be used to alter the design of waste treatment and disposal systems on a fairly site-specific basis for individual cold regions communities. Such coefficients are used routinely in developing design criteria for waste treatment systems in temperate latitudes; they have not been developed for cold regions.

Attachment 3 develops this research plan sufficiently to characterize the major features of rationale, technical approach, implementation schedule, and costs per task. Field study sites provisionally selected are shown in Figure 1. They are:
- Nuiqsut
- Bethel
- Barrow
o Dillingham
o Noorvik
- Unalaska
- Enmonak
o Adak

These sites are recommended because waste disposal problems are known to exist there in intimate association with marine, estuarine, or freshwater environments. They cover a range of situations from small Native village to major military installation, and potentially lend themselves to cooperative funding involving a variety of sources which could directly benefit from the research.

We wish to recommend more strongly, however, that a completely new alternative research strategy be followed by EPA with respect to waste management. This alternative strategy, presented below, will provide the focus and expertise necessary to ensure that limited funds are expended wisely for maximum usefulness of research results. 


\section{$\underline{\text { APPROACH }}$}

The EPA cold regions research planning program now nearing completion was broad in scope, covering air pollution, habitat modification, and water contamination as well as waste management. The meetings and workshop assembled for planning and review were multidisciplinary. Furthermore, the scope and funding of the waste management portion of the program did not allow an intensive review or workshops devoted exclusively to waste treatment and disposal problems. We are convinced that before funds are expended on research, a much more focused review and planning effort is required.

A recomended research strategy is summarized in Figure 2. It incorporates four work units and encompasses a five-year planning horizon. Each of the work units is briefly explained below.

\section{Work Unit No. 1: Synthesis}

This work unit would be completed within the first three months of implementation. Experts and specialists in cold regions waste disposal are notified that the program is starting, and invited to participate, through a detailed and informative letter, followed as appropriate by telephone contacts to provide further clarification. A comprehensive, labor-intensive information review is conducted, and documented in a draft Information Report. The Information Report is distributed in draft form to the confirmed program participants for review and comment. Following the incorporation of review comments and the examination of additional information sources identified by the reviewers, a final Information Report is prepared and distributed to the program participants prior to initiation of Work Unit No. 2.

Work Unit No. 2: Planning

This work unit would be completed within the first six months. Its purpose is to develop detalled research plans which will guide actual research to be performed by appropriate subcontractors. Planning begins with a carefully structured, thoughtfully conducted workshop. Participants identified and brought into the program during Work Unit No. 1 meet during several days to discuss the Information Report and form a consensus of research priorities. It is expected that workshop participants will include agency representatives, academic specialists, expert consultants, and managers and technicians actually engaged in waste management procedures at cold regions communities in the United States and Canada. It is recommended that the workshop be conducted in Anchorage or Fairbanks, Alaska.

Following the workshop, preliminary research plans are developed in accordance with workshop recommendations. The preliminary plans are distributed to the workshop participants for review and improvement. Following revision, final research plans are developed to the considerable level of detail necessary to allow responsive research proposals to be prepared and evaluated as the first stage of Work Unit No. 3 . 
1. SYNTHESIS

a) Notification

b) Information Review

c) Information Report

- Draft

- Final

2. PLANNING

a) Workshop

b) Preliminary Research Plans

c) Plan Review/Revision

d) Final Research Plans

3. IMPLEMENTATION

a) Liquid Waste

b) Solid Waste

c) Hazardous Materials

4. CONCLUSION

a) Interim Review of Draft Research Reports

b) Colloquia

- Research Recommendations

- Policy Recommendations

c) Final Research Reports

d) Management Report to EPA

- Research Summary

- Conclusions

- Research Recommendations

- Policy Recommendations

Figure 2. Waste Management Program Schedule 
Work Unit No. 3: Research Implementation

This work unit would begin six months after program initiation and continue through the first quarter of the fifth year. Requests for proposals (RFPs) are prepared in accordance with the final research plans produced at the end of Work Unit No. 2. Proposals are reviewed for responsiveness to the RFPs, innovative improvements to the research plans, and cost effectiveness. We envision that research begins during the summer of the first year. Topics for research will span the three categories of liquid waste, solid waste, and hazardous materials as determined during the workshop and carried forth in the research plans. Research programs will be integrated with respect to sequence of implementation and selected study sites to allow the maximum amount of useful information to be obtained per funds expended. As research progresses, draft Research Reports are prepared and submitted to the Management Contractor by contractual schedule. These draft reports are promptly distributed to the review participants (workshop attendees), allowing Work Unit No. 4 to proceed.

\section{Work Unit No. 4: Conclusion}

This work unit would begin at the start of the second year and proceed through the end of the fifth year. As draft Research Reports are produced, they are examined by the review participants, who provide written comments to the Management Contractor. The Management Contractor forwards these comments to the subcontractor principal investigators as feedback to allow adjustments and refinements to be made as research progresses.

Starting towards the end of the second year, colloquia are held on a yearly basis. Colloquia attendees are the sponsor(s) and Management Contractor, the review participants, and the principal investigators. The colloquia will have three functions:

- To review completed research and research in progress, based on the draft Research Reports and presentations by the principal investigators;

- To identify improvements to the research programs, based on new perspectives provided by completed research and research in progress, and to incorporate those improvements into the ongoing research programs; and

- To develop policy recommendations to assist the sponsor(s) in effectively utilizing research results.

Following each colloquium, final Research Reports are prepared by the principal investigators and submitted to the Management Contractor in accordance with a contractually established yearly schedule. The final Research Reports are submitted by the Management Contractor to the sponsor(s). 
After the conclusion of research and the final colloquium in the fifth year, the Management Contractor prepares a Management Report for submittal to the program sponsor(s). The Management Report serves four major purposes:

- To summarize the entire waste management research program with respect to synthesis, planning, research conducted, results obtained, and problems encountered;

- To present clear and succinct conclusions concerning the significance of the research results;

- To provide recommendations for further research, where such a need is indicated; and

- To provide policy recommendations, based on the colloquia, to assist the sponsor(s) in applying the new information obtained from the research program in ways which will alleviate adverse impacts to cold regions environments.

With respect to contractual organization, it would be simplest and probably preferable for the Management Contractor directly to administer the waste management research program. However, it may be advisable to subcontract the management of this program to another entity to allow intensive, full-time attention to be provided from start to finish, as the Management Contractor will have overall responsibility for the air pollution, habitat modification, and water contamination programs as well.

In conclusion, the alternative research strategy for cold regions waste management presented here will provide the strong focus necessary to identify and implement research programs which can actually improve environmental quality at high latitude communities. The planning process now nearing completion has indicated a definite need for such a strategy, and we strongly recomend it for consideration. 
ATTACHMENT 1 - Waste Management

Waste disposal topics recommended for inclusion in research prioritization workshop.

WASTE DISPOSAL TOPIC

1. Cost-Effective Waste Treatment and Disposal Alternatives for Rural Alaskan Communities

2. Small-Scale Treatment Technologies for On-site Greywater Disposal in Permafrost Soils

3. Solid Waste Generation Rates and Predictive Model for Rural Alaska

4. Effect of Arctic Climate on Solid and Liquid Waste Decomposition

5. Freeze-Thaw Cycle Effects on Concentration and Migration of Contaminants at Disposal Sites and Settling Ponds

\section{REASON FOR INCLUSION}

- Inappropriate, outmoded procedures in effect at most communities.

- Wastes persist and accumulate yearly in cold climates.

- No integrated program exists to provide practical solutions.

- Septic tanks and leach fields inefficient in permafrost areas.

- Alternative cold-climate sewage treatment systems exclude greywater from treatment.

- Greywater often dumped untreated around residences or facilities.

- Yet greywater treatment is required by State of Alaska regulations, creating a regulatory dilemma.

- No cost-effective solution has been identified for single-residence or single-family use.

- No available information exists on waste generation rates for rural Alaskan communities.

- This lack of knowledge limits agency ability to develop effective waste management and resource recovery procedures.

- Results will allow projection of disposal site life expectancies and enable realistic planning and design of new sites.

- No data available for arctic conditions.

- Wastes persist and accumulate year after year at disposal sites.

- We need to know if certain wastes should be disposed of differently in cold climates, and how to do so efficiently.

- At disposal sites and settling ponds, the yearly freeze-thaw cycle may produce zone concentration of contaminants in far greater concentration than the waste stream.

- Innovative design features can avoid build-up of heavy metals or other contaminants in bottom sludge at these sites. 
ATTACHMENT 1 - Waste Management (cont.)

Waste disposal topics not recommended for inclusion in research prioritization workshop.

WASTE DISPOSAL TOPICS

1. Control of Arsenic Contamination

from Mine Tailings

2. PCB Waste Management in Alaska:

Associated Problems and State-ofthe-Art Procedures

3. Restoration of Hazardous Waste Sites and Spill-Damaged Areas

4. A Community (Smail and Rural) Model for Handling Hazardous Material Transportation Emergencies

5. Innovative Technologies to Detect Waste Plume Movements in Multimedia Environments

6. Landfill Design for Permafrost Soils

7. Acid Mine Drainage

8. Effects of Acidity from Snowmelt

9. Spray Atomization of Wastewater at Remote or Mobile Camp Facilities

10. Oceanic Disposal of Non-Hazardous Solid wastes

11. Alternative Technologies for Disposal of Seafood Processing Wastes

12. Control of Suspended Fines from offshore Dredging and Artificial Island Construction
REASONS FOR PROVISIONAL EXCLUSION

- Site-specific, case-by-case monitoring and mitigation will be conducted by industry and agencies.

- Agency concensus that this is not a current problem.

- Funding should be provided by private sector.

- Not sufficiently research oriented.

- Agency need not demonstrated for Alaska.

- Integrated into "Cost-Effective Waste Treatment and Disposal Alternatives for Rural Alaskan Communities."

- Site-specific, case-by-case monitoring and mitigation will be conducted.

- Review comments indicate low priority.

- ADEC may investigate this possibility in-house.

- Application probably not practical for small communities.

- Brown and caldwell study now in progress.

- Energy and mining industries giving attention to this problem through privately funded studies. 
ATTACHMENT 1 - Waste Management (cont.)

\section{WASTE DISPOSAL TOPICS}

13. Processing of Metalliferous Gravels and Muds at offshore or Coastal Facilities

14. Effects of Suspended Drilling Mud Components and Dissolved Additives on Marine Plakton

15. Optimum offshore Disposal Techniques for Drilling Mud, Cuttings, and Conditioners

16. Control of Leachate Runnoff from Highly Mineralized Mine Tailings

17. Putrescible Waste Management at Remote Camps

18. Gas Turbine Stack Injection of Liquid Waste

19. Effects of Waste Disposal on Pathogen Distribution in Lakes and Lagoons

20. Restoration of Settling Ponds and Reserve Pits Following Mining or Drilling
REASONS FOR PROVISIONAL EXCLUSION

- Activities are subject to agency monitoring.

- Energy industry giving attention to this problem through privately funded studies.

- Energy industry giving attention to this problem through privately funded studies.

- Private industry and agency monitoring programs will be available.

- Technology available; increased compliance enforcement required.

- Now under study by Northwest Alaskan Pipeline Company and ADEC.

- Transferred to Water Quality Group for review.

- More appropriate for industryfunded programs. 
Results of Environmental Research Prioritization Workshop at Chena Hot Springs, Fairbanks, Alaska, March 30 - April 2, 1982. Shown are the relative rankings for 49 research topics considered by all workshop participants and by subgroupings of those participants according to scientific discipline or agency affiliation.

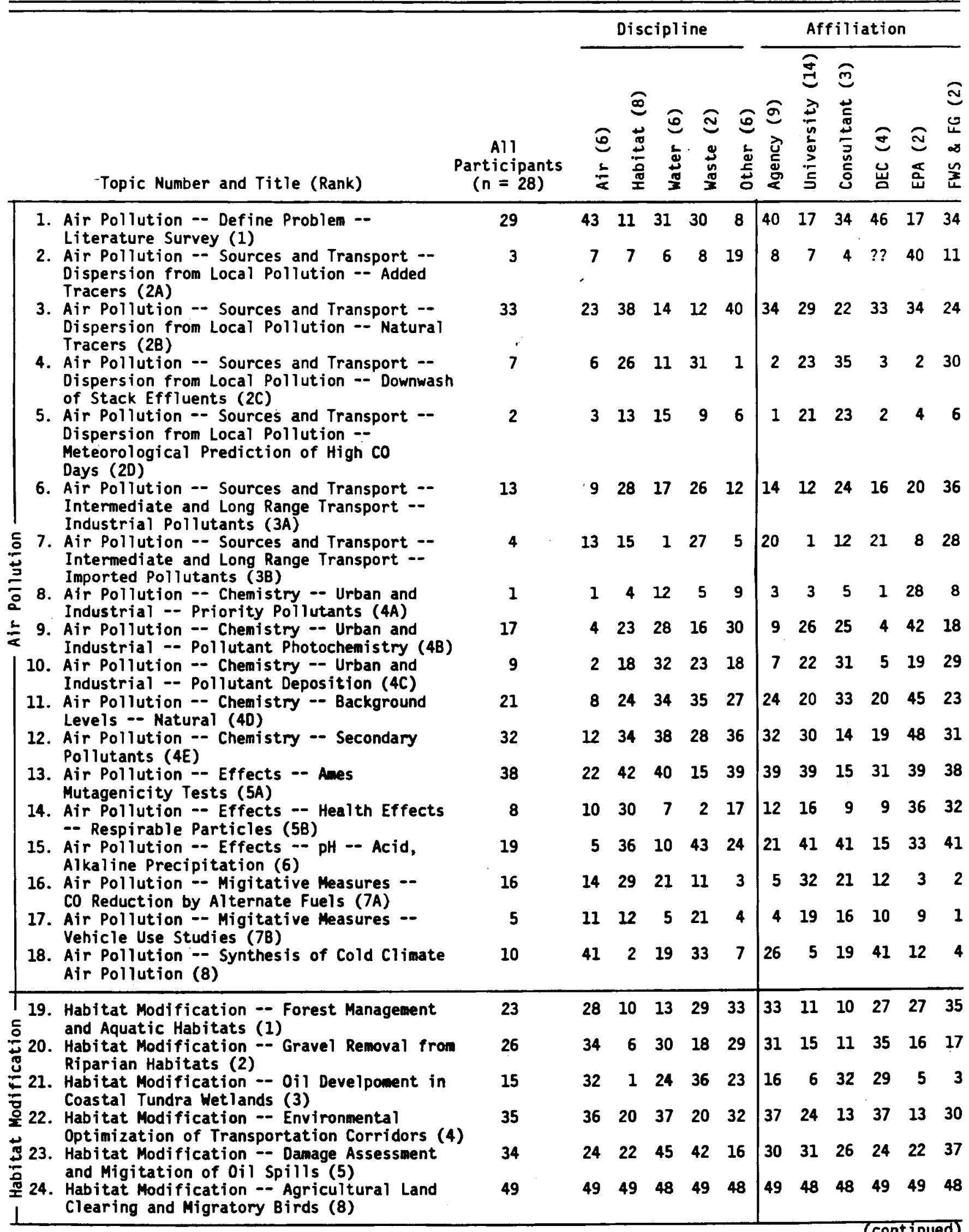




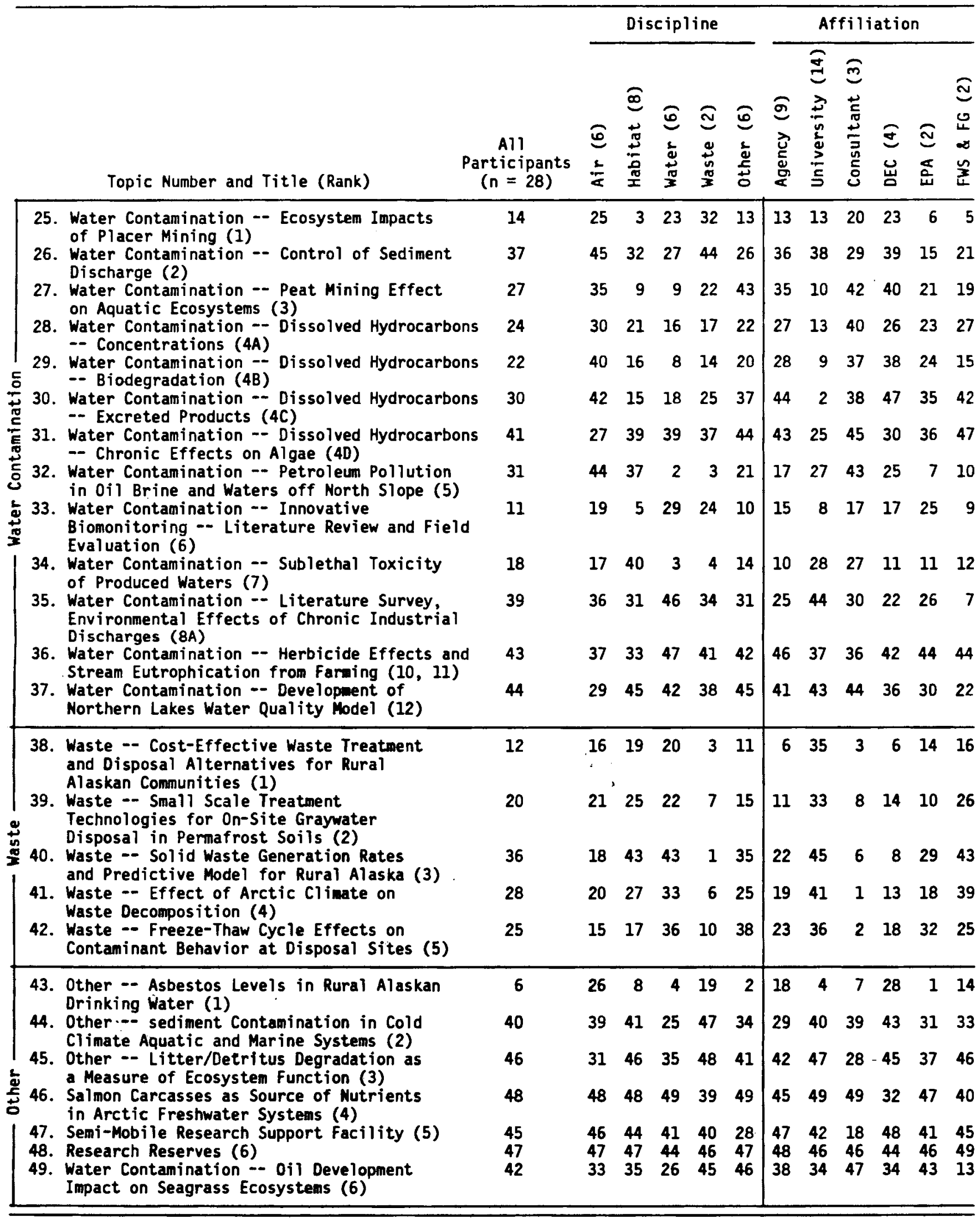


RESEARCH PLAN TO DETERMINE THE EFFECT OF THE ARCTIC CLIMATE ON RISK OF FECAL CONTAMINATION

\section{Introduction}

Arctic climates may impact accepted relationships for water borne pathogens to the extent that predictions are inaccurate. Consequently, a research plan has been devised to evaluate the effects of climatic factors on survival and growth of pathogens and their indicators. First there is a brief presentation of the problem. Then research objectives are stated. These sections are followed by a research plan where in the overall research concept and specific tasks are briefly discussed. A time frame and manpower estimate are the final sections.

\section{Problem}

Arctic climates differ from temperate climates in terms of temperature, light, humidity, and transport. These factors vary in range and in pattern. The effects of the arctic climate on survival and disinfection of fecal bacteria and other organisms have not been quantified and cannot be accurately predicted. Bacteriocidal effects, growth conditions, transport and mixing have significant effects on pathogenic microorganisms, and affect the exposure of human populations. With the burgeoning Alaskan population, the probability of exposure will increase due to increased sources of pathogens as well as increased use of water resources. Exposure of humans will depend on the interaction of sources, exposure route, and control measures.

Fecal pathogens include bacteria, viruses, protozoa, and multicellular parasites. Special techniques can be used to isolate and measure specific organisms but standards and criteria are often set using composite bacteriological and physical indicators. Total coliforms, fecal coliforms, and fecal streptococci are often used as indicators of fecal microorganisms. Turbidity or suspended solids are often used to assess the presence of potential risk of exposure to protozoan cysts and to parasites. These indicators may be totally inaccurate in arctic climates because of differential rates of survival, encystment, and growth of pathogens. It will be necessary to characterize conventional indicators and specific pathogens to adequately determine risk.

Sources of fecal pathogens include all human waste disposed to the environment. The major sources will be liquid wastes from waste treatment plants and solid waste disposal sites or dumps. Survival of pathogens from these sources and potential exposure pathways should be elucidated to evaluate risk of exposure.

Exposure generally occurs by one of two ingestion of food. Atmospheric transport generally negligible. Survival of organisms routes: drinking water or via particles and aerosols is in water will need to be 
ATTACHMENT 3 - Waste Management (cont.)

evaluated because this will be the major exposure route since contamination of food with solid wastes (sludges, raw waste, etc.) is prohibited. Removal of pathogens in drinking and process water is accomplished by filtration and disinfection. Filtration is essentially particle removal and is not included in the scope of this project. The effects of arctic climatic factors on disinfection of indicators and pathogens will need to be determined. Ozonation and chlorination are potential disinfection processes that must be evaluated.

A major factor affecting exposure is the survival and growth of pathogens under typical environmental conditions. The environmental survival of pathogens will depend on the fate and transport of the waste material and the interaction with climatic factors. Transport of pathogens as individual or clumped organisms, as well as on clay particles, will depend on a variety of hydraulic and hydrologic factors. Although groundwater transport is generally an effective filtration method, there may be conditions due to the Alaskan environment and climate that affect filtration and survival. For example, viruses are not always filtered effectively. Although marine and estuarine ecosystems are not sources of drinking water, biological filtration by shellfish can serve to concentrate pathogens for later ingestion by humans.

\section{Objectives}

This brief description of the problem of pathogens in cold climates identifies several important objectives that need to be satisfied for protecting the public health in Alaska. These include:

- Evaluating survival of common indicator and selected specific pathogenic organisms in waste disposal sites and in ground and surface waters (fresh and marine).

- Evaluating effectiveness of disinfection methods for the common indicators and selected pathogens in wastes and aquatic ecosystems.

- Developing and confirming methods for evaluating treatment and disposal alternatives so that public health risks are minimized.

Research Plan

To accomplish these objectives a brief but detailed research plan should be developed. The plan should include a conceptual analysis, experimental design, cost and time schedule. At least six tasks with specific objectives should be incorporated:

- Literature search 
ATTACHMENT 3 - Waste Management (cont.)

- Field site characterization

- Laboratory studies

- Development of detailed analytical procedures and assessment methodology

- Field confirmation of methodology

- Final report

The scope of the research plan is to provide a detailed methodology with backup experimental work within a three-year research period. The final report will consist of: a detailed listing of survival times, growth rates, and die-off coefficients in various environmental media for specific pathogens and indicator organisms, the effects of disinfection on specific pathogens and indicator organisms, and development of an assessment methodology with field confirmation. Field confirmation should be performed for hydrologic basins (catchment, stream, estuary, marine) at a minimum of two widely differing locations (e.g., west coast versus north slope).

\section{Organization of Study}

The conceptual framework of the study will be developed first. It is expected that this design could be changed as the study is performed but will serve to guide the research and facilitate proper experimental design. Experimental design will be performed for the conceptual framework so that high confidence will be obtained for important risks and lesser confidence for lesser risks. This is intended to minimize costs while maximizing research benefits. Each task will be briefly discussed to illustrate this integration of concepts with specific research needs.

The overall concept consists of developing growth and survival relationships for bacteria and viruses under natural cold climate conditions. Pathogens generally do not grow outside the body and concern is primarily associated with survival. However, indicator organisms (e.g., coliforms) can grow under suitable conditions. The effects of temperature, light exposure (phototoxic effects), particulates, BOD and other organic matter, nutrients, and other factors that affect survival and growth must be evaluated, both for indicators and for pathogens. Bacteriostatic and bacteriocidal factors should be identified and evaluated relative to the cold climate environment. Filter feeders (shellfish) should be evaluated since they remove particles including microorganisms and can represent a potential exposure route if they are eaten by humans.

Waste and drinking water disinfection are related to the processes discussed in the previous paragraph. Both ozonation and chlorination processes are substantially affected by temperature. Chemical equilibria are temperature sensitive, and organisms vary their responses with temperature. Other physical, chemical, and biological factors will further affect these responses. 
ATTACHMENT 3 - Waste Management (cont.)

The tasks necessary to evaluate these concepts and relationships are integrated as shown in Figure 3. The relationships between the tasks and the inputs and outputs of the research are also delineated. The major output of this research program will be a report describing the methodology and how it can be applied by state and local government personnel.

\section{Task 1. Literature Search.}

Detailed analysis of previous research on survival and growth of total coliforms, fecal coliforms, fecal streptococci, specific bacterial pathogens, viral pathogens and indicators, protozoans and parasites will be performed. Focus will be on fresh, estuarine, marine, and groundwater systems. Field and laboratory studies will be evaluated. Existing models will be evaluated and used to organize literature data. In addition, disinfection studies will be assessed. Temperature will be the major factor studied, but other factors will be determined where available. Selected literature sources will be studied in detail, especially U.S. arctic and antarctic research centers, and Soviet, Canadian, and Scandinavian research centers. The product of this task will be a report containing a bibliography, review of pertinent literature, a review of growth and survival algorithms, tables of die-off coefficients, etc., and the conceptual design and listing of research topics for later phases.

\section{Task 2. Field Site Characterization}

This task will be an abbreviated but important task. Types of potential and existing Alaskan sources of microbial pathogens will be identified and listed. Criteria will be prepared to select field confirmation sites (Task 5). This task will also serve to limit the scope of the laboratory research by eliminating environmental processes not judged important in Alaska.

A cross-section of waste sites would be selected for field measurements of critical environmental parameters. These parameters include:

For Solid Waste Sites

Temperature

Depth of Soil

Soil Characteristics (Grain Size,

Organic C, N, P)

Depth to Permafrost

Operating Mode
For Waste Disposal Lagoons

Temperature

Depth of Water

Water Quality (Salinity,

$N, P, T O C$ )

Depth of Freezing

Discharge Characteristics

(F lowrate, BOD, SS,

$T$ and $F$ Coliforms)

The field data would be used to select conditions for the laboratory tests to be conducted under Task 3 . 


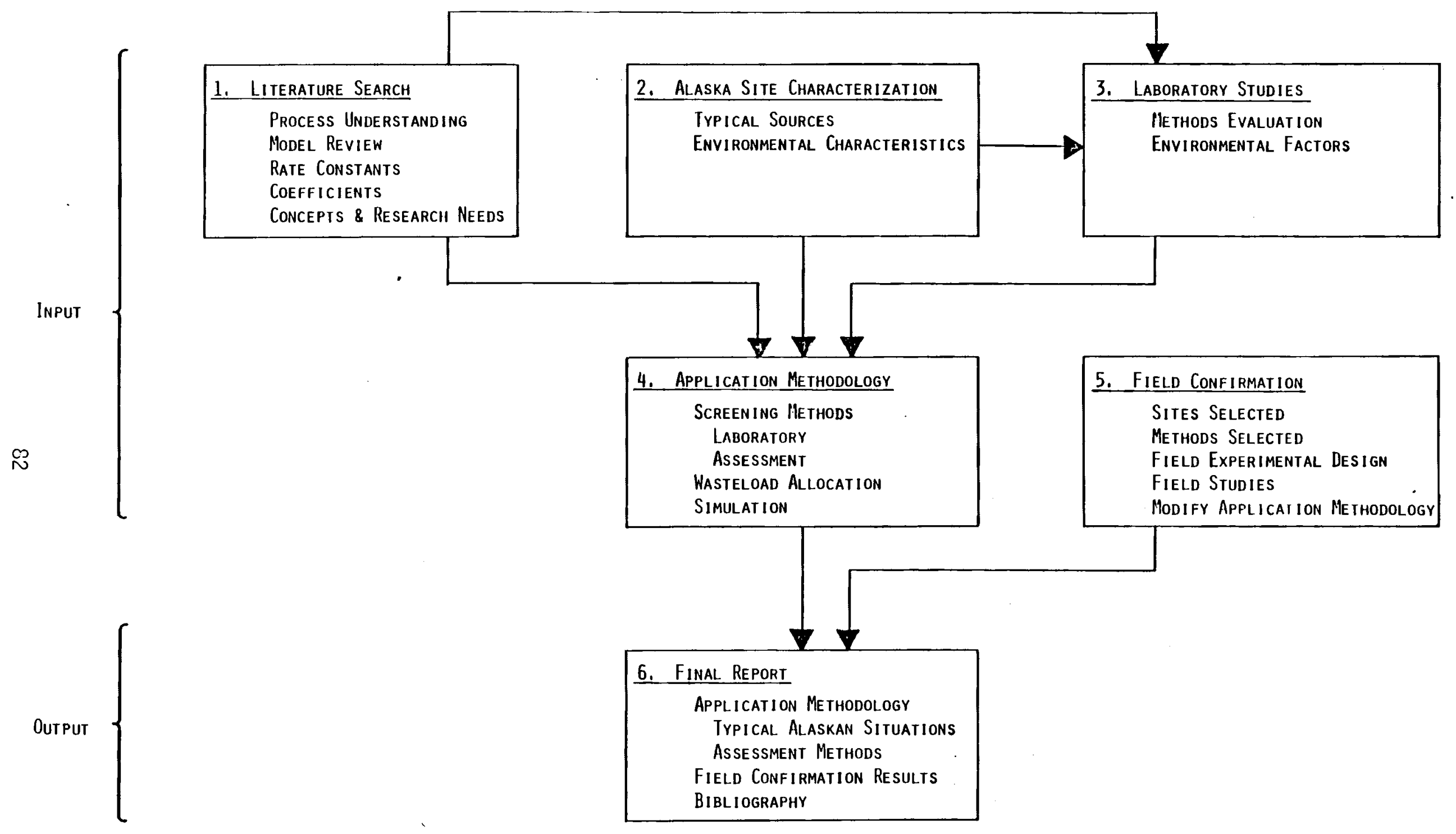

Figure 3 Integration of Tasks to Produce a Usable Methodology 


\section{Task 3. Laboratory Studies}

Data on laboratory analytical methods will be compiled to determine the variance of different methods. An experimental design will be prepared to evaluate the critical questions identified in Task 1 . Important variables will include temperature, salinity, light inhibition, nutrients and organic matter, mixing, and disinfection (chlorine, ozone) in a variety of aquatic and soil systems (Figure 4). Methods will be checked statistically, in advance of studies, to determine whether an hypothesis can be evaluated (rejected). If not, the design will be changed, or if the risk is great, research on new or improved methods will be performed. Criteria for these decisions will be defined during the experimental design phase of this task. Coefficients and relationships will be defined relative to models identified in Task 1. Changes in models will be discussed where appropriate.

\section{Task 4. Application Methodology}

The intent of this task is to make it possible to implement control of fecal pathogens to protect public health in Alaska. Calculation methods (die-off models, waste load allocation models, fate models, etc.) are an integral part of the application methodology. A methodology for applying the results of research will be prepared. This will be applied in Task 5 (Field Confirmation), and will be reevaluated, and changed if necessary, based on the results of the field studies. Suitable algorithms, coefficients, and other information will be identified, and suitable ranges and best estimates provided, so that accurate quantification of risk to the public health (e.g., standard setting will be obtained).

\section{Task 5. Field Confirmation}

At least two river-estuary basins will be assessed. An experimental design based on the literature (Task 1), typical Alaskan sites (Task 2), and laboratory studies (Task 3) will be prepared. The actual approach will be based on the methodology described in Task 4. The field experiments will be designed on the basis of a priori statistical testing of methods to determine whether hypotheses can be actually assessed. Field confirmation will be based on probabilities of exceeding exposure criteria. Based on laboratory results, indicator organisms and pathogens will be studied. Tracer organisms may be utilized under specific conditions to insure adequate characterization of microorganism survival and fate.

\section{Task 6. Final Report}

The final report (probably multiple volumes) will include summaries of the results and methods used in tasks 1 through 3 . Field and laboratory data will be included in a separate appendix. The application methodology will provide the major focus of the report. This volume will describe the screening and assessment methods and the use of wasteload allocation methods and simulation models. The ranges and typical values for coefficients and constants in arctic climates needed to use the application methodology will 
ATTA.CHMENT $\not \equiv$ - Waste Management (cont.)

be identified. Worked out examples of the methods and sample input and output for the models will be included. The field confirmation studies will be described showing how the methods were used at existing Alaskan waste disposal sites.

\section{Time Frame and Staff}

The attached graph (Figure 5) shows the scheduled mileposts for this project. It is expected that key personnel will include a microbiologist with laboratory and field expertise, an environmental or sanitary engineer, and staff with field, statistical, and hydrologic expertise. Required manpower and time allocated for each task are shown in Table 1. 


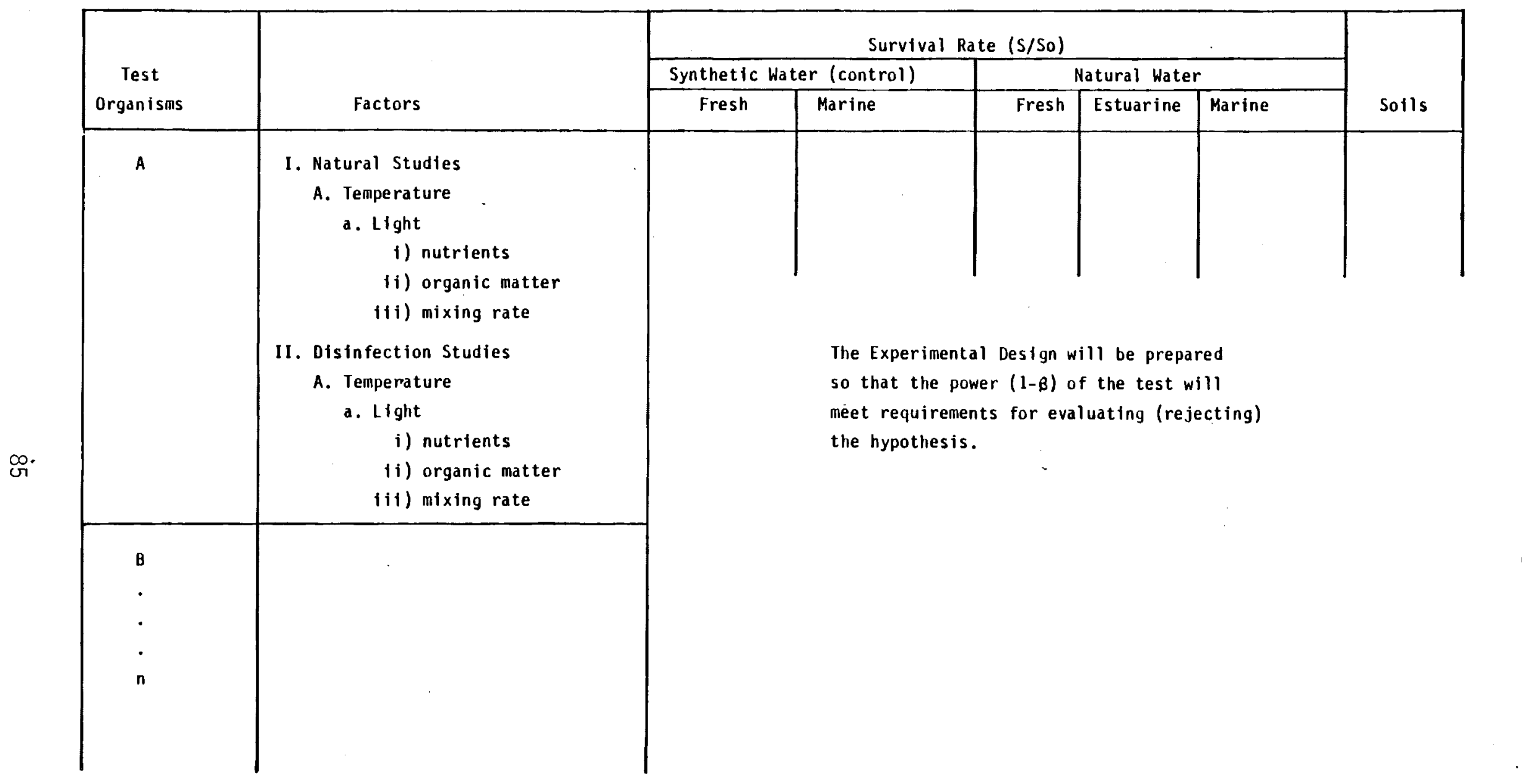

Figure 4. Hypothetical Experimental Design to be Proposed on the Basis of Statistical Hypothesis Testing 
TASKS

1. Literature Search

a) Literature Search

b) Compile bibliography

c) Prepare model review

d) Prepare data tables

e) Prepare list of studies

2. Field Site Characterization

a) Sources

b) Characteristics

3. Laboratory Studies

a) Methods evaluation

b) Experimental design

c) Experiments

4. Application Methodology

a) Screening methods

b) Wasteload allocation methods

c) Simulation Modeling

d) Write up

5. Field Confirmation

a) Site selection

b) Methods selection

c) Field experimental design

d) Field Studies

6. Final Report

Figure 5. Mileposts for Project 
Table $z$

MAN-YEARS FOR EACH TASK

\begin{tabular}{|c|c|c|c|c|c|}
\hline \multirow[b]{2}{*}{ Task } & \multicolumn{3}{|c|}{ Level $^{\mathrm{a}}$} & \multirow{2}{*}{$\begin{array}{c}\text { Total } \\
\text { MY } \\
\end{array}$} & \multirow[t]{2}{*}{$\begin{array}{l}\text { BURDENEI } \\
\text { COST }\end{array}$} \\
\hline & II & III & IV & & \\
\hline 1 & 0.2 & 0.2 & 0.1 & 0.5 & $\$ 40 \mathrm{~K}$ \\
\hline 2 & 0.4 & - & - & 0.4 & $26 \mathrm{~K}$ \\
\hline 3 & 0.5 & 0.5 & - & 1.0 & $74 \mathrm{~K}$ \\
\hline 4 & - & 0.6 & 0.1 & 0.7 & $60 \mathrm{~K}$ \\
\hline 5 & 0.3 & 0.2 & 0.2 & 0.7 & $58 \mathrm{~K}$ \\
\hline 6 & - & 0.3 & 0.1 & 0.4 & $36 \mathrm{~K}$ \\
\hline Total & 1.4 & 1.8 & 0.5 & 3.7 & $\$ 294 \mathrm{~K}$ \\
\hline ENED COST & $\$ 92 \mathrm{~K}$ & $\$ 147 \mathrm{~K}$ & $\$ 55 \mathrm{~K}$ & & $\$ 294 \mathrm{~K}$ \\
\hline
\end{tabular}

BURDENED COST $\$ 92 \mathrm{~K} \quad \$ 147 \mathrm{~K} \cdot \quad \$ 55 \mathrm{~K}$
Level II is experienced laboratory or field technician; level III is
experienced engineer or scientist with MS equivalent; level IV is senior
engineer or scientist. 

$m$

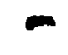

$\infty$

$-$

n

$-$

.

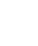

$-$

m
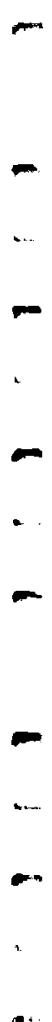

-...

$\infty$
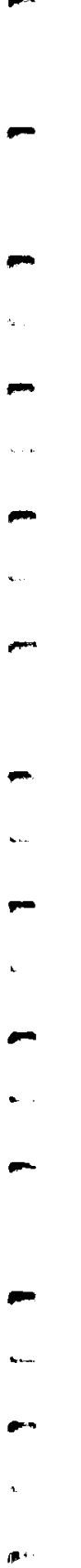

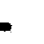

$\cdots$

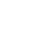

4

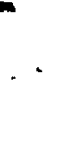

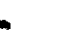

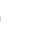

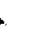

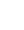

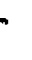




\title{
APPENDIX B \\ PRELIMINARY RESEARCH SKETCHES \\ FOR \\ EPA COLD CLIMATE RESEARCH PROGRAM \\ Offered at Chena Hot Springs Workshop \\ 30 March - 2 April, 1982
}

\author{
University of Alaska Task Leaders \\ Gunter Weller -- Air Pollution \\ Don Button -- Water Contamination/Consumption \\ Terry Chapin -- Habitat Manipulation/Modification \\ Tetra Tech, Inc. Task Leader \\ Robert Sener -- Waste Disposal
}




\section{ERRATA}

The following errors have been noted but not corrected in this appendix:

P. 23 - line 20, numbers 1 and 8 should read 1 and 18 .

P. 42 - reference to Table 6 should read Table 5 .

P. 40-42 - Table 5 should follow rather than precede page 42 .

P. 67 - Table number left blank; should read Table 6 .

P. 74 - line 27 topic number reads number 42; should read number 41 


\section{CONTENTS}

INTRODUCTION - $\quad-\quad-\quad-\quad-\quad-\quad-\quad-\quad-\quad-\quad-\quad-1$

PRELIMINARY RESEARCH SKETCHES - $-1-1-1-1$

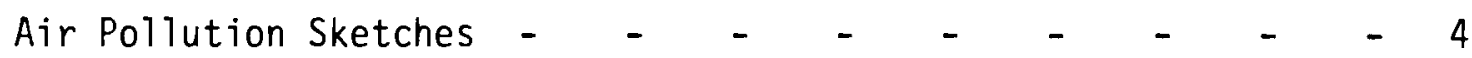

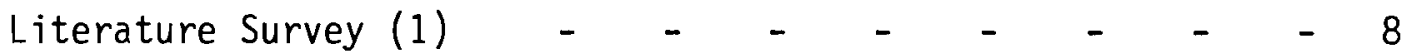

Dispersion from Local Sources, Added Tracers (2) - $\quad$ - 9

Dispersion from Local Sources, Natural Tracers (3) - - 10

Dispersion from Local Sources, Downwash of Stack Effluents (4) 10

Meteorological Prediction of High CO Days (5) - $\quad$ - $\quad 12$

Intermediate and Long-Range Transport - Industrial
Pollutants (6)

Intermediate and Long-Range Transport - Imported

Pollutants (7) - $\quad-\quad-\quad-\quad-\quad-\quad-\quad-\quad-13$

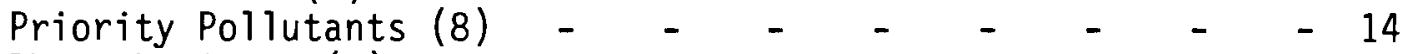

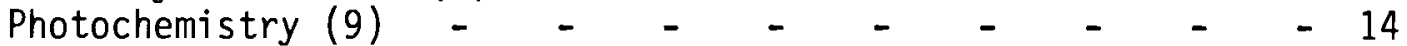

Deposition of Air Pollutants (10) - $\quad-\quad-\quad-\quad-\quad-15$

Natural Backgrounds of Pollutants (11) - $\quad-\quad-\quad-\quad-16$

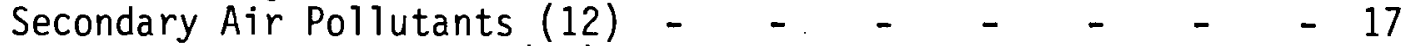

Ames Mutagenicity Tests (13) - $\quad-\quad-\quad-\quad-\quad-\quad-18$

Health Effects - Respirable Particles (14) - $\quad$ - $\quad$ - $\quad$ - 18

Effects of Acid, Alkaline Precipitation (15) - $\quad$ - $\quad$ - 19

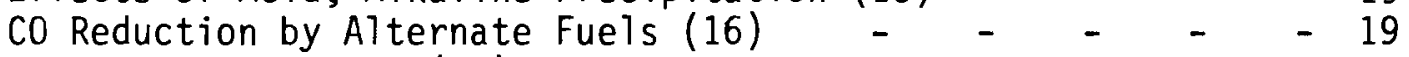

Vehicle Use Studies (17) - $\quad$ - $\quad$ - $\quad$ - $\quad$ - $\quad$ - 21

Synthesis of Cold-Climate Air Pollution (18) - _ _ $\quad$ - 23

Habitat Modification/Manipulation Sketches - $\quad$ - $\quad$ - $\quad$ - 24

Forest Management and Aquatic Habitats (19) - $\quad$ - $\quad$ - $\quad 26$

Gravel Removal from Riparian Habitats (20) - $\quad$ - $\quad-\quad 28$

0 il Development in Coastal Tundra Wetlands (21) - - $\quad 31$

Environmental Optimization of Transportation Corridors (22) - 34

Damage Assessment and Mitigation of 0il Spills.(23) - $\quad 37$

Impact of Agricultural Land Clearing on Migratory

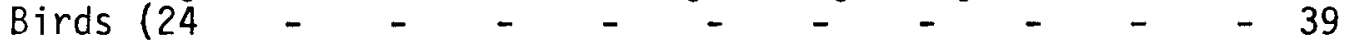

Water Contamination/Consumption Sketches $-{ }_{-} \quad-\quad-\quad-42$

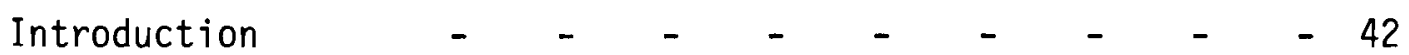

Ecosystem Impacts of Placer Mining (25) - - $-{ }_{-}-42$

Control of Sediment Discharge (26) - $\quad-\quad{ }_{-} \quad{ }_{-} \quad-45$

Peat Mining Effects on Aquatic Ecosystems (27) - $\quad$ - 48

Dissolved Hydrocarbons Overview (28-31) - $\quad$ - $\quad$ - $\quad$ - 49

Dissolved Hydrocarbon Concentrations (28) - $\quad-\quad-\quad-51$

Dissolved Hydrocarbon Biodegradation Rates (29) - $\quad$ - $\quad 51$

Excrete Products of Hydrocarbon Degradation (30) - $\quad$ - 52

Chronic Effects of Hydrocarbons on Algae (31) - - - -52

Petroleum Pollutants in 0il Brine and Coastal Waters (32) - 60

Innovative Biomonitoring - Literature Review and Field

Evaluation (33) - - - $\quad$ - $\quad-\quad-\quad-61$

Toxicity of Produced Water (34) - $\quad$ - $\quad$ - $\quad$ - $\quad 63$ 
Literature Survey - Effects of Chronic Industrial

Discharge (35) - - - - - - - - - 65

Herbicide Effects and Stream Eutrophication from Farming (36)- 65

Development of Northern LAKES Water Quality Model (37) - - 65

Waste Management Sketches - $\quad$ - $\quad$ - $\quad$ - $\quad$ - $\quad$ - $\quad$ - 66

Treatment and Disposal in Rural Alaskan Communities (38) - 68

Smal1 Scale Treatment Technologies for Onsite Greywater

Disposal in Permafrost Soils (39) - $\quad$ - $\quad$ - $\quad 71$

Predictive Model for Sol id Waste Generation in Rural

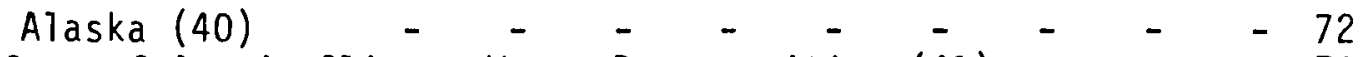

Effect of Arctic Climate Waste Decomposition (41) - - $\quad 74$

Freeze-Thaw Effects on Contaminant Behavior at Disposal

Sites (42)

Research Sketches Added at Workshop - $\quad$ - $\quad$ - $\quad$ - 79

Asbestos Levels in Rural Alaskan Drinking Water (43) - $\quad 79$

Sediment Contamination in Cold-Climate Aquatic Ecosystems - 84

Litter/Detritus Degradation as a Measure of Ecosystem

Function (45) - - - - - - - - - 84

Salmon Carcasses as Source of Nutrients in Arctic

Freshwater Systems (46) - $\quad-\quad-7 \quad-\quad-\quad-84$

Semi-Mobile Research Support Facility (47) - - - $\quad$ - 88

Research Reserves (48) - - - - - - - -88

0 il Development Impacts on Lagoonal Seagrass Ecosystems (49) - 89 


\section{INTRODUCTION}

At Chena Hot Springs, Alaska, 29 collaborating scientists and agency representatives met between 30 March and 2 April 1982 to revise a total of 49 researchable topics, and eventually to rank these according to criteria established by participants. The following text documents the raw material with which the workshop dealt. Some research topic descriptions are missing from this appendix because they were presented orally at the time of the meeting. The semi-mobile research facility (Topic 47), for example (see Table 1) was presented as an idea derived from the meeting, and was designed to accommodate several interdisciplinary research activities. The design would have depended upon the composition of the eventually recommended cold climate research efforts. A complete list of topics considered and results of the participation exercise are given in Table 1 . 
Table 1. Results of Environmental Research Prioritization Workshop at Chena Hot Springs, Fairbanks, Alaska, March 30 - April 2, 1982. Shown are the relative rankings for 49 research topics considered by all workshop participants and by subgroupings of those participants according to scientific discipline or agency affiliation.

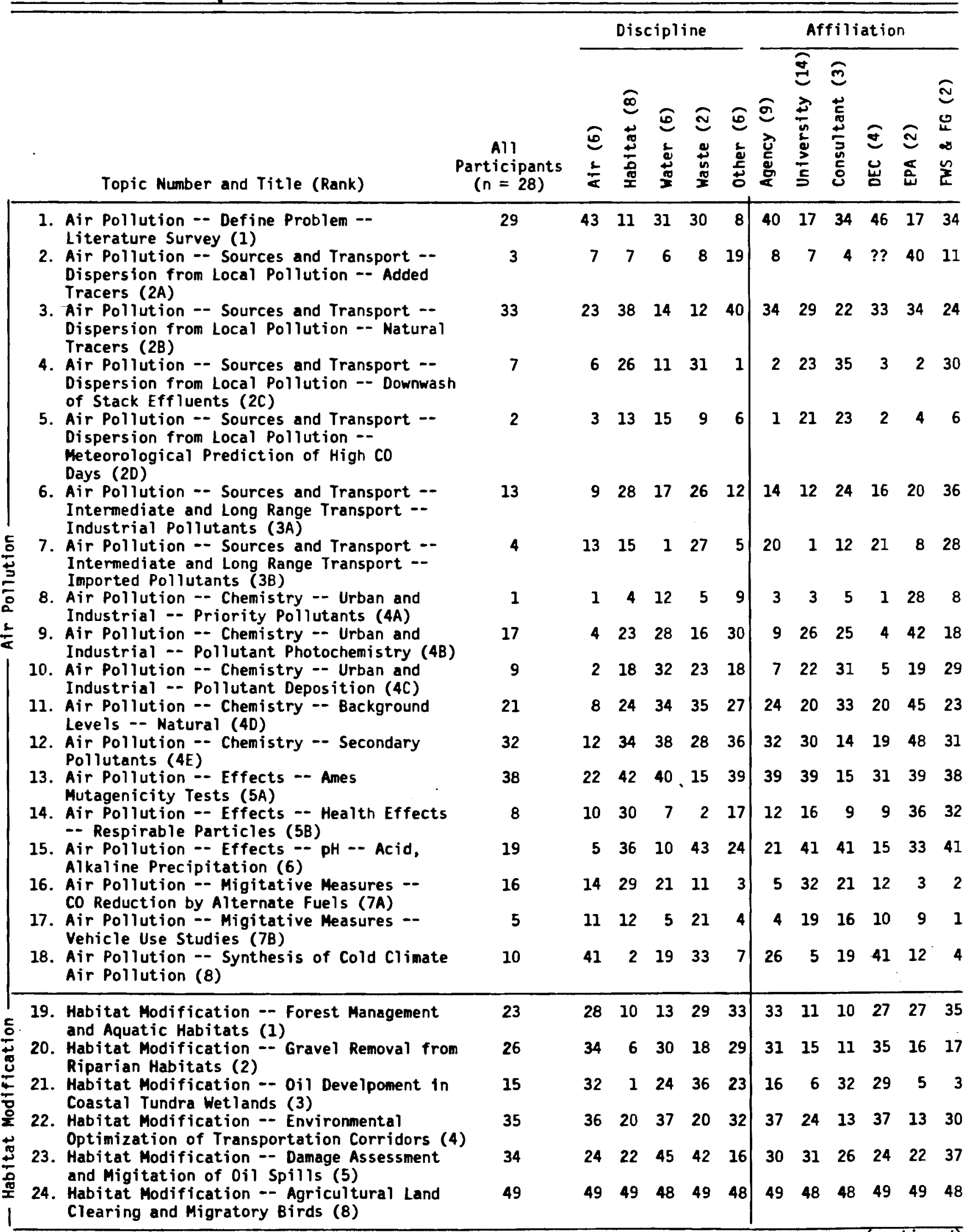




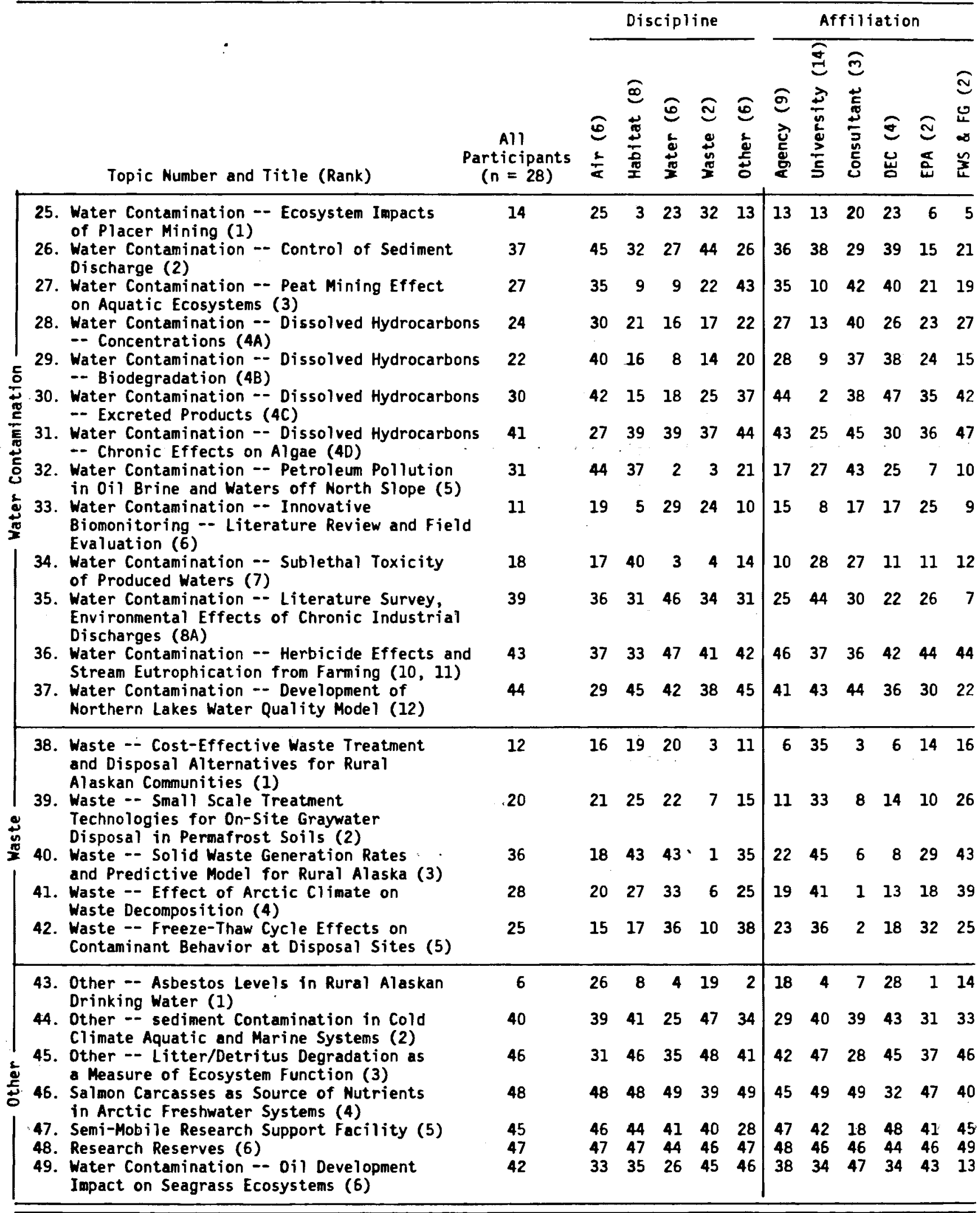




\section{PREL IMINARY RESEARCH SKETCHES}

Research sketches that were prepared for the meeting are provided in the following sections. Each sketch begins with a title followed by the number in parentheses corresponding to its location in the complete list from Table 1. If readers wish to see how a particular research sketch was ranked by workshop participants, they may refer to that table to find the ranking given that item by all participants (first column) or defined subsets of participants (remaining columns).

\section{AIR POLLUTION SKETCHES}

Preliminary sketches dealing with air pollution, along with an estimate of time and dollars for completion, are briefly summarized in Table 2 . This is followed by the full descriptions, as referenced to Table 1 where workshop rankings are provided. Titles differ somewhat between the table and the text because table titles were simplified for ease of data entry in the workshop.

The following precaution, given to workshop participants, is relevant to an understanding of cost projections:

Note to Panel Members

The cost of many of the air pollution projects are high when they are set up as individual projects. If several of the projects were combined so that the same investigators, technicians, equipment, and sampling protocol were employed, there could be a substantial saving.

For example, projects $4 a, b, c, d, e, 5 a, b$, and 6 show a total cost of $\$ 1,180,000$. These projects would be combined for an estimated cost of $\$ 820,000$ (Table 2 ).

Other combinations of projects may be found that would also provide the same product for a lower overall cost. 
Table 2. Brief descriptions of air pollution projects (presenters: Weller, Goxink, Shaw, Verelli).

(Time) and

Project Brief Description

Estimated Cost of

Individual Projects

1. Literature Survey A report combining all known physical, chemical, and health data relating to meteorology and air pollution for the

(3-6 mos)

three climatological regions of Alaska (North Slope,

Interior, and Southern Coastal) and in other cold regions

(e.g. , Canada and Morway).

2. Dispersion Studies a. Added Tracers

(1) 2 years)

$\$ 190 \mathrm{~K}$

A study of air stability classes, stack plume paths, and dispersion on the North Slope and the Interior using sulfur hexafluoride.

b. Natural Tracers

(1 year)

Carbon monoxide in cities is generated primarily by man, and radioactive Radon-222 is produced by nature. Both of thse gases are concentrated under inversions. Vertical as well as horizontal mapping of these pollutants will be done in urban and surrounding areas.

c. Downwash of Stack Effluents

(3-6 mos)

Existing dispersion equations do not apply to the high$\$ 30 \mathrm{~K}$ stability meteorological conditions of Alaska. A wind tunnel study and computer modeling of this effect for the North Slope is proposed.

d. Meteorological Prediction of High Carbon Monoxide Days

(1 year)

An empirical formula exists for the prediction of surface new $l$ ine inversion and consequent trapping of carbon monoxide for interior cities. This formula needs to be checked and verified by examining actual $\mathrm{CO}$ pollution episodes (final report only).

3. Intermediate and Long Range Transport of Air Pollutants

a. Intermediate Range Transport of Industrial Pollutants

Projected amounts of oxides of nitrogen and sulfur from petroleum production (Lease Sale 71 alone will produce up to $\$ 16,000$ tons per year) will be dispersed along several hundred kilometers of the North Slope and its biological habitats, breeding grounds, and national parks. A study of pollution trajectories for the North Slope and for other regions of Alaska is proposed.

b. Imported Pollutant Material Entering Alaska

Pollutants (arctic haze) enter Alaska from distant sources in Europe and As ia in increasing quantities. The polluted air masses present unique opportunities (unavailable in lower latitudes where too many different sources prevent fingerprinting) to study the long-range transport and conversions of polluted air masses, and apply these conclusions to other areas.

4. High Latitude Air

a. Priority Air Polluants (oxides of sulfur and nitrogen, ozone, hydrocarbons, lead, and particulates)

(2 years)

A reasonable body of information about priority air pollution already exists for the various sources and from urban monitoring sites in Alaska. This proposed study would trace their dispersion and conversion downwind from the various sources. This project would interact with projects $2 a, b$, and $c$ above and $4 b, c, d$, and $e$ below.

(2 years) $\$ 100 \mathrm{~K}$

( 3 years) $\$ 300 \mathrm{~K}$

$\$ 200 \mathrm{~K}$ 


\section{b. Photochemistry}

Photochemical ozone and smog production has been $\$ 270 K$ observed at $60^{\circ} \mathrm{N}$ latitude and has been predicted for $65^{\circ} \mathrm{N}$ latitude, at least during the few months surrounding the sumner solstice. Substantial increases in ozone in the air derived from the city of Fairbanks has already been observed on sunny days in June. Non-methane organics (including terpenes) were known to exist in North Slope air, well before any drilling activity was started, at concentrations of about $0.1 \mathrm{ppm}$. All of these factors point to a need to understand photochemistry in Alaska, both for cities and for the surrounding clear areas. Includes ultraviolet light studies and transformations of the priority pollutants.

\section{c. Deposition of Air Pollutants}

(2 years)

The rate of wet and dry deposition of pollutants on the North Slope where the major petroleum activity is and will be taking place is essentially an unknown. This knowledge is essential to dispersion studies and to the environmental and habitat modification studies discussed elsewhere.

\section{d. Natural Backgrounds}

(2 years)

Not all of the pollution observed in Alaska is manmade. Substantial concentrations of ozone arrives at the surface from stratospherid subsidence events. Fairly high ( $0.1 \mathrm{ppm}$ ) concentrations of natural non-methane hydrocarbons exist naturally over tundra areas. Swamps (tundra) produce organic and inorganic sulfides which are converted to $\mathrm{SO}_{2}$ in nature. All of these factors as well as the background arctic haze need to be assessed for an accurate pollution statement.

\section{e. Secondary Pollutants}

(1 year)

There are numerous other pollutants in the air for which information is required for an intelligent assessment of air pollution. These would reguire aldehydes and polynuclear aromatic hydrocarbons, peroxyacetylnitrate, and other heavy metals, etc., tungsten, cadmium, etc. The numbers and size distribution of particulates, as well as just the mass, is needed. Odor compounds from fishery and pulp industries, for example, are not primary pollutants, but are common and present problems.

\section{Health Effects}

\section{a. Ames Mutagenicity Tests}

Health effects are of prime concern in this entire study. The literature survey will indicate what the expected health problems will be, given certain concentrations of the priority poliutants. However, disease is frequently induced by synergistic influences of many different pollutants, most of wich are not included in the priority pollutant list. Ames tests of samples collected over other projects will provide a general disease potential for urban and industrial air. 
Table 2 (continued)

\begin{tabular}{|c|c|c|c|}
\hline & Project & Brief Description & $\begin{array}{c}\text { (Time) and } \\
\text { Estimated Cost of } \\
\text { Individual Projects }\end{array}$ \\
\hline & & $\begin{array}{l}\text { Respirable Particles in Alaskan Urban Centers } \\
\text { The concentration of particles from wood smoke and } \\
\text { vehicle emissions in the respirable size range needs } \\
\text { to be determined (particularly heavy toxic metals, } \\
\text { carcinogenic hydrocarbons, etc.) by use of diffusion } \\
\text { batteries, scanning electron microscope, and } x \text {-ray } \\
\text { spectrometer. }\end{array}$ & $\begin{array}{l}(2 \text { years }) \\
\$ 100 \mathrm{~K}\end{array}$ \\
\hline 6. & $\begin{array}{l}\text { Acid and Alkaline } \\
\text { Precipitation and } \\
\text { Its Effects }\end{array}$ & $\begin{array}{l}\text { Acid rain potential for the North Slope with its projected } \\
\text { releases of oxides of nitrogen and sulfur are of major } \\
\text { concern to habitat modification. Petrochemical development } \\
\text { near urban areas would lead to similar problems. Alkaline } \\
\text { rather than acid snow has been observed in Fairbanks. There } \\
\text { is an urgant need to know how much acid (or base) is being } \\
\text { deposited on the fragile northern ecosystem and into the } \\
\text { air of major population centers. }\end{array}$ & $\begin{array}{l}(2 \text { years }) \\
\$ 100 K\end{array}$ \\
\hline \multirow[t]{2}{*}{7.} & $\begin{array}{l}\text { Vehicle Use and } \\
\text { Fuel Additive } \\
\text { Problems }\end{array}$ & $\begin{array}{l}\text { CO Reduction by Using Gasahol, MBTE Additives, etc. } \\
\text { Determination of the optimal fuel use for reducing Co } \\
\text { concentrations in cold climate areas, plus assessment } \\
\text { of any undesirable side effects. }\end{array}$ & $\begin{array}{c}\text { (1 year) } \\
\$ 18 \mathrm{~K}\end{array}$ \\
\hline & & $\begin{array}{l}\text { b. Vehicle Use Studies, Idling Time, etc. } \\
\text { An assessment of vehicle traffic idling problems, } \\
\text { emissions, etc. in Fairbanks will allow the develop- } \\
\text { ment of strategies reducing emissions to national } \\
\text { ambient air quality standards. }\end{array}$ & $\begin{array}{l}(1 \text { year) } \\
\$ 21 \mathrm{~K}\end{array}$ \\
\hline 8. & $\begin{array}{l}\text { Synthesis of All } \\
\text { Available }\end{array}$ & $\begin{array}{l}\text { A final synthesis of information relating to all pollution } \\
\text { problems in Alaska should be attempted at the end of } 2-3 \\
\text { years of study. This would identify pollution sources, } \\
\text { characteristics and pathways, effects and strategies for } \\
\text { mitigative measures. }\end{array}$ & $\begin{array}{l}(6 \text { mos }) \\
\$ 100 K\end{array}$ \\
\hline
\end{tabular}




\section{Literature Survey and Synthesis (Number 1, Table 1)}

\section{Objectives}

a. To pull together the scattered and diverse information and reports dealing with the physics, meteorology, chemistry, and health problems associated with air pollution in Alaska and other high latitude regions.

b. Synthesize a working document that can be used in the early planning stages by other investigators in this overall project, and for use in the preparation of the final assessment project.

\section{Methods}

This will be a search of reports and records to be found in libraries, weather offices, doctor's and hospital's records, files of various investigators, and environmental conservation agency offices. Foreign offices, e.g., Canada and Norway, should not be neglected.

\section{Expected Results}

A working document should be available within about 6 months that will be useful in guiding subsequent research.

\section{Re levancy to EPA}

A unified report will be available to show the state of our knowledge about priority pollutants in Alaska, respiratory and eye irritation health patterns, secondary pollutants, weather patterns, and where the gaps in our information lie.

\section{Cost}

$\$ 50,000$ 
Fundamental Study of Gas and Particle Dispersion Under Stable Atmospheric Conditions (Number 2, Table 1)

Objectives

To determine the correct vertical dispersion coefficients empirically to the Gaussian gas/particle dispersion equation under stable atmospheric conditions in the arctic and subarctic atmospheres.

\section{Methods}

From a fixed location in the Alaskan arctic, sulfur hexafluoride $\left(\mathrm{SF}_{6}\right)$ perfluoro-methylcyclohexane (PMCH) gas will continuously be released for an hour to be used as a tracer gas. The gas will be sampled three-dimensionally by an aircraft at various locations. The concentrations of the sampled gas will later be measured by an electron gas chromatograph. Several sets of measurements of gas concentration as a function of temperatures will be taken at different levels along threedimensional coordinates to empirically determine the associated dispersion coefficients. The Alaska North Slope area is chosen as the area to carry out the research, since the winds at various elevations are fairly steady and show the same direction. This is not the case for Fairbanks, where pronounced orography produces slope winds, etc. The North Slope is a very "clear cut" or "textbook" situation for this type of work.

\section{Expected Results}

Although the Gaussian gas/particle equation has been widely used for estimating gas and particle dispersion, its validity in the arctic under stable arctic conditions has been questionable, especially in the vertical direction. The equation and applied studies have shown that the available vertical diffusion coefficients are only valid for an elevation lower than $12 \mathrm{~m}$ from the ground surface under normal temperature profile conditions. The experiments proposed here will provide correct coefficients for the lowest $1000 \mathrm{~m}$ under several temperature conditions, including stable air.

\section{Relevancy to EPA}

Almost all the dispersion and modeling estimates are based on Pasquill's equation (Gaussian gas/particle diffusion equation) as the best estimates. The empirical values of the correct diffusion coefficients derived from an organized experiment will be relevant to EPA's concern about pollution concentration and dispersion.

\section{Cost}

1. Aircraft and operation and sampling analysis are the major expenses in addition to the scientists' salaries. This will cost $\$ 80 \mathrm{~K} / \mathrm{yr}$ for 2 years.

2. Data processing and analysis will cost $\$ 15 \mathrm{~K} / \mathrm{yr}$ for 2 years. 
Atmospheric Radon-222 Concentrations in the Fairbanks Area (Number 3)

Objectives

To determine the source(s) and the extent of high Radon- 222 concentrations in the atmosphere of the Fairbanks area, and the factors affecting these concentrations.

Methods

Air samples will be taken with a portable high-volume air sampler on ultrapure cellulose filters during the winter months. Gamma-ray spectra of the filters will be determined immediately with a gamma-ray spectrometer. Special attention will be paid to the Bi-214 spectrum between 0.1 and $1.7 \mathrm{Mev}$. The analytical results will be related to the meteorologic and seismic data for the Fairbanks area for the sampling period to explain the variability in the Rn222 atmospheric concentrations.

\section{Expected Results}

We expect to determine the source(s) of $\mathrm{Rn}-222$ in the Fairbanks area and some of the factors affecting variations in its concentration.

\section{Relevancy to EPA}

This study bears on atmospheric pollution under very cold temperature conditions. It will provide baseline data for the Rn-222 concentrations in the area and how these concentrations are affected by meteorologic and seismic factors. It will also provide data on the relative importance of point sources of pollution such as coal-fired power plants and will provide data to permit an evaluation of the health hazard posed by the Rn-222 concentrations encountered during periods of intense cold.

$\underline{\text { Cost }}$

$\$ 69,309$. Seven man-months total and including $\$ 19,000$ equipment and contractual services.

Duration

One year. Begin Juḷy 1, 1982, and end July 30, 1983.

\section{COLD CLIMATE RESEARCH}

Atmospheric Downwash of Emitted Gaseous Pollutants (Number 4)

Problem Definition

Recent air quality dispersion modeling of gaseous pollutants emitted from gas turbines has identified that typical climatic conditions exhibited at the north slope of Alaska may result in downwash of these pollutants to the ground surface at a relatively short distance from the 
point of emission. Several site-specific parameters, some of which cannot be adequately simulated by the model, control the occurrence, relative frequency, and magnitude of the downwash events. As a result of the downwash activity, pollutants contained in the turbine exhaust plume are impacted upon the ground surface at a higher concentration than would normally be expected because of the limited plume transport time.

\section{Justification}

A significant frequency of this downwash phenomena may result in a much greater impact than previously projected upon the health of resident workers an the terrestrial and aquatic ecosystems at the north slope of Alaska. Although the probable air quality impacts of this occurrence have been initially addressed in a recent modeling exercise, it is the Department of Environmental Conservation's opinion that these models do not adequately incorporate all of the site-specific parameters which may control the downwash event. Because of the anticipated future growth of industrial activities within this geographic area, it is necessary to more accurately define the atmospheric conditions and facility parameters under which downwash of emitted pollutants may actually occur.

With this knowledge, it will be possible to accurately define when and where air quality standards are in jeopardy of violation. In the absence of this research activity and utilization of the knowledge it may generate, it may be necessary, based upon current limited technical knowledge, to place some restrictions upon future industrial growth at these locations to protect public health and welfare.

\section{Approach}

It is anticipated that the best manner in which to assess the downwash occurrence, its frequency and magnitude, is to simulate climatic conditions, turbine exhaust plumes, and facility parameters in a series of wind tunnel experiments. These experiments are to assess the plume downwash phenomena for two discrete facility scale models subjected to a variety of wind speeds, facility orientation, and barometric pressures.

\section{Time Frame}

The study could be performed during a three- to six-month period such as to be completed by October 1983.

Cost, Manpower, and Facilities

The selected contractor must be one knowledgeable in conducting similar wind tunnel studies and the algorithms incorporated into air quality dispersion models. It is necessary for the contractor to own or have access to a wind tunnel.

The cost of the research effort is anticipated to be approximately $\$ 30,000$. 


\section{Results}

The selected contractor is to submit a detailed scope of work which is to include individual experiment design, a draft final report, and a final report.

$\underline{\text { Sites }}$

The study is to specifically address climatic conditions exhibited at the north slope of Alaska; however, the actual research need not be performed on-site or even in Alaska. It is likely that adequate test facilities do not exist in Alaska for this project.

Meteorological Model to Predict Potentially High Carbon Monoxide Days (Number 5)

$\underline{\text { Task }}$

To determine optimum meteorological conditions that would cause co levels to concentrate above the acceptable limits.

Justification

The co levels in Alaska are influenced by the meteorological conditions (i.e., temperature and stability). When the forecasting of certain conditions predicts these phenomenon, strategies could be implemented to help maintain lower co levels.

Objective increase.

Determine meteorological conditions that cause co concentrations to

Develop and calibrate model using selected co samples.

Time Frame

Winter 2-3 years.

Location

Anchorage and/or Fairbanks.

Output

Prediction model to forecast potentially high co level periods.

Intermediate and Long Range Transport -- Industrial Pollutants (Number 6) (not actually prepared, included with other writeups) 
Imported Pollutant Material Entering Alaska (Number 7)

Objectives

To assess the concentrations, composition, and transport pathways of trace gases and particles imported into Alaska from Eurasia and Northeastern U.S.A.

Methods

1. Collect data on anions, cations, heavy metals, trace gases $\left(\mathrm{O}_{3}\right.$, NO , $\mathrm{SO}_{2}, \mathrm{NH}_{3}$ ), carbon, aerosol size spectra in interior and arctic Alaska.

2. Identify transport pathways.

3. Study conversion processes: gas to particle nucleation, $\mathrm{H}_{2} \mathrm{SO}_{4}$ aerosol neutralization, etc.

\section{Expected Results}

1. Establishment of baseline statistics on which to judge future changes.

2. Identification of physical processes acting in well-aged polluted air masses, especially the assessment of neutralization of acid rain by $\mathrm{NH}_{3}$ and vapor pressure enhancements due to sorbed $\mathrm{NO}_{3}$.

3. Predictive information to assess buildup of arctic haze over Alaska from future industrial sources constructed at high latitude.

4. An assessment of global climatic perturbation brought about by the presence of carbon aerosol placed over the reflecting polar surface.

Relevancy to EPA

1. Basic knowledge of impact of source emissions far from emission region (i.e., acid rain in Canada from U.S. industrial emissions).

2. Sensitivity of high-latitude regions to air pollution; increased knowledge of the contribution of arctic-wide air pollution from U.S. emissions.

$\underline{\text { Cost }}$

1. Routine collection and analysis of necessary data, $\$ 100 \mathrm{~K} / \mathrm{yr}$.

2. Interpretation and model development, $\$ 50 \mathrm{~K} / \mathrm{yr}$. 


\section{Priority Pollutants (Number 8 )}

\section{Objectives}

1. To observe the dispersion, formation, and transformations of pollutants in the first few to tens of kilometers downwind of sources.

\section{Methods}

A combination of field observations (aircraft and mobile surface laboratory) and theoretical calculations. The latter will depend on the availability of the former and the existence of other monitoring data. The substances to be investigated include the oxides of sulfur and nitrogen, ozone, hydrocarbons, lead, and particulates.

\section{Expected Results}

Occurrence, concentrations, and spatial and temporal distribution of primary pollutants will be defined for various regions of Alaska, including urban, industrial, and undisturbed areas.

Relevancy to EPA

The information generated will allow EPA to determine whether mitigative measures are appropriate in certain areas, and when they should be applied.

$\underline{\text { Cost }}$ before.

First year, $\$ 100,000$. Second year, $\$ 90,000$. To start in: FY84 or

\section{Additional Information}

Emissions of primary pollutants from specific sources are reasonably well known. Dispersion of the pollutants in many urban areas of Alaska does not fit the models very well, and the photochemistry is mostly unknown for these latitudes. It would be very helpful if some in situ measurements on a vertical as well as horizontal grids were made.

\section{Photochemistry (Number 9)}

\section{Objectives}

1. To verify the predicted (and observed) photochemical activity at $65^{\circ} \mathrm{N}$ latitude (and possibly higher).

2. To ascertain the probable duration and intensity of photochemical reactions at high latitudes.

3. Support information for projects $4 d$, and e. 


\section{Methods}

Observations of ultraviolet radiation intensity, organic material and ozone in the air in the vicinity of urban areas and industrial centers, particularly in the March through September time period. Some modeling with existing photochemical parameters coupled with field data will be done in the second year.

\section{Expected Results}

Reports at the end of each summer period on the occurrence and intensity of photochemical activity and some of its products in nature, in large urban areas, and if warranted, for the Prudhoe Bay area.

\section{Relevancy to EPA} mission.

Ozone and photochemical irritants are of primary concern to the EPA

$\underline{\text { Cost }}$ before.

First year, $\$ 145,000$. Second year, $\$ 125,000$. To start in: FY84 or

Deposition of Air Pollutants (Number 10)

\section{Objectives}

1. To determine the rate of dry and wet deposition of pollutants at high latitudes through the widely varied climatic conditions of the state.

2. To provide support information for projects $2 c, 3,4 a$, and 6 .

$\underline{\text { Methods }}$

Field Observations throughout the year with seasonal reports over a two-year period. Chemical analyses of precipitation and filter materials. Organic and inorganic components to be analyzed.

\section{Expected Results}

Reports will be of great use to those studying the ultimate fate of pollutants (habitat modifiation, impact on lakes and streams, etc.). Also of use to studies on visibility impairment (haze formation).

Relevancy to EPA

This information pertains to the particulate matter and acid rain concerns of the EPA. 
$\underline{\text { Cost }}$ before.

First year, $\$ 95,000$. Second year, $\$ 75,000$. To start in: FY84 or Additional Information

Samples will be of rain and snow, or dry fallout, and of ambient aerosols (high volume sampler) concurrent with rain and dry fallout. Lake surface sediment and topsoil will have a record of past events stored in it for some comparison measurements. A sampling of the snowpack before melt in the spring will yield a set of filters which integrate six months of pollution fallout.

\section{Natural Backgrounds of Pollutants (Number 11)}

\section{Objectives}

1. To ascertain the fraction of pollution that is natural at high latitudes so that the concentrations observed in urban and industrial areas can be properly evaluated.

2. To allow assessment of whether there are long-term trends in the presence, concentration, and composition of pollutants.

3. To provide additional information for projects $3,4 a$ and 3 , and 5 .

\section{Methods}

Field observations of clean air upwind of urban and industrial centers over a two-year period. Seasonal reports will be generated.

Expected Results

Benchmark data to assess the state of pollution at present, against which future changes can be compared.

\section{Relevancy to EPA}

Natural backgrounds of pollutants have been known to exceed EPA guidelines. For example, we do not have the high altitude ozone natural problem of locations such as Denver, but we do have stratospheric subsidence episodes that carry down occasional high concentrations of ozone. This information is necessary to evaluate man's impact on the Alaskan environment.

$\underline{\text { Cost }}$ before.

First year, $\$ 110,000$. Second year, $\$ 120,000$. To start in: FY84 or 


\section{Additional Information}

Ozone and organic material can naturally exhibit a substantial fraction of the EPA recommended limits. Particulates and heavy metals show similar high natural responses. Organic and inorganic sulfides will also be investigated. There are many $\mathrm{SO}_{2}$ precursors in nature, namely organic and inorganic sulfides, and the new catalytic converters on automobiles produce some reduced sulfur and nitrogen compounds which should be evaluated for cold climates.

Secondary Air Pollutants (Number 12)

\section{Objectives}

1. To assess as many of the non-priority pollutants as is practical. A partial listing would be aldehydes, polynuclear aromatic hydrocarbons (PAH), peroxyacetylnitrate (PAN) and related compounds, sulfides, ammonia and amines, trace elements other than lead, nitrated organic material, etc.

2. Assess fisheries and wood pulp odors.

3. Support for projects $4 b$ and $d$ and 7 .

\section{Methods}

Field observations over a one-year period with reports for winter and summer periods. Standard analytical techniques are to be employed. To be done in urban areas and near industrial sites.

\section{Expected Results}

Semi-annual reports for the evaluation of potential health hazards and aesthetics (e.g., fishery and pulp mill odors).

Relevancy to EPA

Information about these types of compounds is relevant to EPA's health standard and related concerns.

$\underline{\text { Cost }}$

$\$ 80,000$. To start in: FY85.

Additional Information

Odor compounds from fisheries and pulp industries, for example, are not primary pollutants, but are common and present problems. Furthermore, these compounds oxidize in nature and produce nitrates and sulfates downstream. 
Objectives

To screen samples of urban, industrial, and clean air for its mutagenic properties.

Methods

Ames tests on air samples will be run in the laboratory for samples supplied from various sources around the state, and for different seasons.

\section{Expected Results}

Health information about the composite air samples, with all synergistic effects, will be available in report form at the end of the one-year study.

Relevancy to EPA

This information is directly related to the general health concerns of this agency.

$\underline{\text { Cost }}$

$\$ 30,000$. To start in: FY84.

Additional Information

This is the only generally recognized method for us to obtain some health-related information about air pollutants.

Assessment of Respirable Particles in Alaskan Urban Centers (Number 14)

Objectives

To determine the concentration of wood smoke and vehicular emissions in different particle size ranges, especially in the respirable size range. To determine the composition of respirable particles and assess their possible deleterious health effects.

\section{Methods}

1. Size particles with diffusion batteries, aerosol spectrometers, etc. in regions affected by vehicular emissions and by wood smoke combustion.

2. Determine concentrations, broken down by size, for heavy toxic metals and carcinogenic hydrocarbons (dioxins, PAH, PAN, etc.). Use scanning electron microscope, $x$-ray spectrometry, and NAA on impactor collections. 
Expected Results

Evaluation of health hazards associated with respirable particles.

Relevancy to EPA

Aerosol composition in unindustrialized but heavily polluted arctic and subarctic communities needs to be known.

$\underline{\text { Cost }}$

$\$ 50 \mathrm{~K} / \mathrm{yr}$ for 2 years.

$\mathrm{pH}$, Anion, and Cation Analyses of Precipitation (Number 15)

Objectives

1. To measure the acid rain potential in urban areas and downwind of the Prudhoe Bay complex.

2. Support information for projects $2 c, 4 a$ and $c$, and for other research groups concerned with habitat modification and lake and stream degradation.

Methods

Field collection of rain and snow for analysis of acidity, titration capacity, and the principal ions.

Expected Results

Quarterly reports over a two-year period will show the effects of existing and potential increases in acid rain fallout, and the input of species such as nitrate to the tundra system which can add to the acidity due to biological use of the nitrate.

Relevancy to EPA

Directly applies to the "effects" interests of EPA in the growing petroleum industry in the northern regions of Alaska. Also will provide similar information for urban areas.

$\underline{\text { Cost }}$ before.

First year, $\$ 60,000$. Second year, $\$ 40,000$. To start in: FY84 or

Cold Climate Research -- Alternate Fuels Project (Number 16)

Objectives

This study will determine the optimal fuel for use in reducing carbon monoxide concentrations in cold climate areas. 


\section{Scope of Work}

The program will involve research in five major areas as follows:

1. Types of Alternate Fuels. This would include all fuels listed under the generic name of gasohol, octane boosters such as MTBE, and other appropriate fuel mixtures.

2. Technical Feasibility. The list of fuels documented in Section 1 will be investigated for operational feasibility in cold climate areas.

3. Air Quality Impact. The most promising fuels will be investigated for their air quality impact. Automotive engine emissions will be analyzed, both for the Federal Test Procedure cycle and for cold-start conditions.

4. Availability. The availability in cold climate areas (i.e., Fairbanks, Anchorage) of the most promising fuels will be investigated. Discussions with private refiners, distributors, potential industrial plants (such as Alaska Interior Resources Company) should be included in this section.

5. Economic and Institutional Feasibility. Private industry will be surveyed to get realistic costs to industry and to the consumers for use of each of the most promising fuels. The feasibility of marketing such fuels will also be discussed. Discussions will include the possibility of such fuel use as only a wintertime seasonal strategy as well as such use as a year-round strategy.

An analysis will be done to determine how government could subsidize such consumer fuel costs and how much such a program would cost.

Upon completion of the five segments of the study, a recommendation will be made on the best alternate fuel for use in cold climate areas.

Rationale

Preliminary research has shown that the alternative fuels strategy appears to have the greatest potential for reduction of automotive carbon monoxide emissions of all realistically available strategies. However, very little is known about many of the available fuels. Data gaps include impacts on cold-start emissions, availability in cold climate areas, and technical, economic, and institutional feasibility. This study would answer such questions and provide a recommendation of the optimal alternate fuel for use in cold climate areas.

\section{Schedule}

One year. 
Location

Sections 1, 2, and 3: Fairbanks. Sections 4 and 5: Fairbanks and Anchorage.

\section{Reports}

Monthly progress reports will be required.

Draft final reports will be submitted for review to the appropriate government agencies. Such agencies will have one month for review prior to the issuance by the contractor of final report.

\section{Costs}

Projected at $\$ 18,000$.

Transportation System Characterization Study (Number 17)

Objectives

This study will provide data on several aspects of cold temperature vehicular operation which will be used to validate assumptions made in development of the Fairbanks North Star Borough Air Quality Attainment Plan.

\section{Scope of Work}

Several assumptions used in preparation of the Borough's Attainment Plan will be checked. Items which will be investigated include:

1. Current average vehicle occupancy rates

a) Downtown vs. areawide traffic

b) Commuter vs. non-commuter vehicles

c) Rates vs. temperature

2. Vehicle Idling

a) Unattended idling

1) Percent of total vehicles vs. temperature

2) Average length of time per vehicle vs. temperature

3) Downtown vs. areawide

b) Attended idling, prior to vehicular movement

1) Average length of time per vehicle vs. temperature 
2) Downtown vs, areawide

c) Emissions

1) Average length of time attended idling prior to vehicular movement versus total emissions from each segment of driving cycle

2) Development of emission factor for unattended idling vs. temperature

3. Vehicle population projection

a) Diesel Vehicles. Using national projections and consulting with local car dealers, a projection will be made of the future trends in light-duty diesel vehicles as a percentage of total light-duty vehicles.

b) Average engine displacement

1) Past and Future Trends. Past vehicle registration data and future care dealer projections will be used to determine trends in average engine size.

2) Emissions. Cold-start emission factors will be developed as a function of engine size and temperature.

c) Future Emssion Projections. Based on the results of a and b, projections will be made of future emissions resulting just from changes in the vehicle population profile.

4. Vehicle cold starts

a) Percent of vehicles starting cold vs. temperature

1) Percent starting after sitting one hour or less

2) Percent starting after sitting four hours or less

3) Downtown vs. areawide

After these items have been completed, the results will be compared to assumptions made in the Borough's Attainment Plan. If there are large differences, corrections will be made.

Rationale

The entire concept of the attainment planning process is to develop strategies which achieve a total reduction in emissions sufficient to allow an area to attain the national ambient air quality standard. Such a paper exercise must then be checked against actual monitoring data to determine if supposed reductions are actually occurring. 
If a difference appears between calculated and actual ambient concentrations, it is nearly impossible to easily discover the source of the discrepancy. Therefore, the fewer assumptions used in preparation of the attainment plan, the less likely it is that such discrepancies will occur. Any initial verification of assumptions that can be done will substantially reduce the amount of work and the number of future changes required in the attainment plan.

Schedule

Nine months.

Location

Fairbanks.

Reports

Monthly status reports will be required.

A draft final report will be submitted to the appropriate government agencies. The agencies will have one month for review of the draft prior to issuance by the contractor of the final report.

$\underline{\text { Costs }}$

Projected at $\$ 21,000$.

Literature Search, Synthesis, and Assessment of Air Pollution in Alaska (Numbers 1 and 8 )

\section{Objectives}

1. At the beginning of the project, compile a synthesis of all available information on air pollution in Alaska. This is to include sources, chemical characteristics, transport, effects of the pollutants, and mitigative measures taken to date.

2. At the end of the project or 2-3 years after its beginning (whichever comes first), perform a similar synthesis as described under objective 1. This should be an assessment of the ozone air pollution potential and problems for the entire state.

\section{Methods}

The literature search should include EPA and DEC papers and files on the subject, as well as the University of Alaska and other institutions. Published papers, reports, and unpublished material should be included. The purpose is not so much to produce a systematic, computerized list of references, however, but a synthesis of the available information. Foreign sources of cold climate air pollution problems, particularly from Canada and Scandinavia, should be included. 


\section{Expected Results}

A compilation of data and results in the form of two reports with a comprehensive bibliography (one at the beginning of the project, one at its end).

\section{Relevancy to EPA}

These up to date summaries of data and results should allow EPA (and DEC, municipalities, etc.) to:

a. Plan future studies, since data and information gaps will be apparent from the reports (particularly the first one).

b. Plan mitigative measures to reduce pollution problems (control standards, siting of industry, routing of traffic, etc.).

$\underline{\text { Cost }}$

Initial literature survey and synthesis -- $\$ 50 \mathrm{~K}$ (6 mos.). Field synthesis and assessment at end of project -- $\$ 100 \mathrm{~K}$ (6 mos.).

\section{HABITAT MODIFICATION/MANIPULATION}

Table 3. Priority listing of habitat manipulation/modification sketches.

\begin{tabular}{|c|c|c|c|c|c|c|c|}
\hline & & Topic & 1982 & 1983 & 1984 & 1985 & 1986 \\
\hline 1. & $\begin{array}{l}\text { Forest Management and Aquatic } \\
\text { Habitats }\end{array}$ & 19 & $\$ 125 \mathrm{~K}$ & $\$ 125 K$ & $\$ 125 K$ & $\$ 50 \mathrm{~K}$ & \\
\hline 2. & $\begin{array}{l}\text { Gravel Removal from Riparian } \\
\text { Habitats }\end{array}$ & 20 & $\$ 50 \mathrm{~K}$ & $\$ 150 \mathrm{~K}$ & $\$ 150 \mathrm{~K}$ & $\$ 150 \mathrm{~K}$ & \\
\hline 3. & $\begin{array}{l}\text { Oil Development in Coastal } \\
\text { Tundra Wetlands }\end{array}$ & 21 & $\$ 50 \mathrm{~K}$ & $\$ 150 \mathrm{~K}$ & $\$ 150 \mathrm{~K}$ & $\$ 150 \mathrm{~K}$ & \\
\hline 4. & $\begin{array}{l}\text { Impact of Transportation } \\
\text { Corridors }\end{array}$ & 22 & & $\$ 50 \mathrm{~K}$ & $\$ 130 \mathrm{~K}$ & $\$ 130 \mathrm{~K}$ & $\$ 130 \mathrm{~K}$ \\
\hline 5. & $\begin{array}{l}0 i 1 \text { Spills and Terrestrial } \\
\text { Vegetation }\end{array}$ & 23 & & $\$ 50 \mathrm{~K}$ & $\$ 100 \mathrm{~K}$ & $\$ 80 \mathrm{~K}$ & $\$ 50 \mathrm{~K}$ \\
\hline 6. & $\begin{array}{l}\text { Agricultural Land Clearing } \\
\text { and Migratory Birds }\end{array}$ & 24 & & & & $\$ 50 \mathrm{~K}$ & $\$ 50 \mathrm{~K}$ \\
\hline
\end{tabular}

Literature view, initial survey, or followup.

Intensive research.

Tentative phasing, cost, and priority of habitat and modification projects. 
Table 4. Brief description of habitat manipulation/modification sketches [presenter(s): T. Chapin].

\begin{tabular}{|c|c|c|c|c|c|c|c|}
\hline Topic & & Title & Generic Issue & Product & $\begin{array}{l}\text { Time } \\
\text { Frame }\end{array}$ & $\begin{array}{l}\text { Cost/ } \\
\text { Year }\end{array}$ & Presenter \\
\hline 23 & 1. & $\begin{array}{l}\text { Oil Spills and } \\
\text { Terrestrial } \\
\text { Vegetation }\end{array}$ & $\begin{array}{l}\text { Accidents/oil and gas } \\
\text { development }\end{array}$ & $\begin{array}{l}\text { Habitat-specific season- } \\
\text { specific cleanup } \\
\text { recommendation. }\end{array}$ & 3 yrs & $\$ 100 K$ & Chapin \\
\hline 19 & 2. & $\begin{array}{l}\text { Forest } \\
\text { Management and } \\
\text { Stream Habitats }\end{array}$ & $\begin{array}{l}\text { Cumulative effects } \\
\text { logging of streamside }\end{array}$ & $\begin{array}{l}\text { Report of effects of } \\
\text { habitats and recommendation } \\
\text { of logging stipulations for } \\
\text { interior Alaska. }\end{array}$ & 4 yrs & $\$ 125 \mathrm{~K}$ & Chapin \\
\hline 22 & 3. & $\begin{array}{l}\text { Impact of Off- } \\
\text { Road Vehicles }\end{array}$ & $\begin{array}{l}\text { 0il product } \\
\text { transport; cumulative } \\
\text { effects }\end{array}$ & $\begin{array}{l}\text { Report recommending stipu- } \\
\text { lations for use of off-road } \\
\text { vehicles and specifying } \\
\text { effects of vehicle use in } \\
\text { specific habitats. }\end{array}$ & 3 yrs & $\$ 80 K$ & Chapin \\
\hline$x$ & 4. & $\begin{array}{l}\text { Fire Control } \\
\text { Program }\end{array}$ & Cumulative effects & $\begin{array}{l}\text { Report recommending habitat- } \\
\text { specific fire control } \\
\text { measures. }\end{array}$ & 3 yrs & $\$ 50 K$ & Chapin \\
\hline 20 & 5. & $\begin{array}{l}\text { Gravel Removal } \\
\text { From Riparian } \\
\text { Habitats }\end{array}$ & $\begin{array}{l}0 \text { il and gas develop- } \\
\text { ment }\end{array}$ & $\begin{array}{l}\text { Report describing sensi- } \\
\text { tivity of diferent riparian } \\
\text { habitats and potential } \\
\text { wildlife loss. }\end{array}$ & 3 yrs & $\$ 150 \mathrm{~K}$ & Chapin \\
\hline 21 & 6. & $\begin{array}{l}0 \text { il Development } \\
\text { in Coastal } \\
\text { Tundra Wetlands }\end{array}$ & $\begin{array}{l}0 \text { il and gas develop- } \\
\text { ment }\end{array}$ & $\begin{array}{l}\text { Report describing sensi- } \\
\text { tivity of different } \\
\text { habitats to different types } \\
\text { of disturbance. } \\
\text { Map of potential disturb- } \\
\text { ance sensitivity guide to } \\
\text { air photo interpretation } \\
\text { of potential sensitivity. }\end{array}$ & 4 yrs & $\$ 150 K$ & Chap in \\
\hline 22 & 7. & $\begin{array}{l}\text { Impact of } \\
\text { Transportation } \\
\text { Corridors }\end{array}$ & $\begin{array}{l}0 \text { il and gas develop- } \\
\text { ment }\end{array}$ & $\begin{array}{l}\text { Recommendations on types of } \\
\text { roads or trails for } \\
\text { specific transport } \\
\text { requirements. } \\
\text { Recommendation for dust } \\
\text { control. }\end{array}$ & 3 yrs & $\$ 100 K$ & Chapin \\
\hline 24 & 8. & $\begin{array}{l}\text { Agricultural and } \\
\text { Migratory Birds }\end{array}$ & Cumulative effects & $\begin{array}{l}\text { Report on bird use of } \\
\text { agricultural fields and } \\
\text { recommendations of } \\
\text { procedures to minimize } \\
\text { conflicts with } \\
\text { agriculture. }\end{array}$ & $2 \mathrm{yrs}$ & $\$ 50 K$ & Chapin \\
\hline$x$ & 9. & $\begin{array}{l}\text { Impact of Air } \\
\text { Pollution on } \\
\text { Tundra } \\
\text { Vegetation }\end{array}$ & Cumulative effects & $\begin{array}{l}\text { Report of annual pollution } \\
\text { input and effect of } \\
\text { differing } \mathrm{SO}_{2} \text { levels on } \\
\text { vegetation and soils. }\end{array}$ & 3 yrs & $\$ 50 K$ & Chapin \\
\hline
\end{tabular}


Logging and Interior Alaska Streams: The Effects of Vegetation Removal on a Stream Ecosystem (Number 19)

Research Question

What are the impacts of forest harvest upon subarctic stream ecosystems?

The objective is to determine the effects of removal of streamside vegetation on an interior Alaskan stream ecosystem. The experimental design should allow examination of the effects of timber harvest without confounding effects of logging roads, activities of heavy equipment, etc.

Justification

Forest harvest and management in central Alaska is expanding dramatically. Demand for firewood is rapidly accelerating from less than 1000 cords/year in 1982 to more than 35,000 cords/year in 1982. Demand for commercial saw timber is similarly increasing. The sustained yield wood production (annual allowable cut) for the "Fairbanks Working Circle," encompassing roughly a 50 mile radius around Fairbanks, is now set at 4.1 MMBF of saw timber (white spruce) and 31,100 cords of fue 1 wood (hardwoods). This sustained annual production will impact approximately 3000 acres per year, in this "working circle" alone, of statecontrolled forest-classified land. These figures do not include Borough lands, federal lands, private lands, or native villages and regional corporation holdings. The latter in particular are currently subject to increasing harvest and management activity, and are expected to increase to the level now occurring in state lands in the future.

The regional cumulative effects of harvest activities of this magnitude are large. Much harvest activity takes place on the most productive sites, in river valleys and adjacent to streams. The potential consequences of harvest on headwater streams is of particular interest, since small headwater streams are considered both most susceptible to impact and most "pristine" and productive of highest-quality water.

Quantitative, documented information of either undisturbed or managed subarctic upland landscapes and associated stream systems is extremely scarce. Agency response to state and federal land management and regulation directives, notably Section 208 of Public Law 92-500 (non-point source pollution), is hampered by the current lack of knowledge of both the permafrost-dominated taiga upland environment and the response of that environment to resource management practices.

The study recommended here is designed to investigate specific impacts of timber harvest in interior Alaska's forest on headwater stream systems. This proposal is in direct response to the 1981 ACST report, "Living Resources and Habitat Protection: Research Priorities and Recommendations." That document (rightly, in our view) notes that "Timber harvesting in the interior of Alaska is also increasing, and even 
less is known of its impact on fish and wildlife." A specific call is made for research on "... the effects of logging on the fish and wildlife resources of interior Alaska."

We emphasize study of stream systems; there is increasing recognition of the conceptual and functional interrelations between streams and their watersheds. Study of a freshwater stream and its biota is best accomplished in the context of developing adequate understanding of the watershed/stream system as an integrated whole.

In published reviews and position papers concerning non-point or diffuse-source pollution in wild lands, references to subarctic or taiga forest systems are invariably superficial, vague, or (most commonly) entirely absent.

The primary source of actual or potential non-point source pollution (NPSP) problems in relation to subarctic forest resource management are not considered to be (1) forest harvesting and attendant road/skid trail activities, and (2) wildfire, including both burning and fire control procedures.

A recent survey of water quality problems in relation to timber harvesting, prepared for the state of alaska in response to Section 208, PL 92-500, stresses (1) the very limited amount of information available concerning interior Alaska (taiga) environment and existing water quality relationships, (2) the limited but growing role of forest harvesting in subarctic interior Alaska, (3) the low level of supervision or regulation currently applied to forest harvesting in the region, (4) the probable importance of temporary and permanent roads, including skid trails, and stream crossings in producing increased sediment loading streams, and (5) the need for research on the entire question of timber harvest/water quality relationships in interior Alaska.

EPA identifies nine "appropriate" research and development activities; No. 3 (Water Quality) and No. 9 (Anticipating Environmental Problems) are specifically addressed under the proposal "Forest Management and Stress Habitats: Task of Habitat Modification." The recommended research would provide previously unavailable information on pollutant loading (including sediments) and stream habitat alteration (pollutants, effects on aquatic organisms). Attention to forest harvest in central Alaska (activity 3), and response and recovery of two stream systems to forest harvest (activity 3 ). This research is anticipating (activity 9) in that forest harvest and applied forest management is increasing rapidly in Alaska's interior (state lands alone, within 60 miles of Fairbanks, are protected) for impact 3000 acres/year to provide the sustained yield of forest products (saw timber, house logs, fuel wood) needed in the Fairbanks vicinity.

Research Approaches

Effects of vegetation removal would be examined by both before and after studies and "upstream-downstream" studies following timber harvest. The guiding hypothesis is that vegetation removal will shift the 
energetic basis of the stream community from dependence upon leaf input from riparian vegetation to increased primary production within the stream itself. This shift should produce a predictable change in community structure of stream invertebrates and changes in utilization of invertebrates by stream fishes. Primary production by stream autotrophs, secondary production of stream invertebrates, and community structure of primary producers and invertebrates will be used as integrative measures of changes in stream energetics following vegetation removal. Changes in stream bed sediment loads will be investigated as well.

Time Frame

3-5 years. Suggested site: Caribou-Poker Creek.

Resources Required

$\$ 125,000 /$ year. 2-3 principal investigators.

Anticipated Product

Quantitative data and reports on the consequences of specific forest management activities for aquatic and terrestrial habitats in the taiga. Such information is needed for state and federal regulatory agencies, in order that such regulations be based on realistic assessment of (1) before-harvest stream and habitat conditions and of (2) probable consequences of forest management and harvest activities.

\section{Relationship to Other Research}

This proposed reearch would coordinate with ongoing watershed management and forest management research in taiga ecosystems being conducted in central Alaska by the Institute of Northern Forestry, USDA-Forest Service, and with the ongoing research program in freshwater streams/aquatic biology of the Division of Life Sciences, University of Alaska, Fairbanks. One phase of the proposed research would also closely coordinate with a funded project in intensive forest biomass production, being conducted by the Forest Soils Laboratory, UAF.

Riparian Habitats of Arctic Alaska -- Effects of Gravel Removal and $0 i 1$ and Gas Transportation (Number 20)

Research Question

To what extent does removal of gravel from, and routing of oil and gas pipelines and associated with areas through, riparian habitats of arctic Alaska endanger the unique and unusually productive biological resource of these areas?

\section{Research Objectives}

a. Provide a classification and survey of riparian habitats of the arctic slope of Alaska to identify those that are particularly productive, critical to animal populations, or vulnerable to development. 
b. Document the plant diversity, community structure, and productivity of representative riparian stands with respect to seasonal flooding and stage of riparian succession.

c. Document the use of riparian communities by grazing vertebrates, invertebrate herbivores, and nesting birds, and assess the importance of riparian communities to populations of these animals on the arctic slope of Alaska.

\section{Justification}

Consideration of the need for habitat protection should begin with habitats that support an unusually diverse, abundant, or valuable biological resources and with habitats that are directly threatened by development activities. When these are found in a single habitat, immediate action is called for. This is the case for riparian habitats of the arctic slope of Alaska.

The major river systems of the arctic slope flow north from the Brooks Range to the Arctic Ocean, bringing nutrient-rich basic sediments to the acid tundra of the Arctic Coastal Plain. The plant and animal communities of arctic riparian systems are rich in species and higher in productivity than surrounding tundra. The presence of medium to tall shrubs (1-2.5 m), especially willow (Salix spp.), in riparian stands far north of their distribution on open tundra is particularly conspicuous. The reasons for this are not altogether clear. Possible reasons include (a) protection from winter winds, (b) deeper soil thaw, warmer soil temperatures, and rapid decomposition and nutrient cycling in coarse, well-drained alluvial sediments, and (c) the annual input of nutrients from spring flooding.

The willows and herbaceous perennial plants of riparian communities are highly preferred by a number of herbivorous animals. Moose extend all the way to the arctic coast and are increasing in abundance in riparian communities; they are rarely found away from riparian willow stands. The rapid increase in the musk ox population introduced to the Sadlerochit River drainage is related to their use of extensive riparian communities. Populations in the Canning and Hulahula River drainages, with less extensive riparian communities, have not increased as rapidly. Riparian areas are the most important winter and spring habitat for ptarmigan, which feed upon willow buds and catkins. Ground squirrels burrow along river bluffs and forage extensively in adjacent riparian stands. The herbivorous insects using deciduous shrubs, especially willows are far more diverse and abundant than those of other plant growth forms, and these insects provide the prey for a rich assemblage of breeding birds. Willow warblers, gray-cheeked thrushes, and northern shrikes are only a few of the bird species associated with riparian habitats in arctic Alaska.

Riparian habitats are particularly vulnerable to development for at least two reasons. First, they provide an easily-accessible and abundant source of gravel for the roads and work pads that are needed for development in the arctic. The huge quantity of gravel used at Prudhoe Bay has 
been removed from the Sagavanirktok, Putuligayuk, and Kuparuk Rivers. Gravel removal produces a large, but local effect: total loss of habitat. In addition, river valleys are the most economical and feasible routes for roads and pipelines, as is clearly indicated by the routing of the oil pipeline and Dalton Highway. The likely construction of a gas pipeline, which could require a work pad entirely separate from that of the oil pipeline, and the development of new oil and gas fields with feeder lines to the major oil and gas pipelines, will contribute to a cumulative and regional alteration or loss of riparian habitat. An evaluation of habitat values must enter the early phases of development planning to prevent the gradual loss of valuable habitat.

Research Approach

The first objective, a survey of riparian habitats of arctic Alaska, will be addressed using high altitude aerial photography. Ground truth in the eastern part of the arctic slope is available in extensive vegetation surveys already completed in the Sadlerochit River drainage, and planned for other rivers from the Canning to the Jago in the Arctic National Wildlife Refuge. The intensive study area described below will provide ground truth in the Sagavanirktok River system. Additional ground truth in the Colville River and other river systems to the west will probably be advisable.

Objectives $b$ and $c$ will be addressed by establishment of an intensive study site somewhere along the Sagavanirktok River, easily accessible from the Dalton Highway. The site will be chosen to provide extensive stands of a variety of riparian communities, within walking distance of each other, to minimize logistic requirements. Study plots within these stands will be used for regular, systematic observations. Study plots will extend onto adjacent, non-riparian tundra to determine the use of such habitat by riparian species. We hypothesize that the presence of riparian habitat will increase the use of adjacent, nonriparian habitat, so that the riparian effect will actually be greater than the extent of riparian habitat.

Time Frame

We propose a one-year study of existing photo imagery followed by a three-year field program.

$\underline{\text { Cost }}$

We envisage faculty-graduate student-undergraduate student assistant teams as the most cost-effective means of conducting this research. One might propose six such teams, as follows:

Riparian inventory (photointerpretation)

Vegetation

Large mammals

Small mammals

Birds

Insects 
Each would involve one month of faculty support $(\$ 4,000)$, a graduate research assistantship $(\$ 7,500)$, and undergraduate summer salary $(\$ 2,500)$. These teams should share in logistics and study plots and would be approximately $\$ 150,000$, including logistic support.

\section{Anticipated Projects and Outputs}

a. Six masters theses filed at the University of Alaska containing detailed reports of field observations and their interpretations.

b. A series of papers published in the scientific literature describing the most interesting scientific discoveries of the research.

c. Annual reports and a final project report to EPA emphasizing integration and synthesis of results in a manner useful to environmental managers responsible for decisions regarding developments.

d. Specific recommendations regarding habitats deserving special attention and protection, and steps that might be included in development programs to minimize their effects upon riparian habitats and the organisms that use them.

\section{Interrelationships with Previous or Ongoing Research}

Since riparian areas make up only a small part of the terrain of arctic Alaska, they received limited attention in early biological studies. A clear exception to this is studies of birds, which are much more diverse in riparian areas than in other habitats (Kessel and Cape, 1953; Childs, 1969). Research on the process of herbivory at Atquasuk, on the Meade River, clearly showed the concentration of palatable plants and of herbivory in riparian habitats (Batzli, 1980). Studies on musk oxen reintroduced to the North Slope were concentrated in the Sadlerochit River drainage, which is occupied by a rapidly increasing population.

Impact of $0 i 1$ Development Upon Coastal Tundra Wetlands (Number 21)

Problem Definition

What major wetland types occur on the coastal plain of northern Alaska? What are the major impacts of large scale oil development upon these wetlands habitats, and what are the major avenues of impact $(\mathrm{e} . \mathrm{g}$. , altered drainage, discharge of effluents, dust, chemical pollutants such as salt and sulfur dioxide, off-road vehicles)? What types of wetland habitats are most sensitive to each impact?

The objectives of the proposed research are:

a. To summarize existing reports and information on the impact of oil development upon the Prudhoe Bay environment.

b. To define the major community types in North Slope wetlands in terms of vegetation composition, primary production, and soil properties. 
c. To compare impacted and control areas in each major habitat with respect to the following disturbances -- altered drainage, dust, drilling mud, production waters (i.e., those contaminated with oil), sulfur dioxide, and brine.

d. To determine why certain disturbances are particularly detrimental in sensitive habitats.

e. To rank the habitats with respect to sensitivity to each type of disturbance.

f. To recommend guidelines for habitat use and for permissible levels of each disturbance type.

\section{Justification}

$0 i 1$ and gas development on the North Slope of Alaska has potential for extensive regional impacts as oil development continues to expand. The existing field at Prudhoe Bay covers approximately 150 square miles; drill pads are spaced approximately 2 miles apart (a drill pad/2560 acres). Drill pads are connected to a central road and other oil field facilities (gathering centers/flow stations, operations centers, power plants, camp pads, and service company pads) by a network of access roads and pipeline pads. The Kuparuk field is expected to spread over 600 square miles; drill pads are now spaced every two miles but may eventually be spaced every mile. Development of the Milne Point Area is just beginning and the Point Thompson Area will soon be underway. Thus, a large area of coastal tundra will be directly affected by oil development.

Impacts from oil field development have been shown for caribou which live in areas of projected oil field expansion, for shore birds that migrate to the arctic coastal plain from throughout North America, and for the vegetation itself which is in delicate balance with an extreme environment. Past research has shown that some wetland types are much more sensitive to disturbance than others, although their relative sensitivity depends upon the nature of the disturbance. Beyond the direct loss of wetlands due to gravel fill, impact may be cause by:

a. Altered drainage patterns due to gravel placement and inadequate culverting.

b. Dust from road traffic and pads.

c. Toxic materials from drilling mud disposal pits, oil spills on the facilities pads, and oil-contaminated waters used for dust control.

d. Air pollution (particularly $\mathrm{SO}_{2}$ ) from refineries.

e. Brine that is being reinjected into wells. 
Information on the extent of impacts due to oil field development on the North Slope is needed by the Environmental Protection Agency (EPA) in exercising their oversight authority of the Section 404 dredge and fill permitting program (Clean Water Act of 1977) as outlined by the "Guidelines for Specification of Disposal Sites for Dredge or Fill Materials" (40 CFR Part 230, Vol. 44, No. 249). Specifically, information on the extent of impacts due to drainage alteration, dust, and introduction of toxic materials related to wetland types will be useful for permitting and policy decisions; careful definition of the impacts is important in defining ecologically sensitive habitats and in defining the types of human activities that most strongly affect each habitat.

\section{Research Approaches}

a. Carry out an extensive literature search of the impact of oil development upon coastal tundra. Much of this work has already been summarized.

b. Select habitat types on the basis of an existing community classification scheme (Walker and Webber) in which communities can be recognized from infrared aerial photography. Compare heavily disturbed, lightly disturbed, and control areas with respect to each disturbance factor (e.g., dust, impoundment, salt, oil) in each habitat type. Parameters measured would include pattern of phenological development, primary production and biomass by species, plant chemical analysis, soil temperature, thaw depth, soil pH, soil salt content.

c. Similar measurements would be made with respect to the same disturbance factors and habitats, comparing dated disturbances of different ages to determine the time course of community response (either degradation or recovery).

d. Similar measurements would be made with respect to the same disturbance factors and habitats, setting up manipulations intended to stimulate the different disturbances in controlled field experiments.

Time Frame

Three years. 1 year to set up manipulations and begin survey of existing disturbances. Years 2 and 3 to complete survey and analyze results of manipulations. Suggested sites: Prudhoe Bay and Kuparuk fields.

\section{Costs}

$\$ 150,000$ per year over 3-4 years; manpower required: 2 principal investigators -- 2 months; technician -- 12 months; 2 field assistants -3 months. No major facilities required. 


\section{Anticipated Products}

Year 1. Literature survey pinpointing probable effects of impact and likely recovery rates from each impact.

Year 2. A guide for managers including description of major vegetation types, representative air and ground photos of these types, and estimates of sensitivity to and recovery from these impacts.

Year 3. Final report describing observed rates of degradation or recovery of vegetation from major environmental impacts. Open literature publication of results.

\section{Interrelationship with Other Research}

This research will summarize relevant past research at Prudhoe Bay and other coastal tundra sites (e.g., vegetation mapping by walker and Webber and Everett, work on offroad vehicles by CRREL). Work will be coordinated with ongoing work of habitat use by birds and mammals and on brine impact at Prudhoe Bay.

\section{Environmental Effects of Transportation Corridors in Permafrost Regions}

\section{(Number 22)}

\section{Problem Definition}

Resource extraction in northern Alaska, especially oil and gas, required that transportation systems such as the Trans-Alaska (oil) Pipeline System be constructed across wilderness areas to bring products to market. Such systems inevitably impact land, air, and water quality to some extent. Future transportation impacts may be substantial and can dwarf the size of localized development. For example, development of the Prudhoe Bay oil field necessitated some $200 \mathrm{~km}$ of gravel roads, while its associated oil pipeline require a new $577 \mathrm{~km}$ road plus a longer gravel work pad. Possible future transportation routes include east-west routes both north and south of the Brooks Range for both $0 i 1$ and gas and mineral deposits.

\section{Objectives}

a. To identify and quantify cumulative impacts of transportation corridors in arctic and subarctic Alaska.

b. To predict the extent of future impacts.

c. To devise environmentally acceptable methods for mitigating air and water pollution associated with transportation corridors.

d. To establish regulations for controlling habitat damage and destruction along northern transportation routes. 
Justification

This project directly deals with a number of high priority EPA generic issues. Perhaps the two main issues are the fifth and sixth ranked issues, namely cumulative and regional effects through habitat modification/removal and effects of $0 i 1$ and gas product transport and storage through habitat modification/removal. Other issues include eighth and eleventh ranked non-fuel mineral extraction effects and the twenty-ninth ranked oil and gas transport effects on air emissions.

\section{Research Approaches}

Impacts will be quantified using one or more of three major approaches. First, existing information will be synthesized in order to assemble a data base and to identify research needs. Next, by examining multiple transportation systems of differing ages or a single system over 3-5 years, long-term impacts can be quantified. Finally, short-term experimental studies of 3-5 years duration will be established and monitored in order to be able to analyze the major types of impact and mitigation techniques under similar conditions. These conditions should examine the following areas:

a. Gravel extraction of pipelines and permanent roads in permafrost areas require large amounts of gravel for insulation, sometimes in locations with very limited gravel deposits. Gravel mining both destroys habitat and may cause sedimentation and pollution of water. Road gravel is especially pertinent to EPA concerns in the arctic and the subarctic, since many roads are located by rivers within wetland areas. A synthesis should be done to determine what area of a certain habitat type, percentage of total habitat of that type, and for how long is habitat lost from upland versus riparian gravel sites. What are the road gravel maintenance needs and how can habitat loss be minimized by optimizing the location and type of gravel sites for long-term maintenance? Finally, what restoration methods can mitigate habitat loss and sedimentation from gravel sites?

b. Road dust: The high frequency of gravel roads make road dust a common air, water, and land pollutant in the North. Road dust may also induce early snow melt along roads and influence wildlife feeding. Therefore, it is important to know what the cumulative effects of road dust are. Also, how much and how far is dust transported? Finally, how effective are dust control techniques (watering, oiling, hydrophilic chemicals) and what are their environmental impacts?

c. Expedient roads: Frequently, roads are required only for short periods of 1-3 years or in areas of little or no gravel. Snow and ice roads can be readily constructed during the arctic and subarctic winters but they do impact underlying vegetation, soil thermal regime, and spring runoff to some extent. More understanding is needed of cumulative effects and of damage differences between vegetation types and road construction types (e.g., crushed ice, compacted snow, etc.). 
d. Off-road vehicles: Off-road vehicles are widely used for transportation in Alaska where the existing road system is quite limited. ORV's impact permafrost communities in terms of changes in community composition and function in addition to soil thermal alterations. Further information is needed to determine under what conditions trails recover and under what conditions they deteriorate. Existing vehicle tracks will be selected for study on the basis of ages verified by aerial photography, frequency of use, and type. For example, some trails prepared by blading for winter ORV use may be examined.

\section{Time Frame/Products}

a. Synthesis on existing information and studying different aged roads, a preliminary analysis of existing impacts can be compiled within one or two years.

b. A final report summarizing the associated experimental studies will be available for 3-5 years of monitoring. This report will include guidelines for selecting upland or riparian gravel sites, and recommendations for controlling road dust, construction of expedient roads, and route selections for ORV's. Possible study sites include the Dalton Highway from Livengood to Prudhoe Bay completed in 1974, and localized road systems near northern Alaskan villages. Snow and ice roads in the National Petroleum Reserve of Alaska may also be used.

Cost

$\$ 130 \mathrm{~K}$ for 3-5 years.

Possible study sites include the Dalton Highway from Livengood to Prudhoe Bay completed in 1974, the Demster Highway in Yukon Territory, Canada, completed in 1978, and localized road systems near northern Alaskan villages. Snow and ice roads in the Northern Petroluem Reserve of Alaska may also be used.

\section{Interrelationships with 0ther Programs}

a. U.S. FWS has conducted riparian gravel studies which can provide information on environmental damage.

b. The Joint Alaska-Federal Fish and Wildiife Advisory Team has information on the extent of areas disturbed for gravel along TAPS.

c. CRREL is currently conducting studies along the TAPS right-of-way examining both engineering aspects and some botanical studies. This study will end in 1982 and would provide some related data to these proposed studies. 
0il Spill, Impact, Cleanup, and Recovery of Permafrost Ecosystems (Number 23)

Problem Definition

Numerous petroleum spills have occurred in Alaska, particularly along TAPS and its associated highway system. Although there has been extensive research on the short term impact of crude oil spills in Alaska [Arctic 31(3):1978), there is little quantitative information on ecosystem damage.

\section{Objectives}

a. To assess the effectiveness and damage resulting from cleanup techniques on various types of oil-impacted permafrost terrain.

b. To predict the recovery rate of oil-damaged permafrost communities with and without active cleanup or restoration methods.

c. To provide a quantifiable measure of reduction (including duration) in overall habitat quality from oil spills (i.e., a damage index).

\section{Justification}

This study would provide information for EPA's fourth highest generic issue, namely the "effect of oil and gas accidents through habitat modification." It would also provide a mechanism for an objective assessment of civil penalties and for selecting cleanup approaches of oil spills.

\section{Research Approach}

The research effort should be a multidisciplinary integrated effort involving the areas of plant biology, soil physics, chemistry and biology, and hydrocarbon quantitative-qualitative monitoring. The major focus of the effort should be functional in nature so that there is the greatest probability of generating information useful in directing cleanup revegetation management plans for different areas contaminated by oil/gas spills. Initially, a brief literature review will be used to develop an experimental damage index. The index will then be field tested at actual oil spills to determine its usefulness. Both damage and persistence (i.e., recovery) will be incorporated into the index as well as wildlife impact.

Research sites should utilize existing accidental or research spill areas where sufficient documentation of cleanup, revegetation activities exist. New sites should only be established in areas not covered by the above and recognized as high risk areas (i.e., reasonable chance of a spill in an area of high damage potential from the oil and cleanup restoration activities). At each site, several cleanup strategies (passive, no action; manual, mechanical) and restoration (passive, no action, reseeding, reseeding-fertilizer application, nurse crop-native plant reseeding, native transplants, oil-adapted plant transplanting; oil-adapted, non-adapted mycorrhizal amendments) should be attempted. 
This will permit an effective battery of options to be available to the Agency for planning the most effective steps to be taken in the event of an $0 i 1 \mathrm{spill}$.

In all cases, site strategy studies should include (1) plant biology: root growth, nutrient processing and uptake, mycorrhizal studies, and general plant demography. (2) Soils, extent and stability of the permafrost; chemical and physical state and dynamics of the active layer and the location and mobility of $0 i 1$ in the soil; biology of decomposition of soil carbon and oil and nutrient dynamics. (3) Fate of oil -- this should be monitored so that the amount and chemical composition of the oil is known with time (important relative to the cleanuprevegetation strategy for direct toxic or secondary soil interactions with plants).

\section{Time Frame/Products}

a. 3-5 years duration.

b. Year 1: Preliminary damage index.

c. Years 2-3: Assessment of cleanup effectiveness and impact.

d. Years 4-5: Final report of damage index, recovery times as influenced by both cleanup and restoration techniques, and recommendations for selecting techniques.

e. If desired, with additional funding in the fourth and fifth years an atlas could be prepared to indicate both damage potential and suggested cleanup-restoration technologies along the TAPS route:

Sites: Prudhoe Bay, Trans-Alaska Pipeline Corridor, particularly checkvalves 3 and 23, Steele Creek; Poker-Caribou Watershed.

$\underline{\text { Cost }}$

$\$ 75-\$ 100 \mathrm{~K}$ per year for 3-5 years.

See 5 .

\section{Interrelationships with Other Programs}

a. Previous oil spill studies will be used to develop a damage index.

b. Vegetation/soil mapping studies on the North Slope could be used to develop an atlas if desired.

c. If possible, industry oil spill studies will be used to assess restoration techniques. Unfortunately, these are often proprietary. 
Impact of Agricultural Land Clearing on Migratory Birds (Number 24)

Problem Definition

What is the damage done by migratory water fowl to barley crops in terms of trampling and grain removal? What is the impact of the Delta barley project upon timing of staging and migration and upon fat and pesticide levels in migratory waterfowl?

\section{Rationale}

Barley development is rapidly developing in central Alaska along the normal flyway and at important staging areas for migratory waterfowl. These waterfowl seem to spend longer time at these staging areas than normal because of the opportunity to feed on barley. This may result in damage and grain loss to the farmer, a disruption in normal migratory patterns of birds, and increased pesticide loads in migratory birds.

\section{Research Approaches}

The impact of barley development upon waterfowl would be studied by comparing the numbers of birds that use staging areas adjacent to barley fields with simliar areas distant from barley development. The timing of migration, bird density, and pesticide loads would be examined in each site. To examine impact of waterfowl on barley, the density of bird use and damage would be compared between fields harvested early and those harvested late. Also, initial surveys would be conducted to determine whether proximity to nesting areas or other habitats influenced waterfowl use of barley.

\section{Time Frame}

2 years Delta.

\section{$\underline{\text { Resources }}$}

$\$ 50,000 /$ year.

\section{Anticipated Products}

Report on effect of intensive agricultural development on migratory birds. Recommended guidelines on developing of new agricultural lands to minimize impact on waterfowl.

\section{Interrelationships with Other Research}

The research would be coordinated with agricultural planning efforts by the state of Alaska and the Agricultural Experient Station. 
Table 5. Brief description of water contamination/consumption sketches.

\begin{tabular}{|c|c|c|c|c|c|c|c|c|}
\hline Topic & & Title & Question & Generic Issue & Product & $\begin{array}{l}\text { Time } \\
\text { Frame }\end{array}$ & $\begin{array}{l}\text { Cost/ } \\
\text { Year }\end{array}$ & $\begin{array}{l}\text { Page } \\
\text { No. }\end{array}$ \\
\hline 25 & 1. & $\begin{array}{l}\text { Ecosystem Impacts } \\
\text { of Placer Mining }\end{array}$ & $\begin{array}{l}\text { What does placer } \\
\text { mining do to } \\
\text { aquatic } \\
\text { ecosystems? }\end{array}$ & $\begin{array}{l}\text { Non-fuel } \\
\text { minerals }\end{array}$ & $\begin{array}{l}\text { Report of a } \\
\text { synthesis meeting } \\
\text { relating results } \\
\text { to Agency } \\
\text { stipulations }\end{array}$ & 4 yrs & $\begin{array}{l}\$ 160 K- \\
50 K\end{array}$ & 3 \\
\hline 26 & 2. & $\begin{array}{l}\text { Control of } \\
\text { Sediment Discharge }\end{array}$ & $\begin{array}{l}\text { What is the best } \\
\text { way to remove } \\
\text { sediments from } \\
\text { placer mining? }\end{array}$ & $\begin{array}{l}\text { Non-fuel } \\
\text { minerals }\end{array}$ & $\begin{array}{l}\text { Technical } \\
\text { paper(s) } \\
\text { reporting recom- } \\
\text { mended technology }\end{array}$ & 5 yrs & $\$ 75 \mathrm{~K}$ & 10 \\
\hline \multirow[t]{2}{*}{27} & 3. & $\begin{array}{l}\text { Peat Mining } \\
\text { Effects on Aquatic } \\
\text { Ecosystems }\end{array}$ & $\begin{array}{l}\text { What will peat } \\
\text { mining do to } \\
\text { aquatic } \\
\text { ecosystems? }\end{array}$ & $\begin{array}{l}\text { Coal extraction } \\
\text { effects }\end{array}$ & $\begin{array}{l}\text { Conceptual model } \\
\text { of impacts } \\
\text { documented in } \\
\text { report }\end{array}$ & 5 yrs & $\begin{array}{l}\$ 40- \\
140 \mathrm{~K}\end{array}$ & 15 \\
\hline & 4. & $\begin{array}{l}\text { Dissolved } \\
\text { Hydrocarbons }\end{array}$ & & $\begin{array}{l}0 i 1 \text {, gas, and } \\
\text { coal extraction } \\
\text { and processing }\end{array}$ & & & & 17 \\
\hline 28 & & a. Concentration & How much occurs? & & $\begin{array}{l}\text { Report change in } \\
\text { Valdez } \\
\text { concentrations }\end{array}$ & $1 \mathrm{yr}$ & $\$ 30 \mathrm{~K}$ & \\
\hline 29 & & $\begin{array}{l}\text { b. Biodegrada- } \\
\text { tion Rates } \\
\text { and Popu- } \\
\text { lations }\end{array}$ & $\begin{array}{l}\text { How fast do they } \\
\text { biodegrade? }\end{array}$ & & $\begin{array}{l}\text { Forecast accumula- } \\
\text { tion of hydro- } \\
\text { carbons and } \\
\text { microflora }\end{array}$ & $1 \mathrm{yr}$ & $\$ 70 K$ & \\
\hline 30 & & $\begin{array}{l}\text { Excreted } \\
\text { Products } \\
\text { of Bio- } \\
\text { degrada- } \\
\text { tion }\end{array}$ & $\begin{array}{l}\text { What products } \\
\text { result from } \\
\text { hydrocarbon } \\
\text { biodegradation? }\end{array}$ & & $\begin{array}{l}\text { Identify the non- } \\
\text { hydrocarbon input } \\
\text { from ballast water }\end{array}$ & $1 \mathrm{yr}$ & $\$ 90 K$ & \\
\hline 31 & & $\begin{array}{ll}\text { d. } & \text { Chronic } \\
\text { Effects on } \\
\text { Dinoflagel- } \\
\text { late/Diatom } \\
\text { Ratios }\end{array}$ & $\begin{array}{l}\text { Is it important } \\
\text { if low } \\
\text { concentration of } \\
\text { hydrocarbons } \\
\text { accumulate? }\end{array}$ & & $\begin{array}{l}\text { Report of } \\
\text { threshold levels } \\
\text { that shift popula- } \\
\text { tions towards } \\
\text { dinoflagellates }\end{array}$ & 3 yrs & $\$ 60 \mathrm{~K}$ & \\
\hline 32 & 5. & $\begin{array}{l}\text { Petroleum } \\
\text { Pollutants in } 0 i l \\
\text { Brine and Waters } \\
\text { Off North Slope }\end{array}$ & $\begin{array}{l}\text { What is the } \\
\text { chemistry of } \\
\text { produced water } \\
\text { and current } \\
\text { background } \\
\text { hydrocarbon } \\
\text { concentrations? }\end{array}$ & $\begin{array}{l}\text { Oil and gas } \\
\text { development }\end{array}$ & $\begin{array}{l}\text { Published } \\
\text { analysis of } \\
\text { produced water } \\
\text { and natural } \\
\text { hydrocarbon } \\
\text { levels }\end{array}$ & $1 \mathrm{yr}$ & $\$ 90 K$ & \\
\hline$x$ & 6. & $\begin{array}{l}\text { Oil Development } \\
\text { Impacts on } \\
\text { Seagrass } \\
\text { Ecosystems }\end{array}$ & $\begin{array}{l}\text { How are seagrass } \\
\text { communities } \\
\text { likely to change } \\
\text { in response to } \\
\text { oil or dredging? }\end{array}$ & $\begin{array}{l}0 \text { il and gas } \\
\text { deve lopment }\end{array}$ & $\begin{array}{l}\text { Conceptual model } \\
\text { of potential } \\
\text { effects }\end{array}$ & 5 yrs & $\$ 230 K$ & 37 \\
\hline 33 & 7. & $\begin{array}{l}\text { Biomonitoring } \\
\text { Review and Field } \\
\text { Evaluations }\end{array}$ & $\begin{array}{l}\text { What biological } \\
\text { manifestations of } \\
\text { oil pollution are } \\
\text { most useful in } \\
\text { cold climates? }\end{array}$ & $\begin{array}{l}0 i 1 \text { and gas } \\
\text { development }\end{array}$ & $\begin{array}{l}\text { Reports and } \\
\text { papers relating } \\
\text { relative effects } \\
\text { to oil pollution }\end{array}$ & 3 yrs & $\begin{array}{r}\$ 50- \\
75 K\end{array}$ & 42 \\
\hline 34 & 8. & $\begin{array}{l}\text { Toxicity of } \\
\text { Produced Water }\end{array}$ & $\begin{array}{l}\text { What are accept- } \\
\text { able disposal } \\
\text { practices for } \\
\text { produced water? }\end{array}$ & $\begin{array}{l}0 i 1 \text { and gas } \\
\text { development }\end{array}$ & $\begin{array}{l}\text { Reports of } L C_{50} \\
\text { and threshold } \\
\text { concentrations }\end{array}$ & $1 \mathrm{yr}$ & $\$ 75 K$ & 46 \\
\hline
\end{tabular}


Table 5 (continued)

\begin{tabular}{|c|c|c|c|c|c|c|c|c|}
\hline Topic & & Title & Question & Generic Issue & Product & $\begin{array}{l}\text { Time } \\
\text { Frame }\end{array}$ & $\begin{array}{l}\text { Cost/ } \\
\text { Year }\end{array}$ & $\begin{array}{l}\text { Page } \\
\text { No. }\end{array}$ \\
\hline \multirow[t]{7}{*}{35} & $8 a$. & $\begin{array}{l}\text { Environmental } \\
\text { Effects of } \\
\text { Continuous } \\
\text { Industrial } \\
\text { Discharges in } \\
\text { North Latitude } \\
\text { Embayments }\end{array}$ & & & & $1 \mathrm{yr}$ & $\begin{array}{r}\$ 20- \\
30 \mathrm{~K}\end{array}$ & \\
\hline & 9. & $\begin{array}{l}\text { Relation Between } \\
\text { Gardia Infection } \\
\text { and Drinking Water }\end{array}$ & $\begin{array}{l}\text { Is resistance } \\
\text { build up to } \mathrm{G} \text {. } \\
\text { lamblia in } \\
\text { humans? }\end{array}$ & $\begin{array}{l}\text { Cumulative } \\
\text { regional } \\
\text { effects }\end{array}$ & No writeups & & & 49 \\
\hline & 10. & $\begin{array}{l}\text { Effect of Acid } \\
\text { Rain on Lakes }\end{array}$ & $\begin{array}{l}\text { What is the } \mathrm{pH} \\
\text { change in Alaskan } \\
\text { lakes? }\end{array}$ & $\begin{array}{l}\text { 0il, gas, and } \\
\text { coal extraction }\end{array}$ & & & & 50 \\
\hline & 11. & $\begin{array}{l}\text { Delta Farming } \\
\text { Impacts }\end{array}$ & $\begin{array}{l}\text { Herbicide } \\
\text { decomposition and } \\
\text { stream } \\
\text { eutrophication? }\end{array}$ & $\begin{array}{l}\text { Renewable } \\
\text { resource } \\
\text { utilization }\end{array}$ & & & & 51 \\
\hline & 12. & $\begin{array}{l}\text { Nitrate in } \\
\text { Groundwater }\end{array}$ & $\begin{array}{l}\text { What is the } \\
\text { chemistry of well } \\
\text { water? }\end{array}$ & $\begin{array}{l}\text { Renewable } \\
\text { resource } \\
\text { utilizatio }\end{array}$ & & & - & 52 \\
\hline & 13. & $\begin{array}{l}\text { Metals in Mine } \\
\text { Wastewater }\end{array}$ & $\begin{array}{l}\text { What chemical } \\
\text { changes will } \\
\text { occur in stream } \\
\text { water due to } \\
\text { mining? }\end{array}$ & $\begin{array}{l}\text { Non-fuel } \\
\text { minerals }\end{array}$ & & & & 53 \\
\hline & 14. & $\begin{array}{l}\text { Temperature } \\
\text { Coefficients of } \\
\text { Biodegradation }\end{array}$ & $\begin{array}{l}\text { What do changes } \\
\text { in temperature do } \\
\text { to the rates of } \\
\text { organic-concen- } \\
\text { tration-dependent } \\
\text { biodegradation } \\
\text { rates? }\end{array}$ & $\begin{array}{l}\text { Renewable, non- } \\
\text { renewable, and } \\
\text { regional } \\
\text { effects }\end{array}$ & & & & 54 \\
\hline
\end{tabular}




\section{WATER CONTAMINATION/CONSUMPTION SKETCHES}

\section{Introduction}

Water quality in Alaska is a matter of health, economics, and aesthetics. Many changes due to resource development can be forecast from the experiences of the warmer states. In addition, cool temperatures slow natural depuration rates, and young frozen soils contribute to fragility of systems which are then subject to perturbation by less major insults.

The water quality group has chosen to direct focus on the following selected problems based on the mission of the Environmental Protection Agency, relevance to cold climate issues, relationships to projected developments, seriousness of impact, and tractability (Table 6).

Continued contamination of water, by both fossil fuel residue and mineral extraction, is a certainty. Whatever indicators of pollution are used, it should be established that these are indeed relevant to the environment impacted.

Seagrass systems are among the major marine communities potentially impacted by oil spills, corridor construction, and perhaps gold dredging activity. Dissolved hydrocarbons and their products of partial biodegradation are a component of the estuarine environment already building, and increased fossil fuel extraction and processing promises to bring more. Both placer and peat mining hold promise of significantly altered stream morphology, ecology, and chemical change which may reach some shallow water table supplies. The problem of acid rain on lakes seems less significant than in some industrial areas, but representatives of our many lakes bear monitoring.

These problems have surfaced as among those which are important, not addressed elsewhere, and ones for which answers can be formulated within a reasonable time frame.

Ecosystem Impacts of Placer Mining in Alaska (Number 25)

Research Question and Description

What does placer mining do to stream ecosystems?

The renewal of placer mining activity in Alaska has placed a pollutant burden upon several of Alaska's streams and estuaries. Although the introduction of large amounts of suspended particulate matter is the most obvious of the resulting impacts, other potentially more serious perturbations may arise through other less visible insults such as the introduction of heavy metals and large quantities of dissolved and particulate organic matter. These impacts could have either deleterious or positive impacts on stream biota depending upon whether additions were toxic (e.g., mobilized arsenic) or a potential food source to invertebrates (suspended peat particles). Very little coherent information is available on stream ecosystem alteration by developmental impacts in Alaska and most permitting and regulatory action is based upon 
visible changes in water quality or criteria adopted from temperate latitudes bearing small relevance to the extreme seasonal hydrologic regimes of interior and arctic Alaska.

The research question is posed: Is it possible, through the use of adaptive environmental assessment techniques, to define the impacts of placer mining activities on an Alaskan stream ecosystem, and to evaluate from an ecosystem standpoint the severity of the perturbations to the biota, with due consideration also being given to secondary impacts such as loss of recreational or aesthetic values?

\section{Justification}

Most "environmental studies" address a particular symptom arising from a perturbation to the environment resulting from human activity. In the case of placer mining, which has undergone a resurgence during the last few years in Alaska, the most obvious impacts have been through habitat destruction and the introduction of large amounts of suspended matter to streams. These problems (or more accurately, symptoms) have been addressed by the State Department of Environmental Conservation through permitting requirements and attempts at designing settling ponds for miners and to date has been a notable failure from a technical and environmental protection point of view.

This research project would approach the problem from an ecological standpoint. Selected indicator species of apical or near-apical position in the food webs of the impacted streams would be assessed as to potential impact in a "downward-looking matrix" to predict the likely points of stress on the life cycle or food supply or reproductive requirements of the organisms. These sensitive points would then be studied to see if the perturbations were stressing the organisms. Thus, the focus of the study shifts in an "adaptive environmental assessment" rather than arbitrarily selecting an "obvious" perturbation problem arising from indirect or less visible effects.

\section{Statement of Objectives}

1. Through the use of an interdisciplinary evaluation starting with known apical organisms in a stream, select those species of significant human, aesthetic, or ecological importance to the ecosystem.

2. Through a "downward-looking" matrix, evaluate the potential impacts of these indicator species arising from current or impending perturbations to the stream.

3. Conduct field studies to determine if projected impacts are occurring and to seek additional changes not anticipated or of differing magnitude than projected.

4. After evaluation of interdisciplinary field studies, adapt the environmental studies to fill newly identified research needs or to extend data bases to enable projection of impacts. 
5. Periodically, synthesize the environmental and biological data obtained to assist state and federal agencies in evaluating the magnitude of impacts and to realistically regulate human activity with an awareness of the ecological costs involved.

\section{Research Approaches}

Study Site Selection. State geological survey personnel have identified several areas of Alaska where placer mining is either active or anticipated in the future. For this project, either the Alaska Gold Company's working dredge in the Nome district or the Goodnews Bay platinum dredging in southwestern Alaska are likely candidates for study. other smaller operations in the Fairbanks district would also be evaluated due to their proximity to research centers.

Adaptive Environmental Assessment. This technique of assessing developmental impact has only recently been used in Alaska through the NOAA-Outer Continental Shelf Environmental Assessment Program in their Barrier Island-Lagoon System Study on the coast of the Beaufort Sea. Their success in describing the functioning and impact sensitivities of this remote area were encouragement toward continuation of this type of study. For this effort, a small working group of interdiciplinary scientists would be assembled and a preliminary synthesis of the available data made with an attempt to address the consequence of mining activities. Ideally, biological and physical disciplines would be represented by the scientists most knowledgeable of the processes and environment of the area. Participation by mining industry personnel and Agency personnel would aid in evaluating likely future activity. From this workshop, a study plan would be assembled and the research projects started for the first season.

\section{Field Research}

The projects would be coordinated scientifically and logistically to maximize the efficiency and cost-effectiveness. A field camp would be set up near Nome, for example and common room and board and transportation used to the study site. A degree of flexibility in scientific goals should be maintained to allow maximum response by scientists to emerging shifts in scientific direction.

Syntheses. Following the field season and a reasonable time for data processing, a synthesis meeting by concerned parties would be held to: (1) discuss field and lab data; (2) evaluate the data in respect to project goals; and (3) adapt research objectives to meet the direction indicated by the first two steps. The project manager would then set about implementing the changes while still attempting to preserve continuity and efficiency in the program.

After completion of the final field and laboratory studies, a synthesis meeting would be conducted with the following goals: (1) assemble all of the data and conclusions of the scientific studies; (2) evaluate proposed stipulations and mitigating measures proposed by Agency personnel; and ( 3 ) identify research questions left unanswered and future research direction. 


\section{Time Frames}

An interdisciplinary adaptive environmental assessment program would, by its nature, require, at a minimum, two or three field seasons. A more likely tíme frame would be four or five years.

\section{Suggested Sites}

Although site selection would best be made at the initial synthesis meeting between contract manager and prospective research personnel, likely choices are the Alaska Gold Company operations at Nome, the Goodnews Bay platinum operations, or one of the smaller operations such as the Nyack placer operations near Sleetmute.

\section{Constraints}

The major constraints are logistical and the commitment to a long-term project aimed at optimizing scientific information relative to monetary input. Past experience with NOAA-OCSEAP, state agency, and industry personnel have shown that the long-term benefits are costeffective and valuable to all parties concerned.

\section{Costs}

Projected costs for an interdisciplinary study of this type would require approximately $\$ 1$ M/year.

Types of Output

The results and recommendations arising from this study would be disseminated in three major forms:

1. Real time conveyance through synthesis meetings and Agency conferences.

2. Research reports to the funding source.

3. Scientific refereed papers and presentations following completion.

\section{Control of Sediment Discharge from Placer and Other Surface Mining (Number 26)}

Research Question and Description

What is the best way to remove sediments from placer mining?

Many Alaskan streams are naturally turbid because of the presence of glacial flour in their waters. All streams can be turbid naturally for short periods of time because of excessive runoff caused by melting snow or heavy rains.

Hundreds of miles of Alaskan streams, however, are rendered highly turbid for many months of the year because of the discharge of excessive sediment loads from placer mining operations. In spite of existing 
regulations established to prevent such phenomena, this problem is widespread in Alaska. The potential for placer and other surface mining activities in Alaska in the future will complicate this situation.

The research question is to access currently used and potential sediment control technology. This would involve bench-top laboratory experiments, the collection of field data, and the analysis of the governing fluid mechanics.

Justification

The present situation makes a mockery of existing Alaskan water quality requirements. There has been no serious effort on the part the of Alaskan Department of Environmental Conservation to enforce turbidity standards on placer mining discharge waters. Due mainly to a lack of manpower and money, the state has tried to cooperate with the miners to at least get them to build settling ponds. Even though such ponds have usually not come close to meeting effluent turbidity standards, they would at least remove the bulk of the sediment load, if properly designed and operated.

Very little hard data exists concerning the effect of such sediment discharge on downstream aquatic life. A current U.S. EPA study will al low some data to be collected. From dozens of studies concerning the effect of sedimentation in incubating salmon eggs and other related studies, it seems overwhelmingly probable that excessive sediment discharge into otherwise clear streams can be highly detrimental to downstream aquatic life. Furthermore, such a situation creates an aesthetic nightmare.

Hence, it is highly desirable to immediately provide a systematic assessment of potential mitigating technology. At the present time, the U.S. EPA is attempting to rule on a suit concerning the definition of best practical control technology for placer mining. Unfortunately, this decision making process is suffering from a paucity of engineering data. The State of Alaska and the U.S. EPA recently tried to obtain some of this data via a demonstration project. Unfortunately, much of the necessary data will not be obtained from this demonstration project.

\section{Objectives}

1. Assess existing and potential control technology for removal of suspended solids from placer mining process waters.

2. Make recommendations for future control technology in Alaska.

\section{Approach}

1. Perform literature search.

2. Obtain operational data for several existing settling ponds. This includes both performance data on suspended solids removal and ancillary information on mining activity and pond hydraulics. 
3. Using the same discharge waters, conduct simulation laboratory tests. This will allow one to both assess alternative technologies and better understand scaling laws used in the past to inerpret laboratory data.

4. Analyze all this data using known sedimentation theories.

5. Make an assessment of the potential of settling ponds and other control technologies to remove suspended solids from discharge waters.

6. Recommend which technologies are most suitable for achieving desired receiving water goals.

Time Frame

5 years. Cost per year: $\$ 75 \mathrm{~K}$.

1. Literature Search June 83 - September 83

2. Collect Field Data June 83 - September 83

June 84 - September 84

3. Laboratory Testing October 83 - May 84

October 84 - May 85

4. Data Analysis June 84 - September 85

5. Assessment October 85 - November 85

6. Final Report February 86

Sites

Field data to be collected in interior Alaska (within 200 miles of Fairbanks, say).

Laboratory tests to be performed at UAF.

\section{Constraints}

Obtaining cooperation of miners in collecting data.

Costs

Manpower

P.I. (4 mos $/ \mathrm{yr} \times 3$ yrs $=12 \mathrm{mos}$ )

$\$ 120,000$

Graduate Student $(7 \mathrm{mos} / \mathrm{yr} \times 3 \mathrm{yrs}=21 \mathrm{mos})$

40,000

Technician ( $3 \mathrm{mos} / \mathrm{yr} \times 3 \mathrm{yrs}=9 \mathrm{mos})$

35,000

Facilities, Equipment, Supplies

40,000

Trave 1

$\frac{20,000}{225,000}$ 
output

a. Present results at conference.

b. Complete report for local distribution.

c. Techical paper for journal.

Relationship with Other Research

As mentioned earlier, this will relate closely to two EPA funded studies: one is a demonstrative settling pond and the other is a study of effects of sediment discharged on downstream aquatic life.

Furthermore, these results will be useful for making environmental regulations consistent with available control technology for future surface mining development in Alaska.

Peat Mining Effects on Aquatic Ecosystems (Number 27)

Research Question and Description

What will peat mining do to aquatic ecosystems?

$\underline{\text { Issue }}$

Peat is proposed as a power plant fuel in Dillingham for extraction as power fuel in the Susitna Valley. Mining and dewatering of peat will impact ecosystems via (1) dredging and stripping of wetlands, (2) mobilization of dissolved organic matter; (3) suspension of large quantities of particulate organic matter. Studies in arctic Alaska tundra have shown that peat is active microbiologically and is a major energy (carbon) supply to foodwebs. No data are available on potential impacts due to peat extraction.

EPA Regulatory Problem

No relevant data are available for rational establishment of water quality discharge criteria resulting from peat extraction.

Human Health Issue

Surficial water quality supplies and shallow water tables may be affected in proximity to mining activities.

Long-Term Effects

Since peat is a surficial deposit, long-term extraction will result in extensive habitat loss and the potential for watershed alteration or morphological changes in stream beds. 


\section{Wide-Ranging Effects}

Potential food web impacts would result in downstream ecosystems and, in the case of Dillingham, on estuarine ecosystems there is also the potential in southwest Alaska for impacting salmon streams.

Peat stripping effects in arctic and subarctic ecosystems have not been addressed nor are temperate systems pertinent due to year-round primary production potential at lower latitudes.

Expected Results

An ecosystem conceptual model contrasting impacted and non-impacted areas. Projections of quantitative impacts on sensitive species and long-term assessments would be desired products.

\section{Time Frame}

5 years. Cost per year: $\$ 30-140 \mathrm{~K}$.

Effects of Dissolved Hydrocarbons on the Biochemistry and Microflora of Receiving Waters (Numbers 28-31)

Research Question

What significant changes arise from the introduction of large quantities of anthropogenic hydrocarbons into northern streams and estuaries; is it important if the dissolved hydrocarbon content of seawater is increased by sustained concentrations of approximately 1 $\mu \mathrm{g} / \mathrm{liter}$ ?

\section{Justification}

Need. The sense is that many more southerly estuaries are significantly degraded by pollution, yet little information about dissolved hydrocarbon introduction exists for Alaskan waters. Measurements here will provide evidence of the hydrocarbon concentration changes, their decomposition rates, the products of their biodegradation, and the effects of some major phytoplanktonic processes caused by the addition of dissolved hydrocarbons to selected test organisms.

These issues (1) are significant to the regulatory role of EPA, (2) bear on human health problems because dissolved hydrocarbons can enter groundwater if their supplies persist, and partly oxidized aromatic hydrocarbons are carcinogenic, (3) are cold climate related because bioconversion rates are substantially slowed, (4) are long term because compound half-lives are measured in decades and longer, and (5) range from coast to slope where anticipated oil and coal production is widely dispersed.

Dissolved Hydrocarbon Input is Significant. While most of the hydrocarbons that enter seawater dissolve to form a tranparent solution, most attention has been on the more visible and more inert floating oil 
phase. For example, in Port Valdez all floating oil is removed from tanker ballast water by a treatment plant, while dissolved hydrocarbons are injected into the water column 70 meters below the surface at a rate of about 10 tons per month. Future offshore oil production, coal stockpiling, and synfuel processing possibilities suggest continued additions throughout this century.

Hydrocarbons from both marine and freshwater oil spills are particularly prone to dissolve in cold climate systems. Low temperatures favor dissolved hycrocarbons because evaporation rates are reduced through lowering of the vapor pressure and because hydrocarbon solubility is increased due to the water intermolecular forces between oil and water and between oil and oil change with temperature.

The water solubility of hydrocarbons is surpisingly large. Aromatic hydrocarbons are particularly soluble and exceed alkane solubility by a factor of about 3000, but seawater is subsaturated in hydrocarbons so that even alkanes of fairly high molecular weight will slowly dissolve.

Hydrocarbon Concentrations. Calculations show that the dissolved hydrocarbons of Port Valdez accumulate in approximately $1 \mu \mathrm{g} / 1$ iter in aggregate before flushing out. Current technology is now adequate to quantify this order of concentration in seawater; much lower levels have been established in low latitude systems. Yet no such determinations have been made for Port Valdez outside the plume from the diffuser. Water column concentrations of hydrocarbons should be established because it is known that this level of hydrocarbon is sufficient for biological effects to occur, and the magnitude of this calculated chemical change should be analytically established.

Removal Rates. Dissolved hydrocarbon removal from water is a very slow and largely microbiological process. Only recently has the kinetics (the way metabolism rate changes with concentration) become apparent. This rate depends on (1) the concentration of the hydrocarbon; (2) the quantity, quality (species distribution and induction level), and physical packaging of the microflora; and (3) the temperature. Residence times of dissolved hydrocarbons are exceedingly long, ranging from decades to centuries, so that spilled hydrocarbons accumulate in estuaries and equilibrate with the world ocean.

Inductive Response of Microflora. It is now known that bacteria can become induced to consume hydrocarbons at fast rates by hydrocarbon concentrations as low as $1 \mu \mathrm{g} / \mathrm{liter}$. High populations of toluene oxidizers have been found in Port Valdez and in Aransas Bay in the Gulf of Mexico, but not in Resurrection Bay near Seward, Alaska. Presumably, the microflora in Port Valdez and in Aransas Bay responded to added dissolved petroleum. Oniy sketchy baseline data are available for the distribution of these indicators of petroleum presence because suitable technology is just becoming available. It would appear from comparisons with Resurrection Bay that oil shipping activity in Port Valdez has produced a major change in the microflora. That increased hydrocarbon oxidizers in seawater is an effect of ballast water discharge could be firmly established by a thorough comparison with unimpacted estuaries. 
Changes in hydrocarbon oxidizer activity with time would probably be the simplest and most sensitive available means of monitoring unanticipated loading of seawater with dissolved hydrocarbons.

Products. Partly oxidized metabolic products are an important fate of the microbiological oxidation of dissolved petroleum. Some of these are biochemically reactive (toxic), and all act differently than the parent hydrocarbons. They are produced in both pure and mixed cultures at both high and low concentrations of hydrocarbon, and can amount to nearly half the hydrocarbon metabolized. It is predicted that such products constitute a significant added chemical to Port Valdez. However, neither the quantities nor the effects are currently being examined since only recently has the identity of some of the more important products become apparent.

Site of Removal and Effects. Hydrocarbons are accumulated from the water by the phospholipid partition coefficient of the hydrocarbon. This is calculated to range from 489 for toluene to 28,000 for anthracene. values for large molecules such as the carcinogenic hydrocarbon benzpyrene are much higher. Intramembrane hydrocarbon concentrations are the aqueous concentrations multiplied by the above large numbers.

The cell membrane is one of the two more important functional organelles in all cells (the genetic structure is the other). In aquatic systems, the membrane functions to produce a solution of concentrated nutrients inside microorganisms from one which is dilute outside by a factor of often 10,000 . The membrane also mediates nerve transmissions in higher organisms. Although it would seem that such a large change in the intramembrane chemistry caused by hydrocarbon partitioning would alter functionality, the quantitative and mechanistic aspects of this problem are unclear. However, it is known that higher organisms behave differently in the presence of dissolved hydrocarbons (crab response time to predators, clam habitat selection, amphipod distribution -- organisms which graze herring roe free from fungi and thereby ensure hatchability, fin rot in stressed fishes). The most obvious change in the microflora in response to chronic pollution is the replacement of diatoms with flagellates which is widely regarded as undesirable.

\section{Objectives}

Water Column Hydrocarbon Concentrations (Number 28). Quantify the concentration of dissolved aromatic hydrocarbons (especially benzene, toluene, and $x y l e n e s$ ) in the water column of Port Valdez, but particularly outside the diffusion zone (measurements exist there) in order to confirm concentrations predicted by current system models. Provide control measurements in unimpacted streams and estuaries, including those with high terpene hydrocarbon input.

\section{Rates of Biodegradation and Changes in Microflora (Number 29)}

1. Quantify the decrease in biodegradation rates and the corresponding populations of petroleum-oxidizing bacteria (relative to total) with respect to distance seaward from the ballast water treatment plant 
in Port Valdez using Resurrection Bay as an unimpacted control in order to assess the impact of chronic ballast water discharge on the extent of the transthreptic (bacterial and fungal) hydrocarbonoxidizing microflora.

2. Obtain baseline data on the distribution of the hydrocarbonoxidizing microflora of lakes, streams, and estuaries in order to establish the magnitude of anticipated effects on potential hydrocarbon-receiving cold water systems.

Products Formed During Biodegradation (Number 30 ). Determine the identity and quantity of organic products liberated from the microbial metabolism of dissolved hydrocarbons in seawater in order to document this otherwise unexamined change in seawater biochemistry that is predicted.

Effects (Number 31). Probe the effect of dissolved hydrocarbons on the ability of a diatom to emerge from a semi-resting state and to begin a bloom in the presence of anticipated quantities of dissolved hydrocarbons. Examine two membrane mediated measurable processes as modulated by contaminating hydrocarbons in the membrane: (1) down concentration gradient leakage of internal biochemicals from diatoms to outside the cell during active growth, and (2) membrane-injected proton-driven phosphate transport in diatoms. Focus yet undescribed experiments on the change in activity of hydrocarbon-laden membranes.

Research Approach

Dissolved Hydrocarbon Concentrations in Port Valdez (28). Technology is now available which is adequate to quantify the suspected levels of dissolved hydrocarbons in seawater samples from Port Valdez. As with the hydrocarbon oxidizers population determinations, a few measurements are probably adequate to establish this aspect of the impact of ballast water on Port Valdez, since the system is calculated to be at an approximate steady state. Samples should be obtained in conjunction with local scientists and together with those of proven capacity to perform the required analyses.

Rates of Biodegradation and Changes in the Microflora (29). Begin with unimpacted control measurements in Resurrection Bay near Seward so that corresponding samples for dissolved hydrocarbon concentrations (Part B) can be processed simultaneously, and the proceedings worked out before expensive ship time is required. Seward is believed to provide a particularly good control because some data suggests the addition of naturally-produced terpene hydrocarbons there. Samples can be raised from a small boat and incubated in our marine station there. Total populations are measured according to proven new epifluorescence microscopic techniques. Hydrocarbon oxidizer bacterial populations are measured by the rate of oxidation of added radiolabeled hydrocarbons to fresh seawater samples according to new but proven techniques. 
One careful transect from upper Port Valdez seaward into Prince William Sound can be used to establish the gradient of hydrocarbon oxidizers downstream from the ballast water treatment plant if the system is near a truly steady state as has been supposed. If results are unsatisfactory, then additional transects can be made in following years. Otherwise, initial measurements can be conducted in potentially impacted area such as Norton Sound and and the Beaufort Sea and near potential riverine fossil fuel activity.

Products Formed (30). This important new aspect of pollutioninduced changes in seawater biochemistry might be attacked by direct analysis, or by following the disposition of radioactivity from ${ }^{14} \mathrm{C}$-hydrocarbons. The latter approach is currently enjoying some success and would appear to be the method of choice. The natural microflora of seawater can be allowed to transform common dissolved hydrocarbons for short periods. Products resulting will be collected on affinity columns, eluted, and characterized using their chromatographic mobilities as compared to those of products produced from hydrocarbons by seawater isolates in laboratory culture and characterized by conventional methods of derivatization and spectroscopy. The lifetimes of these products in seawater, suspected to be long because they accumulate in mixed cultures at the expense of parent hydrocarbons, will be estimated from the concentration-dependent rate of in situ incubations with mode $1{ }^{14} \mathrm{C}$ products. One newly discovered and yet unreported stable product of aromatic hydrocarbon metabolism is commercially available in isotopic form and would be an excellent first choice.

Effects (31). A logical common thread through hydrocarbon-induced behavioral changes in higher organisms as well as species distribution changes in lower organisms is at the level of chemical discrimination and transport by cell membranes. These organelles sequester large quantities of hydrocarbons and are functional in effecting very large concentration gradients of nutrients and of ions used in nerve impulse transmission. One of the significant effects of chronic pollution is thought to be a shift from diatom populations for reasons that are unknown. Enhanced levels of shellfish toxin producing dinoflagellates in Alaska is a possible effect of oil production.

Investigations are to focus on the molecular mechanisms of effects produced by chronic low-level exposure to dissolved hydrocarbons in order to generate a broad understanding of the problem. Organize the current literature treating changes in membrane structure in response to small chemical perturbations in order to help design the most productive experiments. Begin experiments which prove an important effect of chronic oil pollution (replacement of diatoms by dinoflagellate populations) and avoid certain problems with whole-system experiments now in progress elsewhere. One consideration is, that in small systems, bacterial populations become atypically active, removing dissolved hydrocarbons before the effects can be established. Another is that, in rich organisms and lipid, coated sediments sequester hydrocarbons before the effects of chronic low levels can be established. 
In order to define cause/effect relationships between sustained dissolved unmodified aromatic hydrocarbons and slightly stressed growing diatom populations, long-term continuous cultures of bacteria-free Thallassiosira pseudonana can be established. Total growth is limited to small population densities by the level of orthophosphate (see below). In these continuous cultures, transient state characteristics such as the onset of rapid growth (blooms) following upwelling from deep water (more light), and possibly warming to stimulate the spring bloom can be established. Compared to the control experiment, test runs will include $\mu \mathrm{g} / \mathrm{liter}$ concentrations of radioactive hydrocarbons to see if the transition to rapidly growing organisms is impeded by oil presence in the diatom membranes.

Very sensitive isotope relaxation procedures are immediately available which quantifies the leakage of phosphate-containing compounds from within cells through the lipid membrane during phosphate-limited metabolism in continuous cultures. Both phosphate retention (resistance to leakage) and phosphate transport are membrane-mediated phenomena, and the membranes are where hydrocarbons accumulate. Moreover, phosphate transport depends directly on an active membrane process which is probably related to the cytochrome-derived ejection of protons from the cel1. The phosphate-limited diatom cultures then form an ideal test bed from which the effects of hydrocarbons accumulated by the cell membrane change the ability of the cell membrane to effect $\mathrm{pH}$-dependent phosphate transport and prevent internal component leakage beyond normal levels.

\section{Product}

a. Report change in Valdez concentrations.

b. Forecast accumulation of hydrocarbons and microflora.

c. Identify the non-hydrocarbon input from ballast water.

d. Report of threshold values that shift population towards dinoflagellates.

\section{Time Frame}

a. 1 year. Cost per year: $\$ 30 \mathrm{~K}$.

b. 1 year. Cost per year: $\$ 70 \mathrm{~K}$.

c. 1 year. Cost per year: $\$ 90 \mathrm{~K}$.

d. 3 years. Cost per year: $\$ 60 \mathrm{~K}$.

The four objectives can most efficiently be accomplished by the sustained efforts of two highly experienced persons plus limited participation by certain specialists over a period of several years. 
Year One

1. Hydrocarbon Concentrations (28). During cruises and trips to Seward, water samples can be stripped, the hydrocarbons collected on columns, frozen, and shipped to proven laboratories for analysis. Much of the first year should be spent ensuring that added $\mathrm{C}^{\mathbf{1 4}}$ aromatic hydrocarbons in double blind standard additions generate acceptable data. This work should be completed before the Port Valdez cruise so that ambient hydrocaron concentrations can be established there during the first year. The added time is about two man-months including sample walk-through at the analytical laboratory chosen.

2. Rates and Populations (29). Establish the gradient of hydrocarbonoxidizing bacteria seaward from upper Port Valdez during one five-day cruise in which ten samples are incubated and processed. Additional samples for total bacterial populations can be obtained for processing later. For the control samples in Resurrection Bay near Seward (an unimpacted estuary), samples can be raised by small boat and incubated in our marine station at limited expense. All these procedures are routine and require only about three months' time of the research associate. Other related activities can proceed in conjunction with these measurements.

3. Products (30). Obtain a number of ${ }^{14} \mathrm{C}$ aromatic hydrocarbons of the type dumped into Port Valdez, subject them to the action of ballast water effluent populations, then separate, identify, and quantify the organic products formed. An easy task this is not, but appropriate procedures are unfolding with limited successes almost assured. Seven months' research associate time are required.

4. Effects (31). Much of the first year should be spent carefully documenting the effect of phytoplankton during transient response to increased levels of light under conditions of nutrient deficiency. During the latter part of the period it may be feasible to begin testing variations in the response due to added dissolved aromatic hydrocarbons. This requires the full attention of a skilled person.

\section{Following Years}

1. Populations (29). Focus on additional oil-producing areas of the Alaskan coast.

2. Concentration (28). Clean up any remaining loose ends on the hydrocarbon concentrations in Port Valdez and then move to other oil-producing areas.

3. Products (30). A complex array of products are most certainly formed, so that this project is never done. Begin testing the lability of these products to the microbial activity of seawater using procedures developed for dissolved hydrocarbon metabolism rates in situ. 
4. Effects (31). Gradually move from the documentation of hydrocarbon concentration-dependent effects on phytoplankton bloom development to the molecular mechanisms causing response.

\section{Personnel}

Principal Investigator

2 months

Research Associate, Microbiology and Populations/Products/ Laboratory Operations

12 months

Post-Doctoral Associate, Kinetics and Mechanism of Inhibition

12 months

Research Associate, Mass Spectroscopic Identifications

2 months

Contracted Analytical Chemist

2 months

\section{Suggested Sites}

Port Valdez, Seward, Arctic Coast, Fairbanks Campus, Tanana River, one additional analytical laboratory.

\section{Constraints}

Experience and preliminary data suggests that all aspects of the proposed program are tractable and that all the experiments and measurements will lead, in due course, to findings that are publishable in respected journals.

$\underline{\text { Costs }}$

$\begin{array}{llr}\text { Salary } & 2.4 \text { man-months } & \$ 101,000 \\ \text { Ship time } & 5 \text { days } & 35,000 \\ \text { Services } & \begin{array}{l}\text { Analytical, Electron Microscopy, } \\ \text { Computer }\end{array} & 10,000 \\ \text { Supplies } & \begin{array}{l}\text { Isotopes, Shipping Material, } \\ \text { Glassware, Incubators, Chemicals }\end{array} & 6,000 \\ \text { Travel } & \begin{array}{l}\text { Including walking samples through } \\ \text { Contractual analytical }\end{array} & 8,000 \\ & \text { laboratories } & \$ 240,000\end{array}$

Costs in subsequent years will remain substantially unchanged. 
Output

Although the investigations lend themselves to potentially publishable findings, additional reports might be necessary which focus on the statistical nature of changes induced by dissolved hydrocarbons. In addition to scientific output, this program should notably focus on providing a report which establishes a firm base for regulatory decisions regarding the quantity and quality of anthropogenic dissolved hydrocarbons.

Dissolved Hydrocarbon -- Concentrations (Summary of 28)

Question

Concentration distribution in Valdez?

Justification

Required for effects assessments. Provides correlation with microflora. Confirm existing model.

Approach

Direct measurement.

Time Frame

One year.

Site

Seward/Valdez/Contract Laboratory.

Resources

\$30K, Alpha Helix.

Product

Distribution of a major chronic pollutant.

Other Research

Texas A\&M, MIT.

Hydrocarbon Biodegradation Rates and Associated Microflora (Summary of Number 29)

Question

Lifetimes of hydrocarbons? Correlation with bacterial populations? 


\section{Justification}

Rate constant for hydrocarbon accumulation. Simple indication of hydrocarbon presence. Measures one result of hydrocarbon pollution. Approach

Radioactive hydrocarbon oxidation rate. Epifluorescence microscopy.

Time Frame

One year.

Site

Seward/Valdez.

$\underline{\text { Resources }}$

$\$ 70 K$, R/V Alpha Helix, Seward Marine Station.

Product

Location-dependent hydrocarbon half-life. Hydrocarbon-dependent bacterial biomass.

Other Research

EPA Laboratory, Georgia -- different approach.

Excreted Products of Hydrocarbon Biodegradation (Summary of Number 30)

Question

What products accumulate in dilute systems?

Justification

Represent apparently significant pollutants.

Approach

Characterize ${ }^{14} \mathrm{C}$ products from ballast water cultures.

Time Frame

One year.

Site

Fairbanks/Valdez. 
Resources

$\$ 90 K$.

Product tion.

An important pollution input quantified for regulatory considera-

\section{Other Research}

Maryland, Seattle, and U. Texas groups.

Dissolved Hydrocarbon Chronic Effects (Summary of Number 31)

Question

Do dissolved hydrocarbons favor dinoflagellates over diatoms?

Justification

Effects of low hydrocarbon concentrations are unclearly documented.

\section{Approach}

Test transition of diatoms from regulating state during a hydrocarbon insult. Stress observations of molecular effects.

Time Frame

Three years.

Site

Fairbanks.

$\underline{\text { Resources }}$

$\$ 60 \mathrm{~K}$.

Product

Identification of threshold levels for chronic effects in wellcontrolled system.

Other Research

Several programs deal with rich mixed systems. 
Question

What is the chemistry of produced water and current background hydrocarbon concentrations?

Problem Definition

Expansion of $0 i 1$ and gas extraction operations in offshore locations in coastal waters of Alaska raises a question of disposal of brine (produced water). Such waters are generated by all $0 i 1$ extraction operations. Rockwell International has examined the chemical nature of brine on offshore platforms in Alaska and the Gulf of Mexico and found them to contain suspended, dissolved, and volatile chemical composition, including pollutants. Rockwell's studies on state-of-the-art treatment on offshore platforms indicate that many priority pollutants remain in the treated effluent and are discuarged into receiving waters in substantial quantities.

\section{Justification}

Disposition of produced water in shallow coastal waters off the North slope raises major environmental and economic questions. It is desirable to dispose of produced water in the most cost-effective manner without harm to the receiving environment. Two methods for disposal are generally used -- treatment and overboard discharge, and reinjection. Selection of the optimum methods depends on the chemical nature of the produced water and the ability of treatment technology to remove chemicals that are potentially detrimental to the environment. Detailed and documented information on chemical characteristics of produced water in the Prudhoe Bay region is not currently available and no rational basis exists for selection of the proper technology for disposal of produced water in offshore oil-production operations.

\section{Approach}

Chemical components of produced water from Prudhoe Bay sources will be characterized in detail using Rockwell-developed methodology for characterization of suspended, disolved, and volatile fractions of oily wastewater. Similar tests will be performed on receiving waters.

Product

Published analysis of produced water and natural hydrocarbon levels.

Time Frame

1 year.

$\underline{\text { Cost }}$

\$90K per year. 
A Literature Search, Conference Forum, and Field Evaluation of Innovative Cost-Effective Approaches to Northern Latitude Aquatic Biomonitoring: A Design to Detect Subtle Biological Responses to Continuous Industrial Discharges in Coastal Embayments (Number 33)

Question

What biological manifestations of oil pollution are most useful in cold climates?

Generic Issue

$0 i 1$ and gas development.

Product

Reports and papers relating relative effects to oil pollution.

Time Frame

3 years.

$\underline{\text { Cost }}$

$\$ 50-75 \mathrm{~K}$ per year.

Researchable Issue/Problem Definition

Monitoring programs have historically emphasized traditional approaches to evaluating biological responses to pollution stress, including community diversity indices, biomass, and population dynamics. All of these measures suffer from not being sensitive enough to detect slow, subtle changes in community health; rather, they are geared towards the rather dramatic changes that accompany a catastrophic pollution event. The majority of coastal Alaska does not have an acute pollution problem, i.e., the concentration of pollutants does not generally reach a high level. Therefore, a monitoring emphasis evaluating the morphological and physiological response of invertebrates and fishes exposed to low levels of waste over a long period is a logical and desirable direction that is just beginning to become appreciated, primarily by regulatory agencies responsible for issuing permits and establishing monitoring provisions. A question remains as to what biological manifestations of pollution stress and what specific speices are most suitable for use as indicators of ecosystem health.

Justification

Biological monitoring, while generally being the most meaningful approach to evaluating environmental health, is also very expensive. This study is necessary to stimulate a concerted effort to provide regulatory and resource managers with new, cost-effective approaches to biological monitoring strategies for inclusion in permits. These strategies will provide sensitive, statistically defensible measures of 
morphological and physiological changes in response to chronic pollution exposure at acceptable cost to industry (when required in permits) or to agencies in their own routine monitoring programs.

\section{Objectives}

-- Through an initial literature search, provide a list of workable, cost-effective, and innovative monitoring strategies for use in developing biological monitoring permit conditions.

-- To solicit and record the ideas and experiences of knowledgable persons in this field in a package for use by agencies and industry.

-- To arrive at a reasonable consensus on the relative applicability of selected monitoring indices in evaluating changes in environmental health in response to continuous, long term discharges of wastes (e.g., ballast, refinery or petrochemical waste, oily discharges) prior to field verification.

-- To provide the basis for site-specific field evaluation of "screened" approaches as a possible phase 2 project which would define the relationship between petroleum exposure and selected indicator responses.

$\underline{\text { Research Approach }}$

Phase 1. Contract to conduct literature searches of bioindicator research and prepare annotated bibliography (abstracts). Emphas is to be placed on invertebrate phyla and fishes as biological receptors. Organize a workshop to discuss ideas and experiences of knowledgeable scientists in this area.

Phase 2. As a logical extension to Phase 1 , conduct field measurements of "screened" indices in selected Alaskan embayments. Selected laboratory verification of cause-and-effect relationships may be a desirable adjunct to field testing.

The Phase 1 approach is the initial step of the proposal and as such could be funded independently from Phase 2 .

Time Frame/Location of Project

Study is broken into two phases.

Phase 1: 1st year. Literature search (annotated bibliography) and scientific conference to evaluate relevant information on biological indices for their relative usefulness (pros and cons) and limitations in northern latitudes.

Phase 2: 2nd-4th year. Field testing of selected indices at existing site-specific industrial discharge locations over a three-year period. Any laboratory work in support of field study would be conducted at established laboratories. 
Phase 1 is northern latitude in scope. Geographic scope for Phase 2 (field approach) could include Port Valdez, Silver Bay (Sitka), and Simpson Lagoon (Beaufort Sea).

\section{Cost/Manpower/Facilities}

Phase 1: $\$ 50-75 \mathrm{~K}$.

Phase 2: $\$ 85 \mathrm{~K}$ annually (continugent on degree of laboratory work conducted).

\section{Products (Output)}

1. Publication of symposium (conference) proceedings and participant recommendations.

2. Annotated bibliography of papers on morphological, behavioral, and physiological monitoring indices for use in northern latitude aquatic environments.

3. Scientific reports and papers (2) reporting the results of field tests of screened indices.

4. Eventual selection of most cost-effective and definitive monitoring conditions for inclusion in discharge permits.

\section{Interrelationships with Other Programs}

The Bureau of Land Management has generally tended towards funding resource assessments prior to development using traditional methodologies in field work; some new techniques have been explored in laboratory toxicology research. Various agencies have required the inclusion of selected subtle monitoring indices in discharge permits which they have issued (e.g., Port Valdez ballast water treatment facility, waterflood discharge). The results of these investigations will shed light on the applicability of these field-tested techniques and allow refinements in new proposals based on previous experiments. The results would provide a complementary approach to be integrated with studies geared towards documenting community processes or population dynamics. Interation with International Mussel Watch and other bioindicator programs would be necessary.

Sublethal Toxicity of 0il Field Brines (Produced Waters) on Alaskan Invertebrates: Morphological, Behavioral, and Physiological Response to Chronic Exposures (Number 34)

Question

What are acceptable disposal practices for produced water? 
Researchable Issue/Problem Definition

Produced waters (oil field brines) are coproduced with oil at the production facility. Historically, offshore disposal of these wastes in Alaska (Cook Inlet) has been through direct marine disposal; reinjection to subsurface strata has been the technique for upland fields in Prudhoe Bay and Cook Inlet. With accelerated oil and gas development of offshore arctic regions, important decisions are being made and will continue to be made by regulatory agencies on acceptable disposal practices for these hydrocarbon-contaminated wastes necessary to maintain the high quality of Alaskan coastal waters. Arctic coastal areas of seasonally sluggish circulation and highsuspended organic material pose the greatest risk of hydrocarbon accumulation and long term exposure to stressful conditions.

\section{Objectives}

-- Document sublethal and acute responses of laboratory test organisms exposed in a flow-through system to varying dilutions of whole Prudhoe Bay or Cook Inlet produced water over at least 30 days.

-- Correlate any abnormal behavior responses to physiological parameters.

-- Quantify the threshold concentration of produced water that elicits a toxic response by test organisms.

-- Determine the relative toxicity of the varying chemical constituents of produced water (dissolved volatiles vs. dissolved nonvolatiles).

\section{Research Approach}

Chronic, flow-through bioassays will be conducted using varied dilutions of Prudhoe Bay field produced waters and results reported with statistical confidence. Air-purged and unpurged test solutions will evaluate the relative contributions of volatile and nonvolatile aromatic components to overall toxicity. Resident species and sensitive life stages will be tested and acute sublethal threshold concentrations documented. Behavioral and physiological abnormalities will be documented. Use of Upper Cook Inlet platforms as a base of operations is a possible alternative location to Prudhoe Bay.

Time Frame/Location of Project

One-year study conducted during a 4-month summer period at Prudhoe Bay, Alaska. Clearance through the United Operator (ARCO) would be necessary). Upper Cook Inlet platforms could be used as an alternative study location. 
Cost/Manpower/Facilities

Laboratory facilities would need to be located at Prudhoe Bay to conduct flow-through tests. Costs on the order of $\$ 75 \mathrm{~K}$ are projected. An alternative approach would include statis tests at established laboratories in the event of logistical problems in siting at Prudhoe Bay.

\section{Products (Output)}

-- Minimum threshold concentrations of aromatic hydrocarbons in produced waters causing sublethal abnormalities in sensitive benthic species or life stages.

-- 96 hour $\mathrm{LC}_{50}$ data as a secondary product.

-- Published results of behavioral and physiological responses of Alaskan organisms to low levels of oil field brines.

Interrelationships with Other Programs

Rockwell International has initiated the characterization of chemical constituents of Prudhoe Bay and Cook Inlet produced waters, highlighting the presence of two major aromatic fractions. Selected laboratories have generated 96 hour $\mathrm{LC}_{50}$ data on ballast water treatment wastes (Valdez); no chronic or acute Alaskan data exist for produced waters.

Literature Survey, Environmental Effects of Chronic Industrial Discharges (Number 35, included in Numbers 33 and 34)

Herbicide Effects and Stream Eutrophication from Farming (Number 36)

Question

Nitrate in streams and groundwater? What is the chemistry of well water? Herbicide decomposition and stream eutrophication?

Generic Issue

Renewable resource utilization.

Cost

$\$ 90 \mathrm{~K}$ for 5 years for both fertilizer and pesticides.

Development of Northern Lakes Water Quality Model (Number 37)

Question lakes?

Effects of acid rain on lakes? What is the $\mathrm{pH}$ change in Alaskan 
Generic Issue

$0 i 1$, gas, and coal extraction.

WASTE MANAGEMENT SKETCHES 
Table _. EPA cold regions research planning: waste treatment and disposal.

\begin{tabular}{|c|c|c|c|c|c|c|c|c|}
\hline Topic & & Topic & Generic Issue & & search Products & $\begin{array}{l}\text { Time } \\
\text { Frame }\end{array}$ & $\begin{array}{l}\text { Estimated } \\
\text { Total Cost }\end{array}$ & Presenter \\
\hline 38 & 1. & $\begin{array}{l}\text { Cost-Effective } \\
\text { Waste Treatment } \\
\text { and Disposal } \\
\text { Alternatives } \\
\text { for Rural } \\
\text { Alaskan } \\
\text { Commununities }\end{array}$ & $\begin{array}{l}\text { *7: Cumulative and/ } \\
\text { or regional effects } \\
\text { through waste } \\
\text { disposal }\end{array}$ & $\begin{array}{l}3 . \\
4 .\end{array}$ & $\begin{array}{l}\text { Summary of } \\
\text { existing } \\
\text { practices and } \\
\text { problems } \\
\text { Recommended waste } \\
\text { treatment and } \\
\text { disposal } \\
\text { technologies } \\
\text { Cost comparison } \\
\text { Use criteria for } \\
\text { future applicatio }\end{array}$ & $\begin{array}{l}3 \text { mos } \\
\text { ons }\end{array}$ & $\$ 35 K$ & Robert Sener \\
\hline 39 & 2 & $\begin{array}{l}\text { Small-Scale } \\
\text { Treatment } \\
\text { Technologies } \\
\text { for On-Site } \\
\text { Graywater } \\
\text { Disposal in } \\
\text { Permafrost } \\
\text { Soils }\end{array}$ & $\begin{array}{l}\text { 7: Cumulative and/ } \\
\text { or regional effects } \\
\text { through waste } \\
\text { disposal }\end{array}$ & $\begin{array}{l}1 . \\
2 .\end{array}$ & $\begin{array}{l}\text { Pilot system } \\
\text { test results } \\
\text { Specific treatmen } \\
\text { and disposal } \\
\text { recommendations } \\
\text { Associated cost } \\
\text { comparison }\end{array}$ & 15 mos & $\$ 75 K$ & Robert Sener \\
\hline 40 & 3 & $\begin{array}{l}\text { Solid Waste } \\
\text { Generation } \\
\text { Rates and } \\
\text { Predictive } \\
\text { Model for Rural } \\
\text { Alaska }\end{array}$ & $\begin{array}{l}\text { \#: Cumluative and/ } \\
\text { or regional effects } \\
\text { through waste } \\
\text { disposal }\end{array}$ & $\begin{array}{l}2 . \\
3 .\end{array}$ & $\begin{array}{l}\text { Quantitative } \\
\text { waste generation } \\
\text { analys is } \\
\text { Predictive model } \\
\text { Model use criteri }\end{array}$ & $\begin{array}{l}15 \text { most } \\
\text { ia }\end{array}$ & $\$ 75 K$ & Robert Sener \\
\hline 41 & 4 & $\begin{array}{l}\text { Effect of } \\
\text { Arctic Climate } \\
\text { on Solid and } \\
\text { Liquid Waste } \\
\text { Decomposition }\end{array}$ & $\begin{array}{l}\text { *7: Cumulative and/ } \\
\text { or regional effects } \\
\text { through waste } \\
\text { disposal }\end{array}$ & $\begin{array}{l}1 . \\
2 .\end{array}$ & $\begin{array}{l}\text { Table of } \\
\text { decomposition } \\
\text { rates } \\
\text { Analysis of } \\
\text { factors } \\
\text { determining } \\
\text { decomposition } \\
\text { rates } \\
\text { Treatment and } \\
\text { disposal } \\
\text { recommendations }\end{array}$ & 18 mos & $\$ 90 K$ & Robert Sener \\
\hline 42 & 5 & $\begin{array}{l}\text { Freeze-Thaw } \\
\text { Cycle Effects } \\
\text { on Concentra- } \\
\text { tion and } \\
\text { Migration of } \\
\text { Contaminants } \\
\text { at Disposal } \\
\text { Sites and } \\
\text { Settling Ponds }\end{array}$ & $\begin{array}{l}\text { *7: Cumulative and/ } \\
\text { or regional effects } \\
\text { through waste } \\
\text { disposal }\end{array}$ & $\begin{array}{l}2 . \\
3 .\end{array}$ & $\begin{array}{l}\text { Quantitative } \\
\text { data on } \\
\text { concentrations } \\
\text { and movements } \\
\text { of contaminants } \\
\text { Mitigative design } \\
\text { and procedures } \\
\text { Criteria for futu } \\
\text { construction and } \\
\text { use of disposal s } \\
\text { and settling pond }\end{array}$ & $\begin{array}{l}24 \text { most } \\
\text { ns } \\
\text { ure } \\
\text { sites } \\
\text { ds }\end{array}$ & $\$ 150 \mathrm{~K}$ & Robert Sener \\
\hline
\end{tabular}


Cost-Effective Waste Treatment and Disposal Alternatives for Rural Alaskan Communities (Number 38)

Problem

The inappropriate and unhealthful disposal of untreated solid and liquid wastes, including human sewage, is a growing problem in rural Alaskan communities. Solid wastes are dumped intact on the land surface within lakes, streams, wetlands, and coastal lagoons. These wastes accumulate from year to year, because burial is not attempted in the permafrost, and little or no attempt is made to cover them. The climate and permafrost retard or eliminate decomposition, and the wastes remain through the year to attract habituated wildlife, leach into the surface water, and augment a continuing threat to health. Where community centers are growing because of development-related opportunities, as at Barrow and Bethe 1, the problem is obvious and severe.

Liquid wastes present an especially difficult challenge. Conventional primary treatment plants are expensive and may generate large quantities of sludge in one location, creating a disposal problem. Instead, raw sewage is dumped from honeybuckets into rivers, lakes, and lagoons. In the winter months, the sewage freezes and accumulates until breakup and creates large concentrations of contaminants which are released into the surface water, persisting where tidal or riverine, flushing is inadequate. Graywater (domestic wastewater) is merely dumped on the ground around and beneath private residences, where it forms persistent pools due to poor infiltration of the permafrost-underlain soils.

In Southeast Alaska coastal communities and elsewhere, solid waste contaminants are introduced indirectly to marine waters through freshwater drainages feeding estuaries. Such cases include seepage of red colored leachates to marine waters near Kodiak, at woodchip piles at Wrange11. Effects have included discoloration of water and altered intertidal macrophyte community structure near these sites. Organophosphates, heavy metals, and chlorinated hydrocarbons are all potential pollutants in lightly industrialized coastal communities, along with fuel and lubricant runoff from derelict vehicles, equipment, and parts abandoned at dump sites.

Justification

In recent years, the federal government has spent millions of dollars building modern central sanitation systems for remote Alaskan communities. However, the operation and maintenance requirements of the systems have rendered them ineffective or inoperable for significant periods, especially in arctic regions. The health and environmental improvement returns of these large federal investments has been poor to nonexistent. Rather than large complex waste treatment systems that seldom work, it would be significantly more effective from an environmental and economic standpoint to utilize dependable small-scale systems. 
An integrated program is badly needed to determine what costeffective and environmentally sound waste treatment and disposal alternatives are realistically available for small-scale use in rural Alaskan communities. A guidance document outlining criteria for selection and use of appropriate treatment and disposal methods would assist the communities, Native corporations, and the Alaska Department of Environmental Conservation is choosing appropriate equipment and developing long-term strategies for alleviating existing health hazards and water quality degradation.

\section{Objectives/Technical Approach}

1. Identify waste treatment and disposal problems common to most Alaskan rural communities.

2. Identify problems unique to specific communities.

3. Review available physical/chemical treatment system designs and operating experience, along with alternative disposal procedures and equipment.

4. Evaluate applicability of innovative treatment alternatives to cold regions (e.g., waste as heat, augmented nutrient balances for lagoons to enhance biodegradation, recently developed smal1-scale systems for on-site treatment and disposal). Determine any changes in design or operations required for adaptation to cold regions.

5. Develop costs of installed and operation/maintenance including energy requirements for those alternatives which appear to be applicable to cold regions.

6. Single out approaches which appear to be realistic and costeffective, and evaluate them further to determine potential effects of discharges on the environment. Identify personnel and skills needed for operation, and any constraints which might influence application.

7. Prepare a matrix comparing alternatives with respect to:

- Cold regions applicability.

- Probable effectiveness in reducing existing health hazards and water quality degradation.

- Overall cost of purchase, installation, operation, and maintenance.

8. Prepare a guidance document which presents criteria and recommendations for the selection and application of specific solid and liquid waste treatment and disposal systems for use in rural Alaskan communities. This document would identify distinct community characteristics (e.g., coastal, river; continuous, discontinuous, or 
absent permafrost, thin volcanic soils; types and quantities of wastes generated) and indicate applicability of specific systems, based on these community parameters.

\section{Research Location}

This would be primarily on office study. Visits to selected communities would allow the range of existing practices and problems to be surveyed and could include:

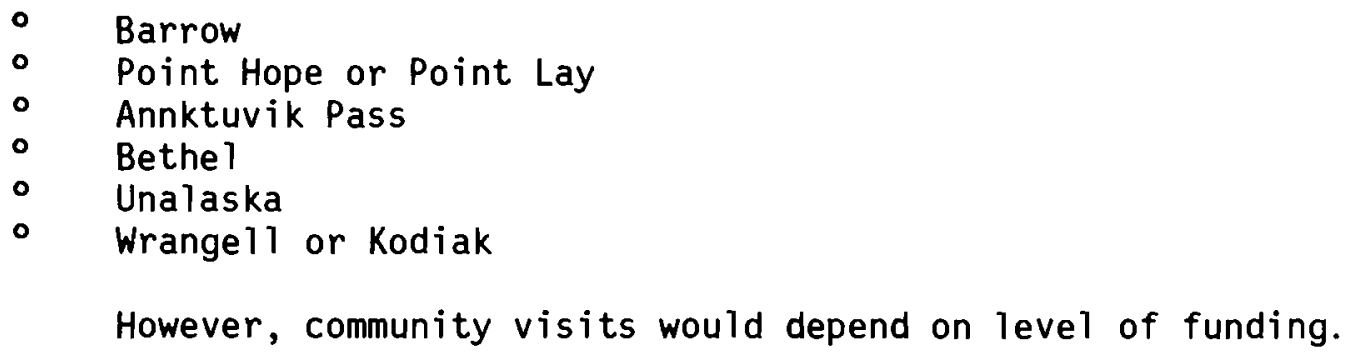

\section{Time Frame}

Minimum 3 months; longer depending on community visited.

\section{Required Resources}

The problem would require funding of $\$ 35,000$ to $\$ 50,000$, depending on the extent of community surveys. Major required expertise: sanitary engineer and water quality specialist.

\section{Products}

A guidance document containing:

1. Summary of existing practices and problems, with specific community examples.

2. Recommended waste treatment and disposal technologies, supported by economic and environmental evaluations.

3. Selection criteria for waste treatment and disposal systems.

\section{Interrelationships with Other Programs}

ADEC is currently preparing a report on alternatives for on-site treatment of domestic sewage wastes under varying Alaskan conditions (including permafrost). However, this program does not include solid wastes or graywater. Other related programs and agencies include:

- Solid Waste Management (ADEC)

- Litter and Resource Recovery (ADEC)

- Village Safe Water (ADEC)

- Hazardous Waste Program (ADEC)

- Alaska Department of Community and Regional Affairs 
Smal1-Scale Treatment Technologies for On-Lot Disposal of Graywater in Permafrost Soils (Number 39)

Problem

Inspection of on-site wastewater treatment systems is required for compliance with state regulations and often as a precondition of lending institutions in providing home loans. On-site wastewater disposal is a significant concern, particularly in areas underlain by permafrost, where traditional soil absorption systems are ineffective. While current research is increasing our knowledge of the alternatives for on-lot disposal of sewage wastes in permafrost conditions, little is known of the available options for the on-lot treatment of graywater (shower, sink, and laundry wastes) under permafrost conditions.

Justification

Improper disposal of graywater may create a hazard to public health. The number of residences being built in areas underlain with permafrost soils is increasing. Rural communities totally lacking in waste treatment infrastructures are growing with increased resource development. As soil absorption systems (septic tanks and leach fields) are ineffective in permafrost areas, individuals often consider the utilization of alternative compositing, incinerating, or chemical treatment toilets which normally require separate systems for treatment of graywater. Alternatives and their effectiveness for treatment graywater under permafrost conditions must be known to regulatory personnel to ensure that approved waste systems do not result in unhealthful water quality conditions. Under Alaska Wastewater Disposal Standards (I8 AAC 72), graywater is considered to be sewage and subject to regulatory control.

\section{Objectives}

1. To identify and describe alternative small-scale systems for the treatment of graywater in permafrost underlain environments.

2. To evaluate the appropriateness, cost, and treatment efficiency of each of these systems in reducing BOD, suspended solids, and fecal coliform bacteria.

3. To provide the findings to the general public and regulatory personnel.

Technical Approach

Identify available graywater treatment systems, including infiltration, disinfection, vaporization, and recycling (water reuse) type systems. System manufacturers, installers, and regulatory personnel will be contacted to identify systems which may have been previously 
installed. Three to six representative system operators in the Fairbanks area will be asked to cooperate in the evaluation of each installed system. Pilot systems will be constructed for untested designs. Each of the systems will be evaluated for cost of maintenance and construction; effectiveness in removing BOD, suspended solids, and fecal coliform bacteria; and for appropriateness under varying permafrost and site conditions.

Time Frame/Location of Project

The description of available treatment systems and selection or construction of test systems can be completed in six months. The Fairbanks area will be the location of the project. Selected test systems will be sampled for effectiveness once per month over a 12-month period. Three additional months will be required to complete report preparation and review.

\section{$\underline{\text { Required Resources }}$}

Costs are estimated at up to $\$ 75,000$ depending on number of systems evaluated and number of systems requiring construction. Six to eight person-months would be required to conduct the study.

Products

\section{A report containing:}

1. Pilot system test results.

2. Specific treatment and disposal recommendations.

3. Cost comparisons of evaluated systems.

\section{Interrelationships with Other Programs}

ADEC is currently preparing a report on alternatives for on-site treatment of domestic sewage wastes (including permafrost). However, the treatment of graywater wastes is not considered in the present project.

Solid Waste Generation Rates and Model for Rural Alaska (Number 40)

Problem

There is no available information on generation rates in Alaskan rural communities. Although there are a few generation rates identified for the larger communities in Alaska, it is suspected that the types and the volumes of waste generated in rural and urban Alaska differ greatly. It is also suspected that these characteristics are changing quickly in rural communities. This lack of knowledge limits the ability to develop efficient solid waste management and resource recovery techniques. It also makes it difficult to project the life expectancy of existing disposal sites or new solid waste management facilities which may be planned. 


\section{Justification}

Generation data and a model could be used to develop more efficient, effective, and environmentally sound solid waste management techniques for rural communities. It will also enable engineers, community officials, and the agencies to estimate the life expectancy of these disposal facilities.

\section{Objectives}

1. Collect data on several representative rural communities, including information about transportation systems and costs, economics, culture, population, utilities, etc.

2. Identify characteristics of the rural village waste stream, including volumes and types of wastes.

3. Identify seasonal differences and their effect.

4. Develop a model to estimate waste generation, given the variables of location, population, access to larger community, industrial activities, etc.

\section{Technical Approach}

Select about six communities of different types in rural Alaska:

- From various regions: Arctic, Interior, Southwest, Southeast. - Of various sizes: less than 500, 500-100.

- With different types of culture.

- On the water or not on the water.

- With and without local government.

These communities should be not be located on a road system.

Make investigations at four times during the year for generation rates. Recommend taking a random selection of home, community, commercial, industrial, and government generation and means of disposal. Include figures on amount recycled, recovered, or reused. Sort by types of waste: ferrous metals (including junked autos and equipment), nonferrous metals, paper, plastic, tires, wood, glass, cloth, animal carcasses, honeybuckets, food, other organics, hazardous, other (identify). Weigh or estimate volume to calculate amount of waste generated. Evaluate variables and conditions which affect waste generation.

Develop a computer model to predict types and quantities of wastes generated, given specific community parameters. 


\section{Time Frame/Location of Project}

Approximately six villages to be selected by consultant. One year for data collection. Quarterly sampling (one week per quarter per community). Two and one half months to tabulate and summarize data and develop model.

\section{Cost/Manpower/Facilities}

On-site invesigations (2-3 people) $\times 1$ week $\times 6$ community Analysis and model development including computer time Report preparation

$\$ 40,000$

$\$ 30,000$

$\$ 5,000$

$\$ 75,000$

\section{Products}

Final report:

1. Socioeconomic characterization of communities investigated.

2. Waste generation analysis by community type.

3. Seasonal variations and their effect on the waste generation.

\section{Model:}

1. System for evaluating the amount and type of waste that would be generated in any given community in rural Alaska.

2. Description of methods used for developing model.

\section{Interrelationships with Other Programs}

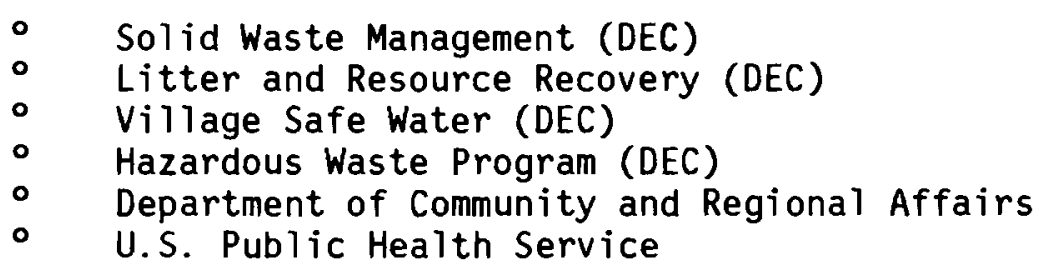

Effect of Arctic Climate on Waste Decomposition and Water Quality Coefficients (Number 42)

\section{Problem}

The effects of arctic climate on waste decomposition processes have not been quantified and cannot be accurately predicted. Certain solid and liquid wastes may persist for many years with little apparent degradation, whether disposed of on the land surface, in ponded dump sites, or buried in permafrost soils. This persistence allows leaching to continue for long periods and may cause high concentrations of contaminants to accumulate. Because normally degradable materials may 
resist decomposition in cold climates, their disposal in accordance with standard practice for temperate regions may be entirely inappropriate in the arctic. Where waste materials come into contact with water -- as they almost always do -- decomposition is accelerated, and water quality degradation may result. In very cold fresh water, potentially pathogenic bacteria and protozoa may survive for unpredictably long periods in local concentrations close to human activities.

At present, the effects of waste disposal operations in freshwater and estuarine or coastal lagoon systems cannot be accurately characterized for cold regions, because data on decomposition processes and rates are not available, and appropriate water quality coefficients (e.g., carbonaceous and nitrogenous BOD decay rates, bacterial die-off rates, absorption rates for metals, biodegradation of organic compounds) have not been developed for cold regions. This lack of data and quantitative tools prevents the development of accurate and consistent waste disposal design criteria and regulatory standards.

\section{Justification}

Data on decomposition of solid and liquid wastes in the arctic are not available, yet they are required for improved design and regulation of waste treatment and disposal systems in communities where severe problems now exist. Coefficients necessary to evaluate rates are normally used by the EPA and state agencies to set permit requirements for NPDES and other programs in temperate regions. Similar coefficients have not been developed for cold regions and are required to allow quantitative standards and design criteria to be established. It is probable that coefficients derived for cold regions will vary significantly from those commonly used by the EPA throughout most of the United States, because these coefficients are dependent on temperature, solar radiation, photoperiod, microbial population density and diversity, and other factors which may differ from temperate regions.

\section{Objectives}

1. Identify decomposition rates for common solid and liquid waste components under landfill conditions -- sample data on how long common materials require to degrade to (a) partial softening or loss of structural integrity and (b) total disintegration (where appropriate).

2. Determine differences in decomposition rates for aboveground and buried representative materials.

3. Prepare appropriate water quality coefficients to allow quantitative standards to be developed for waste discharge, including:

- BOD decay rates.

- Bacterial die-off rates.

- Absorption rates for metals.

- Biodegradation of organics. 


\section{Technical Approach}

1. Test sites will be established at five locations:

- North Slope (Barrow)

- Interior (Fairbanks)

- West (Nome, Kotzebue, or Bethel)

- Southcentral (Anchorage)

- Southeast (Wrangell or Ketchikan)

Each test site will consist of two areas: one dedicated to surface disposal, the other to shallow material. Wire mesh will be used to prvent scattering of materials by the wind.

2. Representative waste materials will be weighed, measured, and deposited. Materials will be re-weighed and re-measured five times during the ensuing 15 months, with detailed observation of structural integrity, evidence of bacterial or fungal action, and presence of detectable leachates.

Additional measurements will include:

- Temperature

- $\mathrm{pH}$

- Dissolved oxygen

- Specific hardness

3. At the same time as the above measurements, samples will be obtained for the laboratory measurement of decay or die-off rates for:

$\begin{array}{ll}- & \text { BOD } \\ - & \text { COD } \\ - & \text { Bacteria }\end{array}$

\section{Time Frame}

- 15 months for experiments and analyses.

- 3 months for report preparation.

- 18 months total.

\section{Locations}

$\begin{array}{ll}- & \text { Barrow } \\ \circ & \text { Fairbanks } \\ \circ & \text { Nome/Kotzebue/Bethel } \\ \circ & \text { Anchorage } \\ - & \text { Wrangell/Ketchikan }\end{array}$

\section{Required Resources}

The program would require funding of about $\$ 90,000$ over 18 months. Major required expertise: water quality chemisty, microbiologist, field technician. 


\section{Products}

A report which fully documents the entire program and presents decomposition rates and coefficients in tabular format.

\section{Interrelationships with OTher Programs}

Decay products were identified by $R$. 0 . Straughn (1972) at test landfills at the Ft. Wainwright and Eilson Air Force Base facillities at Fairbanks. L. Weaver and D. M. Keagy (1952) performed a similar study at Mandan, North Dakota. The EPA has prepared coefficients for establishing waste discharge standard and NPDES permit requirements for national use in the contiguous United States (Zison et al., 1978; Tetra Tech, 1982). The proposed research would extend this program to cold region applications. It would also assist the Alaska Department of Environmental Conservation in implementing the Alaska Litter Reduction for Recycling Act, which requires the use of degradable materials for packaging applications.

Freeze-Thaw Cycle Effects on Contaminants at Disposal Sites and Settling Ponds (Number 42)

Problem

At waste disposal sites and settling ponds, the yearly freeze-thaw cycle may produce a zone concentration effect which results in contaminants migrating downward into the bottom sludge. As the contaminants accumulate, they may reach concentrations far greater than ever existed in the influent or effluent waste stream. At breakup, the relatively dilute surface layers are flushed away, but the bottom sludge may be partially or wholly unaffected, allowing contaminant concentrations to increase from year to year. This problem may exist at wastewater lagoons, natural coastal lagoons and lakes used for rural sewage disposal, and settling ponds established for mining operations.

\section{Justification}

EPA is required to limit discharges of pollutants contained in wastewaters discharged to coastal and freshwater resources. The freeze-thaw cycle can affect conventional wastewater treatment which uses lagoon treatment systems. Aqueous phase dissolved and particulate materials are often concentrated in the liquid portion while the solid portion (ice) is relatively pure water. Concentration factors for contaminants of greater than 90 percent after often obtained through a single cycle of freezing. In wastewater lagoons that discharge by overflow, wastewater materials may be concentrated substantially through this process. After thawing, cleaner water is discharged while waste contaminants are concentrated in the bottom waters through cycles of freezing and thawing. This can have both beneficial and detrimental effects on conventional wastewater treatment proccesses. During times when stratification is maintained, concentration is beneficial because better removal of contaminants is obtained. However, destratification caused by storms or other mixing events could cause sudden and unforeseen 
discharges of higher concentrations of waste materials with subsequent deleterious effects on the environment. It is important to characterize these systems so that discharges and/or treatment can be optimized for the particular system of concern.

\section{Approach}

We propose to investigate several sites by seasonal sampling of influent and effluent, and sampling at different depths of existing conventional wastewater treatment lagoons to characterize the potential for freeze-thaw problems. In addition, bench scale laboratory pilot studies will be done to insure that the wastewater lagoons can be physically modeled. After verification of the freeze-thaw process by studying these conventional wastewater treatment plans and optimizing or otherwise ameliorating problems that might occur in conventional wastewater treatment, a manual will be produced for proper design and operation of conventional wastewater treatment lagoons.

Subsequently, the pilot laboratory study systems will be used to evaluate optimization procedures for freeze-concentrating wastewaters. These optimization steps will be investigated at different temperatures and loadings using idealized organic and inorganic waste streams made up with laboratory chemicals. Then, actual wastewater samples will be collected and treated in the laboratory pilot stream. The optimized approach will be described in a final report along with procedures for doing bench scale design experiments for potential waste dischargers.

\section{Research Location}

- Middle of South Salt Lagoon, Barrow.

- $\quad$ Others to be determined.

\section{Time Frame}

The program will require two years to allow sampling over two freeze-thaw cycles. A minimum of two sampling seasons during the winter and one non-winter sampling period will be required.

\section{Required Resources}

Up to $\$ 150,000$ will be required to fund this two-year study, but the actual requirements may be less, depending on:

a. The number and locations of sampling sites.

b. The detail to which design recommendations or criteria are developed.

Major require expertise: Sanitary engineer and water quality laboratory technician.

\section{Products}

1. Quantitative data on concentrations and movements of contaminants. 
2. Mitigative designs and procedures.

3. Criteria for future construction and use of disposal sites and settling ponds.

\section{RESEARCH SKETCHES ADDED AT THE WORKSHOP}

Asbestos Levels in Rural Alaskan Drinking Water: Relationship to Primary Hepatocellular Carcinoma (Number 43)

Researchable Questions

What are the levels of asbestos (a carcinogenic agent) in Alaskan rivers and other drinking water resources, particularly in watersheds potentially containing asbestos deposits? Does the content of asbestos in drinking water contribute to the development of liver cancer (primarily hepatocellular carcinoma) in areas where hepatitis $B$ virus is endemic?

\section{Rational and Justification}

The asbestos level of the Yukon River at, and downstream from, the confluence of the Fortymile River, which drains substantial asbestos deposits, is above levels EPA considers unfit for drinking $(1,2)$. The levels were in the range of, and sometimes higher than, levels found in San Francisco to be associated with an increased incidence of certain cancers (3). We also measured high levels of asbestos in the lower Yukon, near the confluence of the Andreafsky, in late fall when erosion would be minimal (4). A superficial inquiry regarding the location of potential asbestos-containing rock (5) revealed such deposits to be widespread, particularly around rivers draining into the Yukon, as well as around the Kobuk and the Noatak Rivers. Given that rural populations both in towns, when travelling, or at fish camps utilize the rivers for drinking water, it would be in the interest of public health to systematically measure the asbestos content of appropriate rivers.

An increased incidence of certain cancers is a primary effect of both ingested and inhaled asbestos (6). The Center for Disease Control in Anchorage maintains a cancer registry which delineates the geographical location of cancer among the Native population by cancer type. The peculiar distribution of the liver cancer, primary hepatocellular carcinoma (referred to as hepatoma below), was what prompted the present interest in the asbestos content of drinking water. This type of hepatoma is the most common hard tumor worldwide, particularly in the "Third World" populations. It most commonly occurs as a sequela to infection by hepatitis B virus. Hepatitis B is endemic among the Eskimo population along the lower Yukon and Kuskokwim Rivers; the incidence of both hepatitis $B$ and hepatoma is over 10 times that of the rest of the United States (7). Like other tumors associated with viral infection, it is thought that the hepatoma is most likely to develop in the presence of a second agent acting as a co-carcinogen. The synergistic action of asbestos as a co-carcinogenic agent with cigarette smoke in the development of lung cancer has already been demonstrated ( 8 ). The distribution 
of cases of hepatoma suggest a similar role for asbestos for the development of this cancer. While the cases of hepatitis $B$ virus infection were widespread among the population along both the lower Yukon and Kuskokwin Rivers, the cases of hepatoma primarily occurred in the population of the lower Yukon. None have yet occurred along the Kuskokwim, despite the greater population in this area. Our only measurement of Kuskokwim asbsetos content showed no detectable asbestos in a sample collected after freezeup. This is hardly a conclusive measurement; it needs repeating because there are asbsetos deposits in the Kuskokwim drainage, although apparently not of the magnitude of those along the Yukon and its tributaries.

In conclusion, what is known of the distribution of asbestos deposits and of hepatoma in an area of endemic hepatitis infection would warrant further research into the possibility that asbestos could be acting as a co-carcinogenic agent with hepatitis $B$ virus in the development of hepatoma, the incidence of which is unusually high in western Alaska. Any contribution to the understanding of the relationship between hepatoma and hepatitis $B$ virus would be of major significance not only to Alaska, but also worldwide public health as it is one of the most common cancers.

EPA is charged with developing standards for permissible levels of toxic compounds in air and water. One philosophy is that the standards should be set at a level to protect the most susceptible segment of the population. It is apparent that factors leading to a diseased state rarely act in isolation, but rather in conjunction with other factors, often synergistically. Accordingly, for maximal protection the standard would be set not at a level related to where asbestos had an effect by itself, but rather at a lower level related to where synergistic effects appeared. The present project addresses this problem. At the moment, the effective levels for ingested asbsetos are not very well identified.

Approach

Two interrelated projects with different aims are involved: (A) To see whether exposure to asbestos is associated with an increased incidence of hepatoma; and. (B) to see if the asbestos content of Alaskan rivers is high enough to be a potential public health problem.

A. Is exposure to asbestos associated with an increased incidence of hepatoma? It will be necessary to analyze the actual drinking water sources: (1) from villages in which there have been only cases of hepatitis without hepatoma; (2) from other villages in which there have been cases of hepatitis associated with hepatoma; (3) from villages with hepatoma cases not associated with hepatitis. Background information is available regarding the geographical distribution of hepatitis B infection, of hepatoma cases, and of likely asbestos deposits to aid in choosing villages to sample. Water samples should be collected by one person to ensure a uniform approach to water source selection (wells, springs, and rivers), and to the determination of the extent of use. Samples should be collected at the same time of year, to control for the contribution 
of erosion. Statistical cross-tabulation procedures can be utilized to analyze the data to determine the risk of development of hepatoma in the presence of asbestos. A case history exploration of selected patients who developed hepatoma should also be done to better determine the potential exposure to asbestos through time.

B. What is the asbestos content of Alaskan rivers? This data is of importance for human as well as wildlife exposure. Therefore, samples should involve a cross-section of the river, i.e., samples near the bank as well as in the middle of any one location. Rivers should be selected for analysis on the basis of human population as well as what is known about the presence of possible asbestoscontaining rock in the drainage.

\section{Time Frame/Promising Research Sites}

The medically well-studied and not too mobile population of the lower Yukon and Kuskokwim Rivers offers a unique opportunity to study whether asbestos could be implicated in the etiology of hepatoma. A preliminary study to see of any differences in potential exposure were present could be done in one summer when the contribution of surface erosion would be maximal. To give a minimal indication of variability through time of the asbestos in drinking water and in rivers a sampling period should continue for two years, with sample collection in both summer and winter.

\section{Resources Required}

A. Manpower:

1. Water collection: one person should be selected to travel to villages to determine drinking water sources and their relative use, and to collect appropriate samples (3-5 per village). U.S. Fish and Wildlife Service personnel at bush field stations should be utilized to collect river water samples. The FWS is both experienced in, and interested in, the collection of these samples.

2. Person(s) to examine case histories, analyze data, and coordinate the project.

B. Facilities: The selection of the laboratory to do the asbestos analyses is crucial to the success of the project. The analys is is difficult and expensive ( $\$ 300 /$ sample). Analyses should be done by an experienced laboratory, which has been cross-checked for reproducibility with other laboratories by EPA, in order to ensure comparability of data between studies.

C. Approximate Cost Per Year:

Salaries

$\$ 20,000-30,000$ 
Travel (data collection and consultation between participants

Asbestos samples (summer and winter collection

for 9 villages, plus miscellaneous rivers)

26,000

Other materials, direct costs (including computer use)

1,600

Subtotal

$55,100-65,100$

Plus overhead, e.g., at University of Alaska, $49.8 \%$

$27,600-32,500$

Total (per year)

$82,700-97,600$

Anticipated Products/Output

A. The major rivers draining watersheds potentially containing asbestos will have been measured for asbestos content at a time when little asbestos mining is in progress. A report of this data will be very useful not only to people making decisions about the fitness of the water for consumption but also to people who need to monitor the extent of the pollution by mining activities, which are likely to start up again in the Fortymile River region in the near future.

B. A scientific paper describing the possible role of asbestos in the etiology of hepatoma would be of interest to the scientific and medical community. It would serve to alert public health people, but as it would be the first paper on this topic, the results should be expanded and confirmed. Such a paper would also aid regulatory agencies in the setting of standards for permissible levels of asbestos in water, by addressing the question of the dose at which asbestos might act in synergy with other disease factors.

\section{Interrelationships with OTher Research}

A. The Center for Disease Control has extensive data regarding the epidemiology not only of hepatoma but also of other cancers and diseases. These data are of potential use in evaluating the effects of the environmental toxins and pollutants found in Alaska. The present protocol would open the door for further collaboration.

B. The present proposal regarding asbestos extends the search begun by the Center for Disease Control for possible co-carcinogens acting with hepatitis $B$ virus. Given the worldwide incidence of hepatoma as the most common hard tumor, any information that could lead to its avoidance is a major contribution to public health.

C. The U.S. Fish and Wildlife Service has preliminary data indicating that $f i s h$ in the upper Yukon River have absorbed and retained very high levels of asbestos. Even if this does not affect the life span of fish, it would affect the desirability of the fish for inclusion in food chains which would include man; the significance of this contribution to public health is presently unknown. 
D. The proposed study would at best only suggest that asbestos be associated with development of hepatoma. This question could be pursued further using one of the few animal models (marmots or ground squirrels, both indigenous to Alaska) available for studying hepatitis $B$. The facilities of the state virology laboratory at the University of Alaska in Fairbanks are available; this laboratory is one of the few places where such an experiment could be conducted with appropriate precautions to avoid human infection.

\section{References and Notes}

1. Delaney, P. W. et al. Assessment of the Effects of the Clinton Creek Mine Waste Dump and Tailings, Yukon Territory. Prepared for Cassiar Resources Ltd., Vancouver, B.C.

Metsker, H., U.S. Department of Interior, Fish and Wildlife Service, Anchorage. Personal communication regarding analyses regarding analyses prepared by D. Marklund, Lake Superior Basin Studies Center.

2. Millette, J. R. et al. The Need to Control Asbestos Fibers in Potable Water Supply Systems. Science of the Total Environment 18: $91-102$ (1981).

3. Kaparek, M. S. et al. Asbestos in Drinking Water and Cancer Incidence in the San Francisco Bay Area. Am. ‥ Epidemiol. 112:54-71 (1980).

4. Analyses were made by E. S. Boatman, Head, Division of Environmental Health Biological Effects Research, School of Public Health and Community Medicine, University of Washington, using the same method as Marklund ( $\# 1$ above), both laboratories having been cross-checked for reproducibility by EPA.

5. John Sims, Director, State of Alaska Office of Mineral Development; Robinson, M., Weber, F., Bundzen, T., and Decher, J., U.S. Bureau of Mines and State of Alaska Department of Geological and Geophysical Survey. Personal Communication.

6. Selikoff, I. J. Asbestos -- Associated Disease. In Public Health and Preventive Medicine. 11th ed., John M. Last, ed., Pp. $5 \overline{68-644}$ $(1980)$.

7. Heyward, W. L. et al. Primary Hepatocellular Carcinoma in Alaskan Natives, 1969-1979. Int. ‥ Cancer 28:47-50 (1981).

8. Hammond, E. C. et al. Asbestos Exposure, Cigarette Smoking, and Death Rates. Ann. New York Acad. Sci. 330:473-490 (1979). 
Sediment Contamination in Cold Climate Freshwater and Marine Ecosystems (Number 44)

Problem

A wide-area phenomenon with long-term potential for chronic environmental and human health problems.

Litter/Detritus Degradation as a Measure of Aquatic Ecosystem Function (Number 45)

Problem

Degradation rates are a useful index of ecosystem function. They are rate-limiting on the whole system, so an effect here is an effect on the whole system. Studies could be straightforward comparisons of sediments and associated animals from contaminated and uncontaminated areas. The approach could be applied to fertilizers, pesticides, oils, phenolics, metals, etc.

Salmon Carcass Deposition and Decomposition as a Driving Mechanism to the Nutrient Cycle in Arctic Freshwater Systems (Number 46)

Introduction

During each of the last few years, approximately $500,000,000$ pounds ( 250,000 tons) of salmon carcasses have been naturally deposited in freshwater lake and river systems in Alaska. These salmon are born in freshwater systems but migrate to ocean waters (at a size measured in grams) where considerable growth occurs. Upon their return to freshwater systems, they typically range in size from 1 to $20 \mathrm{~kg}$. Thus, tons of nutrients are transfered from the marine environment to the freshwater environment each year, as has been the case for the last 10-11 thousand years since the ice has receded and the area has been occupied by salmon.

Up to the time commercial fishing commenced less than one hundred years ago, the ecosystems associated with the salmon were presumably in equilibrium, although clearly not one of a static nature. Harvest of salmon through commercial fishing activities changed this in several ways. First, many marginal races have been reduced drastically together with large parts of the peak spawning units. Secondly, commercial fishing activities actually remove approximately $50 \%$ of the biomass. For example, a yearly catch of 25 million salmon (as occured in Bristol Bay in 1981) represents a loss of about 170 tons of phosphorus to the systems in addition to corresponding quantities of nitrogen and other minerals which otherwise would have been returned by the decaying salmon carcasses. Thus, the fishery has not only altered the stocks of salmon directly, but also the stocks of food competitors and predators and the physical environment in which the entire freshwater fish community lives. 
Most watersheds are still in their pristine stage, and the spawning grounds have not been seriously altered. Current emphasis statewide on hydroelectric development and oil-related activities will necessary alter this situation, and when coupled with commercial fishery carcass removals may pose a serious threat to the stability of freshwater systems.

\section{Objectives}

1. Measure the annual production of organic matter by water column phytoplankton and periphyton.

2. Measure the annual consumption and cycling of nutrients ( $N, P$, and $\mathrm{Si})$ associated with water column and periphyton communities.

3. Examine the pathway of released nutrients from salmon carcasses by:

a. field experiments under controlled conditions, or

b. extensive observations of a few selected natural spawning beaches and beaches without spawning.

4. Measure nutrient gradients in the upper few centimeters of sediments from shore to deep water in bays with and without spawning salmon.

5. Supplement existing knowledge of the chemical content of salmon carcasses by additional studies, especially of micronutrients.

6. Clarify the role of released nutrients from the salmon carcasses in sustaining the salmon cycle and describe possible nutrient feedback loops which lead to increased production of organisms which serve as food for fry and juvenile fish such as lake fly larvae and zooplankton.

\section{Approach}

Field activities will be carried out in the Kvichak River system. The emphasis of this research will be placed on (1) assessing the relative significance of primary productivity and nutrient cycling by benthic algal communities in salmon nursery lakes to total lake primary production and nutrient budgets, (2) decribing the relationship of benthic and water column algal primary production to salmon fry and juvenile food production, (3) delineating the role played by decomposing salmon and salmon processing wastes in supplying nutrients to salmon nursery lakes, streams, and estuaries, and (4) examining the role of lake sediments in storing nutrients from decomposing salmon carcasses during peak escapement years for support of progeny resulting from these escapements.

The primary production of the Iliamna Lake water column has been studied for a number of years using the ${ }^{14} \mathrm{C}$ technique (Baxter, 1968), chlorophyll a concentration (Low, 1972), and nutrient cycling (Donaldson, 1967). Little information, however, is available relating to the role that the periphyton communities associated with the lake bottom play in 
the annual lake carbon cycle. Because of the extreme transparency of the water, light penetrates to considerable depths and a substantial portion of the lake bottom therefore lies within the littoral zone and is capable of supporting growth of rooted vegetation and attached epiphytes and periphyton. The supply of nutrients from the sediment may thus be of primary importance in directly supporting plant growth. The primary production associated with the bottom may, indeed, be as large or even larger than that occurring in the lake's water column.

The research relating to the seasonal contributions of both pelagic and periphyton communities to the annual primary production of Iliamna Lake will be conducted in bays and spring-fed ponds without any inlet. The number of spawners vary from a few hundred to a thousand. Thus, they lend themselves ideally to experimental work. Bays and spring-fed ponds in which spawning takes place will be compared to ones in which no spawning occurs. The conventional ${ }^{14} \mathrm{C}$ method of measuring primary production in the water column will be employed. Rates of production at various depths in the euphotic zone will be measured during all seasons of the year and these values will be integrated to determine annual production per square meter within the two dofferent types of bays and ponds. The measurement of periphyton production is somewhat more difficult; however, artificial substrates such as glass slides, plastic plants, or natural substrates such as rocks may be used. The use of styrofoam substrates immersed in lakes has prove to be an effective method of measuring periphyton production (Flint et al., 1977). The algae colonize the styrofoam which has the advantage of having crevices and therefore approximates the natural substrates. After the immersion, the substrate is sampled with a cork borer, then the core is incubated in situ with ${ }^{14} \mathrm{C}$. The algae are later removed with a razor blade and the $\overline{i r}$ ${ }^{14} \mathrm{C}$ content determined and the production per square meter computed. This method will be compared with periphyton production measured by using plastic incubation chambers and rocks (Schindler, 1973) and with incubation on glass slide (Goldman, 1974). Autoradiography techniques have been used to determine the primary production rate and the uptake of certain nutrients by individual species of a phytoplankton community assemblage (MaGuire and Neill, 1971; Stull et al., 1973). We plan to employ this technique to assist in understanding the relationship between the production processes and the density and qualitative composition of the water column phytoplankton and periphyton.

The consumption and production of the nutrients nitrogen, phosphorus, and silicon will be determined from measurements of $15 \mathrm{~N}, 32 \mathrm{p}$, and ${ }^{30} \mathrm{Si}$ uptake by water column phytoplankton and periphyton. Consumption and production of $\mathrm{NO}_{3}, \mathrm{NH}_{4}, \mathrm{PO}_{4}{ }^{3}$, and $\mathrm{H}_{4} \mathrm{SiO}_{4}$ in the previously described two types of bays and ponds will be monitored. Isotopic tracer procedures as described by Dugdale and Goering (1967) for ${ }^{15} \mathrm{~N}$, Goering et al. (1973) for ${ }^{30} \mathrm{Si}$, and Rigler (1956) for $32 \mathrm{p}$ will be employed in these nutrient cycling studies.

The study of the chemical effects of salmon decomposition on the nutrient budgets of salmon nursery lakes will consist of discrete analysis of $\mathrm{NO}_{3}, \mathrm{NO}_{2}, \mathrm{NH}_{4}$, and $\mathrm{H}_{4} \mathrm{SiO}_{4}$ concentrations within the water column and sediment pore water of the two previously described types of 
bays and ponds. These measurements will provide information needed to distinguish the fate and distributions of nutrients released during decomposition.

Because of the localized accumulation of decomposing salmon carcasses along the lake bottom near major spawning areas, the sediment is postulated to be an important recipient of organic matter and nutrients released during decomposition. We therefore plan to determine the net and total rate of $\mathrm{NH}_{4}$ production and $\mathrm{NH}_{4}$ incorporation at different depths in the sediments of the two bays under study. Differences in sediment $\mathrm{NH}_{4}$ turnover between the two types of bays, as well as any yearly differences, especially between years of high and low escapement, should provide data of value to determine the effects of salmon carcass decomposition on the nitrogen chemistry of the sediments, on the rates at which remineralization takes place, and the role that sediments play as a source or sink for nutrients. A detailed study of $\mathrm{NH}_{4}$ was selected because $\mathrm{NH}_{4}$ and dissolved organic nitrogen have been shown to be a valuable method for masuring rates of $\mathrm{NH}_{4}$ turnover in aquatic sediments, using a ${ }^{15} \mathrm{~N}-\mathrm{NH}_{4}$ dilution technique (Blackburn, 1979) will be employed in these studies.

A graduate student at the University of Washington (Pre-Doc. I) will concentrate efforts on primary production and the mechanism whereby this production is transferred to suitable salmon fry and juvenile food. A predoctoral student from the University of Alaska will concentrate efforts on the role nutrients released from salmon decomposition play in the Iliamna Lake production cycle. Dr. J. J. Goering (University of Alaska) and Dr. O. A. Mathisen (University of Washington) will coordinate the overall program research and reporting activities.

$\underline{\text { Costs }}$

Costs are estimated to be $\$ 80,000$ for each year of three years and $\$ 25,000$ for the fourth year.

\section{References}

Baxter, R. A. 1968. Primary production in Iliamna Lake, Alaska. 1961-1967. M.S. Thesis, Univ. Washington, Seattle. 81 pp.

Blackburn, T. H. 1979. Methods for measuring rates of $\mathrm{NH}_{4}$ turnover in anoxic marine sediments, using a ${ }^{15} \mathrm{~N}-\mathrm{NH}_{4}$ dilutions technique. Applied and Environmental Microbiology. April 1979, p. 760-765.

Brickwell, D., and J. J. Goering. 1970. Chemical effects of decomposing salmon carcasses in aquatic ecosystems. In First Intl. Symp. on Water Pollut. Control in Cold Climates, R. S. Murphy, ed., Govt. Printing office, Washington. pp. 125-138.

Donaldson, J. R. 1967. The phosphorus budget of Iliamna Lake, Alaska, as related to the cyclic abundance of sockeye salmon. Ph.D. Dissertation, Univ. Washington, Seattle. 141 pp. 
Flint, R. W., R. L. Richards, and C. R. Goldman. 1977. Adaptation of styrofoam substrate to benthic algae productivity studies in Lake Tahoe, California-Nevada. J. Phycol. 13:407-409.

Goering, J. J., D. M. Nelson, and J. A. Carter. 1973. Silicic acid uptake by natural populations of marine phytoplankton. Deep-Sea Res. 20:777-789.

Goldman, C. R. 1972. The role of minor nutrients in limiting the productivity of aquatic ecosystems. Limnol. Oceanogr.

Low, L. L. 1972. Chlorophyll a, phytoplankton, and primary production in Iliamna Lake, Alask. $\bar{M} . S$. Thesis, Univ. Washington, Seattle. $101 \mathrm{pp}$.

MaGuire, B., and W. F. Niell. 1971. Interactions of light and inorganic nitrogen in controlling nitrogen uptake in the sea. Deep-Sea Res. 19: 209-232.

Rigter, F. H. 1956. A tracer study of the phosphorus cycle in lake water. Ecology 37:550-562.

Schindler, D. W. 1973. Experimental approaches to limnology -- an overview. ‥ Fish. Res. Board Can. 30:1409-1413.

Stull, E. A., E. deAmezaga, and C. R. Goldman. 1973. The contribution of individual species of algae to primary productivity of Castle Lake, California. Verh. Internat. Verein. Limnol. 18:1776-1783.

Semi-Mobile Research Support Facility (Number 47)

Problem

Considerable cost savings and mobility could be achieved with a semi-mobile research facility. Ideally, an integrated package of recommended studies would be done at a single site using such a facility.

Research Reserves (Number 48)

Question

Of what value to of research in cold regions are "Protected, controlled, long-duration observation/experimental fields?"

Justification

A number of presentations have suggested or stressed the need for control, baseline, or secure experimental studies in environments ranging from arctic coastal plain to western Alaska (including lagoon in the Alaskan taiga and in south-central coastal estuaries. Support is needed for formally establishing, maintaining, and (especially) sharing information on such field study sites over time periods of several decades. 


\section{Approach}

1. Using existing information in the Ecological Reserves program, identify sites most important to EPA's Cold Climate Research Program over the next 5 years.
a. construct "type needs" list
b. do an inventory/search matrix
c. search out management/land use conflicts
d. revise site list through negotiation between managers and researchers
e. finalize the site list

2. Prepare detailed establishment reports for the chosen sites.

3. Incorporate the site documentation data into the Ecological Reserves Computerized Information System.

4. Work to secure formal research site designation.

\section{Research Location}

Arctic Coastal Plain

Western Alaska/Several Peninsula Cold

Taiga Uplands

Alpine

South-Central Coastal/Estuarine Habitats

\section{Products}

Established Reserves secure and available for long-term research use. Site documentation descriptive information.

\section{0 il Development Impacts on Lagoonal Seagrass Ecosystems (Number 49)}

Question

What are the consequences of mechanical disturbance and petroleum release on seagrass-dominated coastal lagoons?

Justification

A major component ecosystem of the nearshore sea along most coasts of North America is based structurally and functionally on one or more species of seagrasses (e.g., eelgrass, Zostera marina). Extensive seagrass lagoons are found in Alaska and worldwide. These systems are locally important primary producers, support migratory birds and marine animals, and provide large amounts of detrital plant material to other marine organisms. Seagrasses are rooted, vascular plants that generally 
grow on soft sediments in protected bays and lagoons. The development of these systems is closely coupled with the chemical transformations occurring in the sediments; any change in these processs should be reflected in changes in the plants as well as the associated animal community. These are detritus-based systems that depend on the accumulation and subsequent decomposition of detritus for essential nutrients, forming a kind of symbiotic relationship between the seagrass plants and sediment microbial community.

Izembek Lagoon, the proposed study site, has been the center of research on seagrass-based ecosystems in Alaska since the early 1960's. Over the years, numerous studies of the plant and animal communities in the lagoon have been done; in addition, there have been several studies of nutrient cycling and plant-sediment interactions. In sum, an excellent data base exists for understanding the effects of perturbation experiments. Furthermore, this lagoon sits immediately adjacent to the North Aleutian Shelf oil lease area and it has become the source of concern by several management agencies since it is highly vulnerable to the impact related to oil development.

Over the past decade, basic scientific studies have provided a good understanding of the natural functioning of seagrass-based systems. However, virtually no work has been done to examine the changes in system function that result from stress due to mechanical disturbance (e.g., nearly filling or dredging) or petroleum spillage. This work addresses the following environmental research issues as ranked by Battelle/EPA (New Rank Numbers): 3, 4, 6, 9, 10, 14, 15, and 22.

\section{Statement of the Problem}

The development of petroleum in the coastal waters of Alaska potentially constitues a mechanical and chemical disturbance to natural ecosystems. Disturbance ecology is the understanding of these impacts. In this project, we propose to determine the consequences of mechanical disturbance and petroleum release on the processes that sustain the normal functions of seagrass ecosystems. Our hypothesis is that the biogeochemical regeneration processes of the sediments are crucial to the dynamic maintenance of the seagrass system. We will examine in particular the carbon budget in disturbed and natural systems and will develop a conceptual model of the impact of disturbance due to oiling or mechanical perturbation on a seagrass sediment system.

\section{Approach}

Since seagrass sediment systems are primarily detrital, it will be necessary to study the cycling of chemical compounds known to be important in the degradation of organic matter in marine sediments (sulfate, methane, acetate, lactate, oxygen, ammonia, hydrogen sulfide, etc.). For most of these compounds, both concentrations (pool sizes) and kinetics (turnover rates) need to be measured on a seasonal basis. To fully understand the chemistry of organic matter generation in the seagrass bed, additional parameters need to be measured: plant production, sedimentation, organic carbon, hydrocarbons, plant biomass, temperature, salinity, and interstitial nutrients. 
Product

Conceptual model of potential effects.

Time Frame

First year -- conduct measurements on unperturbed seagrass system. Second year -- Conduct measurements on experimentsl pilots subjected to oil and mechanical stress. Third year -- conduct experiments to test hypotheses generated by second year's work. Fourth year -- develop conceptual model of system function and stress response.

Site

The most appropriate site for this study is Izembek Lagoon on the Alaskan Peninsula. This lagoon contains the largest eelgrass (Zostera marina) meadows in Alaska and is readily accessible to laboratory facilities. The University of Alaska Institute of Marine Science in cooperation with the U.S. Air Force maintains a field laboratory on the shore of the lagoon in a part of the Air Force Base facilities. This laboratory has existed sice the early 1960's and consequently Izembek Lagoon, and particularly its seagrass beds, have been the subject of numerous investigations by students and faculty of the University of Alaska. This background information is invaluable to the proposed studies; it enables design of experiments around known ecological gradients which is essential for extrapolation of the results of other areas.

Izembek Lagoon is recognized as an important part of the coast of Alaska. It is a critical nursery area for Bristol Bay salmon and other commercial fishes. Also, it is the major feeding area for numerous species of Pacific waterfowl. Because of its remote location from the population centers of Alaska, the lagoon is pristine. However, this may not continue to be the case. $0 i 1$ development is now proposed in the next few years in the St. George Basin an the North Aleutian shelf lease areas which are portions of the continental shelf adjacent to the lagoon. This results of these studies will be vital to any management strategies developed for the region.

\section{Constraints}

The only difficulty in this project is making experimental petroleum additions that realistically simulate likely stress situations. However, several promising approaches have been suggested in the literature and can be tested during the first year of the project.

\section{Costs}

Annual cost will be approximately $\$ 100,000$. Cost per year: $\$ 230 \mathrm{~K}$. Senior Investigators

A. Seagrass ecologist familiar with Izembek system -- C. P. McRoy. 
B. Biogeochemist familiar with sedimentary carbon cycling -- $W$. $S$. Reeburgh.

C. Organic chemist familiar with trace analysis of hydrocarbons and products of metabolism. D. G. Shaw.

\section{Facilities Required}

None that are not available at Izembek and the University of Alaska. 

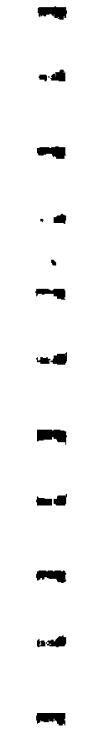

ne

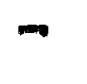

$\Leftrightarrow$

9
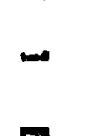

$\rightarrow$

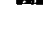


No. of

Copies

OFFSITE

10 Dr. Norman R. Glass

U.S. EPA

Envirormental Research Laboratory

200 S.W. 35th Street

Corvall is, OR 07333

2 DOE Technical Information Center

P.0. Box 62

Oak Ridge, TN 37830

Dr. Larry Bliss

Dept. of Botany

AJ 10

University of Washington

Seattle, WA 98156

Dr. Don Button

University of Alaska

Institute of Marine Science

Anctic Health Research Center

Fairbanks, AK 99701

\section{Alfred A. Galli}

U.S. EPA

Office of Research \& Development

Mail Code RD 682

401 M. St. SW

Washington, DC 20460

Ron Kreizenbeck

EPA Alaska Operations

3200 Hospital Drive

Suite 101

Juneau, AK 99801

Dr. David Norton

University of Alaska

Arctic Project Office

Geophysical Institute

903 Koyukuk Avenue North

Fairbanks, AK 99701
Bill Osborn

Division of Ecological Reseanch

U.S. Dept. of Energy

Washington, DC 20545

Dr. Ken Rahn

Graduate School of Oceanography

University of Rhode Island

Narragansett, RI 02882-1197

Douglas Recbum

Alaska Department of Envirommental

Conservation

Pouch 0

Juneau, AK 99811

Leonand Verrelli

Alaska Dept. of Enviromental

Conservation

Pouch 0

Juneau, AK 99811

Dr. Gunter weller

University of Alaska

Geophysical Institute

903 Koyukuk Avenue

Fairbanks, AK 99701

ONSITE

DOE Richland Operations Office

H. E. Ransom/P. K. Clark

Pacific Northwest Laboratory

Publishing Coordination (2)

Technical Information (1) 
